NATIONAL LABORATORY

\title{
Supplemental Report on Nuclear Safeguards Considerations for the Pebble Bed Modular Reactor (PBMR)
}

May 2010

Prepared by

David L. Moses

Michael H. Ehinger

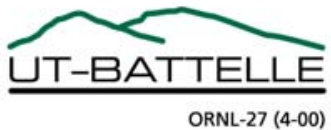




\section{DOCUMENT AVAILABILITY}

Reports produced after January 1, 1996, are generally available free via the U.S. Department of Energy (DOE) Information Bridge.

Web site http://www.osti.gov/bridge

Reports produced before January 1, 1996, may be purchased by members of the public from the following source.

National Technical Information Service

5285 Port Royal Road

Springfield, VA 22161

Telephone 703-605-6000 (1-800-553-6847)

TDD 703-487-4639

Fax 703-605-6900

E-mail info@ntis.gov

Web site http://www.ntis.gov/support/ordernowabout.htm

Reports are available to DOE employees, DOE contractors, Energy Technology Data Exchange (ETDE) representatives, and International Nuclear Information System (INIS) representatives from the following source.

Office of Scientific and Technical Information

P.O. Box 62

Oak Ridge, TN 37831

Telephone 865-576-8401

Fax 865-576-5728

E-mail reports@osti.gov

Web site http://www.osti.gov/contact.html

This report was prepared as an account of work sponsored by an agency of the United States Government. Neither the United States Government nor any agency thereof, nor any of their employees, makes any warranty, express or implied, or assumes any legal liability or responsibility for the accuracy, completeness, or usefulness of any information, apparatus, product, or process disclosed, or represents that its use would not infringe privately owned rights. Reference herein to any specific commercial product, process, or service by trade name, trademark, manufacturer, or otherwise, does not necessarily constitute or imply its endorsement, recommendation, or favoring by the United States Government or any agency thereof. The views and opinions of authors expressed herein do not necessarily state or reflect those of the United States Government or any agency thereof. 
ORNL/TM-2010/244

Global Security and Nonproliferation Programs

\section{SUPPLEMENTAL REPORT ON NUCLEAR SAFEGUARDS CONSIDERATIONS FOR THE PEBBLE BED MODULAR REACTOR (PBMR)}

David L. Moses and Michael H. Ehinger

Date Published: May 2010

Prepared by

OAK RIDGE NATIONAL LABORATORY

Oak Ridge, Tennessee 37831-6283

managed by

UT-BATTELLE, LLC

for the

U.S. DEPARTMENT OF ENERGY

under contract DE-AC05-00OR2272 



\section{CONTENTS}

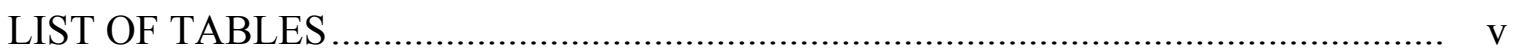

ABSTRACT 1

1. INTRODUCTION AND SUMMARY ........................................................... 1

2. BACKGROUND OF THE CURRENT EVALUATION IN REFERENCE [1] .............................................................................

3. DISCUSSION OF THE REFERENCED PBMR BURNUP ANALYSES [2-4] ....................................................................................... 12

4. DISCUSSION OF THE IAEA PROVISIONAL CRITERIA FOR TERMINATION OF SAFEGUARDS [13-18] ................................................... 14

4.1 Analysis of the IAEA Provisional Criteria for Termination of Safeguards as a Basis for Termination of NMC\&A on Plutonium in Discharged LEU Pebbles

4.1.1 Calculating the critical mass of a bare sphere with a homogeneous loading of plutonium recovered from spent fuel or nuclear waste....... 16

4.1.2 Basis for terminating NMC\&A on plutonium in PBMR used fuel based on IAEA "provisional" criteria for termination of safeguards as presented in Table 4 ......

4.1.3 Basis for terminating NMC\&A on plutonium in PBMR used fuel by applying the criterion given in Footnote " $a$ " in Table 1 of Reference [16]. 20

4.2 Analysis of the IAEA Provisional Criteria for Termination of Safeguards on Uranium in Discharged LEU Pebbles

4.3 Analysis of Other Aspects of Uranium in Discharged LEU Pebbles Not Considered in the IAEA Provisional Criteria for Termination of

Safeguards

4.3.1 Impact of PBMR used-fuel uranium isotopic degradation on its potential reuse

4.3.2 Radiological aspects of PBMR used-fuel uranium isotopic degradation on its potential reuse

4.4 Comparative Analysis of Applying the IAEA Provisional Criteria for Termination of Safeguards on Irradiated Uranium to the Unirradiated Uranium Dilution in Fresh LEU Pebbles

5. THE DOE ECONOMIC DISCARD LIMIT (EDL) FOR TERMINATION OF SAFEGUARDS ON DOE-OWNED SPECIAL NUCLEAR MATERIAL (SNM) [21-24]

6. FORMER SOVIET UNION EDL FOR PRODUCTION OF WEAPONGRADE PLUTONIUM [25(A)] 
7. REPROCESSING OF GRAPHITE-ENCASED COATED-PARTICLE

FUELS

8. DETERMINING THE PLUTONIUM CONTENT OF PBMR PEBBLES BEING DISCHARGED AND APPLYING A NMIS-TYPE

SURVEILLANCE TO PBMR USED FUEL IN STORAGE.................................... 44

8.1 The Limitations of Anti-Neutrino Detection for NMC\&A of Spent Fuel Storage. 44

8.2 A Feasible Option for PBMR Used Fuel Surveillance. 44

9. DISCUSSION OF UNRESOLVED ISSUES IDENTIFIED IN REFERENCE [16] WITH REGARD TO THE IAEA PROVISIONAL CRITERIA FOR TERMINATION OF SAFEGUARDS

10. RECOMMENDATIONS FOR FUTURE WORK

11. REFERENCES 52

APPENDIX A: PEBBLE BED MODULAR REACTOR (PBMR) BURNUP WORKSHEET COMPARING AND RECONCILING INDEPENDENT ANALYSES BY PBMR (PTY) LTD AND IDAHO NATIONAL LABORATORY (INL). 


\section{LIST OF TABLES}

1. Comparison of PBMR discharged fuel at a burnup of $90.8 \mathrm{GWD} / \mathrm{MT}$ to various limits ....................................................................................... 7

2. Comparison of PBMR fresh (unirradiated) fuel to various limits .................. 8

3. Estimated mass and volume of PBMR pebbles to be diverted for recovery of one significant quantity (1 SQ) of plutonium as a function of recirculation pass

4. Conversion of STR-251 (Rev 2) [15] plutonium concentrations in conditioned waste forms from $\mathrm{g} / \mathrm{m}^{3}$ (as presented) to equivalent parts per million (ppm or g/MT) .................................................................... 15

5. Adjusted $\alpha$-phase density bare-sphere critical masses from near $\delta$-phase density plutonium bare-sphere critical experiments

6. Critical mass estimates for JEZEBEL and JEZEBEL-240 using the ROF technique

7. Estimated minimum critical mass of plutonium isotopic mix in a discharged pebble at a burnup of $90.8 \mathrm{GWD} / \mathrm{MT}$

8. Conversion of STR-251 (Rev 2) [15] plutonium concentrations ${ }^{a}$ in unconditioned waste forms ${ }^{b}$ from $\mathrm{g} / \mathrm{m}^{3}$ (as presented) to equivalent parts per million (ppm) in an assumed waste form of a $200 \mathrm{~g}$ graphitized carbon pebble with a net volume (including surrounding voids) in highest density storage ${ }^{c}$ of $0.0001527 \mathrm{~m}^{3}$ per pebble

9. Conversion of STR-251 (Rev 2) [15] low-enriched or natural uranium concentrations in unconditioned waste ${ }^{b}$ from $\mathrm{g} / \mathrm{m}^{3}$ (as presented) to equivalent parts per million (ppm) in an assumed waste form of a $200 \mathrm{~g}$ graphitized carbon pebble with a net volume (including surrounding voids) in highest density storage of $0.0001527 \mathrm{~m}^{3}$ per pebble

10. Comparison of the PBMR used fuel uranium isotopics at $90.8 \mathrm{GWD} / \mathrm{MT}$ and cooled for 5 years to the limits in the reprocessed uranium specification in ASTM C787

11. Reprocessed uranium contained isotopics: specific activities and $\mathrm{A}_{2}$ values

12. $A_{2}$ for reprocessed uranium (Rep-U) from PBMR used fuel ( $9.6 \%$ initial

${ }^{235} \mathrm{U}$ enrichment) at a burnup of $90.8 \mathrm{GWD} / \mathrm{MT}$ and cooled for 5 years with an assumed equilibrium of ${ }^{228} \mathrm{Th}$ and ${ }^{232} \mathrm{U}$ and without ${ }^{99} \mathrm{Tc}$ and plutonium

13. $\mathrm{A}_{2}$ for reprocessed uranium (Rep-U) from a LWR $\left(4.5 \%\right.$ initial ${ }^{235} \mathrm{U}$ enrichment) at a burnup of 48 GWD/MT and cooled for 5 years [7] with an assumed equilibrium of ${ }^{228} \mathrm{Th}$ and ${ }^{232} \mathrm{U}$ and without ${ }^{99} \mathrm{Tc}$ and plutonium

14. $\mathrm{A}_{2}$ for reprocessed uranium (Rep-U) from a LWR $\left(4.1 \%\right.$ initial ${ }^{235} \mathrm{U}$ enrichment) at a burnup of $60 \mathrm{GWD} / \mathrm{MT}$ and cooling for 5 years [7] with an assumed equilibrium of ${ }^{228} \mathrm{Th}$ and ${ }^{232} \mathrm{U}$ and without ${ }^{99} \mathrm{Tc}$ or plutonium

15. Selected IAEA provisional criteria for safeguards termination on uranium-bearing low-activity waste 
A-1. PBMR discharged plutonium isotopics from Reference [2]...........................A-5

A-2. PBMR-400 fully burnt isotopics from Reference [4] ......................................-6

A-3. ${ }^{235} \mathrm{U}$ fission-to-absorption ratios for thermal-neutron-energy-dependent point cross sections and lower energy resonance integrals $(<500 \mathrm{eV})$..............A-7

A-4. $\quad{ }^{235} \mathrm{U}$ and ${ }^{238} \mathrm{U}$ fast fission cross section ratios ..................................................

A-5. Extrapolated estimates of ${ }^{232} \mathrm{U}$ in PBMR used fuel after cooling for

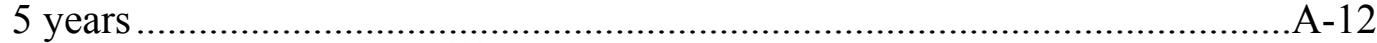

A-6. Extrapolated estimates of ${ }^{233} \mathrm{U}$ in PBMR used fuel after cooling for 5 years

A-7. Extrapolated estimates of ${ }^{234} U$ in PBMR used fuel after cooling for 5 years based on the assumption that ${ }^{234} \mathrm{U}$ is in equilibrium at the time of discharge and increases linearly after discharge

A-8. Extrapolated estimates of ${ }^{237} \mathrm{U}$ in PBMR used fuel after cooling for 5 years

A-9. Minor uranium isotope content in PBMR discharged fuel ( $90.8 \mathrm{GWD} / \mathrm{MT})$ and in the discharged pebble at the time of discharge and after cooling for 5 years after discharge.

A-10. Calculation of plutonium average atomic mass in PBMR pebble A-16 


\title{
SUPPLEMENTAL REPORT ON NUCLEAR SAFEGUARDS CONSIDERATIONS FOR THE PEBBLE BED MODULAR REACTOR (PBMR)
}

\author{
David L. Moses and Michael H. Ehinger
}

\begin{abstract}
Recent reports by Department of Energy National Laboratories have discussed safeguards considerations for the low enriched uranium (LEU) fueled Pebble Bed Modular Reactor (PBMR) and the need for bulk accountancy of the plutonium in used fuel. These reports fail to account effectively for the degree of plutonium dilution in the graphitized-carbon pebbles that is sufficient to meet the International Atomic Energy Agency's (IAEA's) "provisional" guidelines for termination of safeguards on "measured discards." The thrust of this finding is not to terminate safeguards but to limit the need for specific accountancy of plutonium in stored used fuel. While the residual uranium in the used fuel may not be judged sufficiently diluted to meet the IAEA provisional guidelines for termination of safeguards, the estimated quantities of ${ }^{232} \mathrm{U}$ and ${ }^{236} \mathrm{U}$ in the used fuel at the target burn-up of $\sim 91 \mathrm{GWD} / \mathrm{MT}$ exceed specification limits for reprocessed uranium (ASTM C787) and will require extensive blending with either natural uranium or uranium enrichment tails to dilute the ${ }^{236} U$ content to fall within specification thus making the PBMR used fuel less desirable for commercial reprocessing and reuse than that from light water reactors. Also the PBMR specific activity of reprocessed uranium isotopic mixture and its $\mathrm{A}_{2}$ values for effective dose limit if released in a dispersible form during a transportation accident are more limiting than the equivalent values for light water reactor spent fuel at $55 \mathrm{GWD} / \mathrm{MT}$ without accounting for the presence of the principal carry-over fission product $\left({ }^{99} \mathrm{Tc}\right)$ and any possible plutonium contamination that may be present from attempted covert reprocessing. Thus, the potentially recoverable uranium from PBMR used fuel carries reactivity penalties and radiological penalties likely greater than those for reprocessed uranium from light water reactors. These factors impact the economics of reprocessing, but a more significant consideration is that reprocessing technologies for coated particle fuels encased in graphitized-carbon have not progressed beyond laboratory-scale demonstrations although key equipment that has been tested in the past (such as graphite burners and electrolytic disintegration/dissolution devices) are not listed on either the "Trigger List" or the "Dual Use List" for mandatory export controls. Finally, if gross burn-up determined from fission product gamma ray inspection of a discharged pebble cannot be correlated acceptably with predicted plutonium content of the pebble, development and testing may be required on detector concepts for more directly measuring the plutonium content in a discharged pebble to ensure that its placement in the spent fuel storage tanks is for an acceptable "measured discard" of diluted plutonium.
\end{abstract}




\section{INTRODUCTION AND SUMMARY}

The following supplemental report provides a different perspective on the requirements for safeguards applied to "used fuel", from the Pebble Bed Modular Reactor (PBMR) that is not fully nor adequately reflected in a recent joint report [1] to which Oak Ridge National Laboratory (ORNL) contributed.

The quantitative evaluations used in this report are based on the independent analyses provided by the proponent $[2,3]$ and by Idaho National Laboratory (INL) [4], as used in a recent report [1]. However, since the assumptions made and the results reported in these previous independent analyses are not consistent, an attempt has been made to compare, reconcile, and supplement, where appropriate, the different analytical results, as presented in Appendix A, based on documented assumptions and interpretations but without benefit of new calculations. Based on this comparison, the INL analyses [4] were found to be for a much higher burnup than the target burnup used in the proponent's analysis $[2,3]$ and the INL prediction of plutonium content in the discharged pebble appeared to be high as well. The supplemental analysis provided in Appendix A also provides inferred estimates for the uranium isotopics in the PBMR used fuel that were not addressed in the previous analyses.

In addition, the focus on plutonium build-in in recent reports [1, 4], as opposed to the burnup of low enriched uranium (LEU) and the accompanying build-in of ${ }^{232} U$ and ${ }^{236} U$, appears to miss a key issue in that the dilution of the plutonium produced would be perhaps sufficient to terminate safeguards. The residual content of LEU is the major reason for requiring continued safeguards along with the radiation levels that still require physical protection against radiological sabotage. The buildup of ${ }^{232} \mathrm{U}$ in irradiated LEU, especially as the fuel ages before reprocessing, poses a radiological barrier to the subsequent recovery and use of reprocessed uranium $[5,6]$ and provides a radiological signature useful for detecting covert reprocessing. The combination of ${ }^{232} \mathrm{U},{ }^{234} \mathrm{U}$, and ${ }^{236} \mathrm{U}$ present in PBMR used fuel leads to a radiological penalty in reprocessed uranium that exceeds that of reprocessed light water reactor fuel, as determined by the specific activity of the uranium and the effective dose if the reprocessed uranium were released in a dispersible form. The $\mathrm{A}_{2}$ parameter is used in assessing risk limits in the safe transport of radiological materials [5, 7]. In particular, the buildup of ${ }^{236} \mathrm{U}$ appears to be sufficient to penalize core reactivity and burnup for subsequent use of reprocessed LEU from PBMR used fuel, with the following results.

- Some additional enrichment is required as well as extensive blending with either LEU from natural uranium or natural uranium to reduce ${ }^{236} \mathrm{U}$ to the standard specification (ASTM C787) considered necessary for light-water reactors [7-10] to achieve the same burnup as when using LEU from natural uranium.

- Commercial use is limited to highly neutronically thermalized reactors such as the CANDU (CANada Deuterium Uranium) Reactor [11] or the RBMK ${ }^{\dagger}[7]$

\footnotetext{
" "Used fuel" is the terminology currently adopted by DOE to distinguish "spent fuel" from which may still be reprocessed to recover usable nuclear material for sustainability of fuel cycles.

${ }^{\dagger}$ The RBMKs use reprocessed uranium recovered at the RT-1 Plant from the VVER-440 and BN-600 reactors spent fuels.
} 
(Russian reaktor bolshoy moshchnosti kanalniy or High Power Channel-type Reactor) where blending with natural uranium is still required to meet the current specification limits on ${ }^{236} \mathrm{U}$.

- Use as driver fuel may be allowed with some amount of reactivity penalty in a heavy-water-moderated or graphite-moderated production reactor, where the residual LEU in the PBMR used fuel would require both reprocessing and concentration to be effective as a driver fuel.

The presence of a substantial quantity of ${ }^{236} \mathrm{U}$ in the PBMR used fuel also hinders and complicates attempts to produce high enriched uranium (HEU) by re-enrichment of postreprocessed uranium. One reported value from the Soviet era is that the content of ${ }^{236} \mathrm{U}$ in HEU re-enriched from spent production reactor fuel was as high as $25 \%$ [12], implying that the limit on the ${ }^{235} \mathrm{U}$ content in HEU from such reprocessed fuel is likely to be no more than $\sim 70 \%$ without going to much higher separative work units (SWUs) than what would be needed for $90 \%$ enrichment from natural uranium. Therefore, the used fuel from irradiation in the PBMR would not be the most desirable "indirect-use nuclear material" due to the high level of ${ }^{236} \mathrm{U}$ contamination and to the detectable radiation hazard posed by the presence of ${ }^{232} U$.

The purpose of this supplemental report is not to substantiate the bases for the termination of safeguards on PBMR used fuel. Such action would be unlikely and unacceptable under the current policies of the International Atomic Energy Agency (IAEA) for the oversight of spent nuclear fuel. Rather the purpose of this report is to use the "provisional" criteria for termination of safeguards [13-18], as defined by the IAEA, to define and quantify the relative proliferation potential of the plutonium and uranium in the PBMR used fuel in terms of their dilution in the non-fissionable inert material that encapsulates the used fuel. In this regard, the dilution provides one index with respect to IAEA safeguards requirements for continued Nuclear Material Control and Accountancy (NMC\&A). This index will be used to propose acceptable bulk inspection and surveillance requirements for the NMC\&A of the used fuel based on its total fissile content as opposed to its isotopic content, for which an alternative will be proposed based on the quantitative inspection of discharged fuel at the time of discharge from the reactor. In addition, since the IAEA provisional criteria do not address aspects other than dilution as affecting the termination of NMC\&A, this report will attempt to address some of the other aspects of the diluted and radioactive nuclear material with regard to its attractiveness for theft or diversion by would-be proliferators for access to direct-use or indirect-use nuclear material. Finally, the IAEA provisional criteria for termination of safeguards represent a still controversial but largely consensus position that is subject to interpretation. The impact of unresolved issues [16] on the interpretation of provisional criteria given here as applied to the NMC\&A of plutonium in PBMR used fuel is addressed in Section 9 of this report.

This differing perspective on PBMR safeguards requirements can be summarized as follows. 
- The direct-use plutonium content in the discharged pebble is sufficiently low, dilute, and isotopically degraded in the stabilized matrix of the graphitized carbon in the pebble as to satisfy the provisional guidance of the IAEA for termination of safeguards [13-18], given that the methods to recover nuclear material from coated-particle fuels diluted in a substantial graphitized-carbon matrix in a pebble meet the following conditions.

- Have never progressed beyond laboratory scale $[19,20]$ and are likely to be cost prohibitive in a pilot-scale or industrial-scale application, but recognizing that (1) the relevant difference between laboratory scale and pilot scale or above is whether the would-be proliferators are seeking one significant quantity or multiple significant quantities of direct-use nuclear material and (2) the types of equipment tested in the past for coated-particle fuel reprocessing do not appear on either the "Trigger List" $[69,70]$ or the "Dual Use List" [71] for internationally recognized regulated export controls.

- Are difficult to conceal especially when the preferred burn-leach techniques are applied to burning the ${ }^{14} \mathrm{C}$-contaminated graphitized-carbon matrix and fission-product-retaining pyrocarbon coatings of crushed particles.

- Are much less attractive than applying the knowledge base from the exported technology to develop and implement a much less expensive graphitemoderated, natural-uranium-metal-fueled production reactor that is highly amenable to PUREX reprocessing.

- The indirect-use uranium content of the discharged pebble is sufficiently enriched ( $>3 \mathrm{wt} \%$ ) and, depending upon which analysis is accepted by the IAEA, may be found to be diluted insufficiently so as to be above the IAEA provisional guidance to allow termination of safeguards on irradiated LEU; however, the indirect-use uranium is also contaminated with ${ }^{232} \mathrm{U}$ and ${ }^{236} \mathrm{U}$ to the extent that it is less desirable from the standpoints of radiological hazards, detectability in reprocessing, and reactivity penalties in post-reprocessing applications that would be of most interest to the would-be proliferators.

Other aspects of the differing perspective on PBMR used fuel that are discussed and evaluated in this report include the following.

- Consideration of the Department of Energy (DOE) economic discard limit (EDL) criteria for termination of safeguards for DOE-owned special nuclear material (SNM) diluted in solid waste forms from Table I-2 of DOE M470.4-6 [21-24]. The DOE EDL provides historical insights into how a Western nuclear weapons state approached balancing the economic impact of plutonium production with the associated need for waste handling and waste minimization and the need to justify the termination of NMC\&A on discards in a cost-effective manner. Thus, the EDL reflects economic considerations that are not directly included in the IAEA provisional criteria but that are informative as to what may be considered an economic limit for "practicably irrecoverable" nuclear material $[13,14]$, even when minimization of the environmental legacies was not fully addressed in the past decision-making process when compared to today's standards for public acceptability. 
- Consideration of the differing technical aspects of the analogous EDL used for plutonium recovery in the nuclear weapons program of the former Soviet Union [25(a)]. However, the former Soviet EDL for weapon-grade plutonium, which is much lower than the DOE EDL, reflects perhaps the lower limit of what constitutes practicably irrecoverable nuclear material where the cost to the nation was of secondary consideration to its leadership, which largely ignored the environmental legacies in pursuit of perceived national security needs.

- Given the significant dilution of plutonium in the PBMR used fuel so as to be below or only marginal with respect to the IAEA provisional guidance for termination of safeguards, more practical methods for quantifying the fissile content of PBMR used fuel should be considered than that proposed in Reference [1] by expanding one or more of the existing techniques developed to quantify plutonium content in spent fuel. The measurement techniques under consideration would be to quantify that the pebble being discharged to spent fuel storage can be classified as a "measured discard" with regard to its plutonium content and to extend the demonstrated technologies for the Nuclear Material Identification System (NMIS) [26] to the monitoring the fissile content of PBMR used fuel in the spent fuel storage containers.

The main quantitative conclusions from this supplemental analysis are summarized for PBMR used fuel in Table 1, and an equivalent comparison is made for PBMR fresh (unirradiated) fuel in Table 2.

Based on the analysis results presented in Table 1, the PBMR used fuel at the proponent's target discharge burnup of $90.8 \mathrm{GWD} / \mathrm{MT}$ satisfies the IAEA provisional criteria for termination of safeguards on the diluted residual plutonium and may satisfy one method of evaluating the similar criteria for residual uranium without further consideration of the degraded attractiveness for theft or diversion due to the presence of ${ }^{232} \mathrm{U}$ and ${ }^{236} \mathrm{U}$ in the used fuel. In addition, Table 1 illustrates that the discharged pebble separately meets the DOE EDL for termination of safeguards on plutonium and ${ }^{235} \mathrm{U}$ and only barely exceeds the EDL for total SNM based on the sum of the two residuals. However, under the DOE EDL, the PBMR used fuel would still be subject to physical protection requirements from the standpoint of radiological sabotage. The plutonium content shown in Table 1 is within a factor of three of the Soviet EDL for weapon-grade plutonium. The diluted plutonium in the PBMR used fuel is the starting point for the application of an immature, undeveloped, and undemonstrated reprocessing technology, while the former Soviet EDL is the end point with a major investment cost differential between the two points. Since laboratory-scale testing on unirradiated HEU/thorium pebbles from Germany has shown that only $\sim 95 \%$ of the nuclear material is effectively recoverable [20] at a leach timing of 48 hours, applying this factor to the diluted content of plutonium in the PBMR used fuel implies that the potentially recoverable plutonium is only a factor of $\sim 2.7$ above the former Soviet EDL.

The PBMR fresh fuel requires full safeguards with respect to NMC\&A of indirect-use nuclear material (LEU) based on the analysis summarized in Table 2, which is presented to illustrate the margins by which both the IAEA provisional criteria for termination of 
safeguards and the DOE EDL are exceeded by the nuclear material loading in the fresh fuel.

Given the plutonium dilutions limits in Tables 1 and 2, the values for "measured discards" should be compared to those typical of spent assemblies from light water reactors. Where a PBMR used-fuel pebble has a plutonium dilution of a few hundred parts per million (ppm) or $\mathrm{g} / \mathrm{MT}$, a spent light water reactor fuel assembly will have a plutonium dilution of several thousand ppm (or an order of magnitude greater than that of the PBMR used-fuel element). That value will typically double when the metallic structural components of the fuel assembly are removed, leaving only the residual actinide oxide. Thus the pebble more closely resembles a conditioned or stabilized waste form as opposed to a light water reactor fuel assembly that can be disassembled readily by cutting the metal fuel assembly structures giving ready access to the encased leachable fuel material. The cost and effort aspects of recovering such material from pebbles is discussed in Section 7, where the status of coated-particle-fuel reprocessing technology is reviewed along with the results from previous assessments of the costs of recovering materials from "measured discards" on which safeguards had been terminated under the IAEA provisional criteria. 
Table 1. Comparison of PBMR discharged fuel at a burnup of 90.8 GWD/MT to various limits

\begin{tabular}{|c|c|c|c|c|}
\hline $\begin{array}{l}\text { Nuclear } \\
\text { material in } \\
\text { PBMR } \\
\text { pebble at } \\
\text { discharge }\end{array}$ & $\begin{array}{c}\text { Discharged } \\
\text { PBMR pebble } \\
\text { nuclear material } \\
\text { concentration } \\
(\mathrm{ppm})^{a} \text { at } \\
90.8 \mathrm{GWD} / \mathrm{MT}\end{array}$ & $\begin{array}{c}\text { IAEA } \\
\text { provisional } \\
\text { criteria for } \\
\text { termination of } \\
\text { safeguards } \\
(\text { ppm })^{b}\end{array}$ & $\begin{array}{l}\text { DOE Economic } \\
\text { Discard Limit } \\
\text { (EDL) for } \\
\text { termination of } \\
\text { safeguards } \\
\text { (ppm) }\end{array}$ & $\begin{array}{c}\text { Former Soviet } \\
\text { nuclear weapons } \\
\text { program } \\
\text { plutonium/ } \\
\text { recovery EDL } \\
\text { (ppm) }\end{array}$ \\
\hline Plutonium & $\sim 570$ & $\begin{array}{l}500 \text { to } 1143 \text { (in } \\
\text { various solid } \\
\text { waste forms); } \\
\sim 1000 \text { (for a } \\
\text { solid waste form } \\
\text { most similar to a } \\
\text { pebble); } \\
672 \text { (using } \\
\text { Footnote "a" to } \\
\text { Table } 1 \text { in } \\
\text { Reference [16]) }\end{array}$ & 2,000 & $\begin{array}{c}200 \text { (based on } \\
\text { discard sludges } \\
\text { from PUREX } \\
\text { reprocessing and } \\
\text { post-processing of } \\
\text { productions } \\
\text { wastes with } \\
\text { subsequent caustic } \\
\text { precipitation and } \\
\text { nitric acid } \\
\text { processing) }\end{array}$ \\
\hline Uranium & $\sim 41,015$ & $\begin{array}{l}\text { Not specified for } \\
\text { conditioned } \\
\text { /stabilized waste } \\
\text { forms but } \\
\text { inferred to be } \\
\text { 7,635; however, } \\
\text { alternatively, } \\
82,895 \text { (using } \\
\text { Footnote "a" to } \\
\text { Table } 1 \text { in } \\
\text { Reference [16] } \\
\text { for } 1 \text { Significant } \\
\text { Quantity of }{ }^{235} \mathrm{U} \\
\text { in LEU at PBMR } \\
\text { discharge } \\
\text { enrichment) }\end{array}$ & $\begin{array}{l}\text { Not given except } \\
\text { for HEU (see } \\
\text { below) }\end{array}$ & Not given \\
\hline${ }^{235} \mathbf{U}$ & $\sim 1,560$ & $\begin{array}{l}\text { Not specified for } \\
{ }^{235} \mathrm{U} \text { alone nor for } \\
\text { HEU-bearing } \\
\text { wastes }\end{array}$ & 2,000 & Not given \\
\hline
\end{tabular}

${ }^{a} \mathrm{ppm}$ or $\mathrm{g} / \mathrm{MT}$.

${ }^{b}$ Subject to IAEA acceptance as meeting the provisional criteria for termination of safeguards. 
Table 2. Comparison of PBMR fresh (unirradiated) fuel to various limits

\begin{tabular}{|c|c|c|c|c|}
\hline $\begin{array}{c}\text { Fresh } \\
\text { (unirradiated) } \\
\text { nuclear } \\
\text { material in } \\
\text { PBMR pebble }\end{array}$ & $\begin{array}{c}\text { Fresh } \\
\text { (unirradiated) } \\
\text { PBMR pebble } \\
\text { nuclear material } \\
\text { concentration } \\
\text { (ppm) }\end{array}$ & $\begin{array}{l}\text { IAEA } \\
\text { provisional } \\
\text { criteria for } \\
\text { termination of } \\
\text { safeguards } \\
\text { (ppm) }\end{array}$ & $\begin{array}{c}\text { DOE } \\
\text { Economic } \\
\text { Discard Limit } \\
\text { (EDL) for } \\
\text { termination of } \\
\text { safeguards } \\
\text { (ppm) }\end{array}$ & $\begin{array}{c}\text { Former Soviet } \\
\text { nuclear weapons } \\
\text { program } \\
\text { plutonium } \\
\text { recovery EDL } \\
\text { (ppm) }\end{array}$ \\
\hline Plutonium & 0.0 & $>500,<1143$ & 2,000 & 200 \\
\hline Uranium & 45,000 & $\begin{array}{l}\text { Not specified for } \\
\text { conditioned / } \\
\text { stabilized waste } \\
\text { forms; inferred } \\
\text { to be } \\
\text { between } \sim 1,224 \\
\text { (for low activity } \\
\text { waste) and } \\
32,813^{a} \text { for } \\
\text { equilibrium core } \\
\text { fresh pebble) }\end{array}$ & $\begin{array}{l}\text { Not given } \\
\text { except for HEU } \\
\text { (see below) }\end{array}$ & Not given \\
\hline${ }^{235} \mathbf{U}$ & $\begin{array}{l}4,320 \text { (for } 9.6 \mathrm{wt} \\
\% \text { enriched } \\
\text { equilibrium } \\
\text { core); } \sim 2,565 \\
\text { (for } 5.7 \mathrm{wt} \% \\
\text { enriched initial } \\
\text { core load) }\end{array}$ & $\begin{array}{l}\text { Not specified for } \\
{ }^{235} \mathrm{U} \text { alone nor } \\
\text { for HEU- } \\
\text { bearing wastes }\end{array}$ & 2,000 & Not given \\
\hline
\end{tabular}

${ }^{a}$ See analysis in Section 4.3 where the higher value in the table comes from using Footnote "a" to Table 1 in Reference [16] for 1 SQ (75 $\mathrm{kg}$ of $\left.{ }^{235} \mathrm{U}\right)$ in indirect-use LEU at the equilibriumcore enrichment for PBMR fresh fuel. 


\section{BACKGROUND OF THE CURRENT EVALUATION IN REFERENCE [1]}

Detailed information provided by ORNL to Reference [1], which was not incorporated in the final report, included quantitative tabulations of the diluted nature of indirect-use ${ }^{235} \mathrm{U}$ in PBMR fresh fuel and direct-use plutonium (Table 3) in PBMR used fuel from the standpoints of total mass and volumes of fuel material required to be diverted to obtain access to one significant quantity (SQ) of either indirect-use ${ }^{235} \mathrm{U}$ in fresh fuel or directuse plutonium in used fuel. Compared to the data in Table 3 for the plutonium in PBMR used fuel, the diversion of $75 \mathrm{~kg}$ of ${ }^{235} \mathrm{U}$ corresponding to one significant quantity of indirect-use unirradiated LEU would require access to 86,806 fresh pebbles, or $\sim 17.4 \mathrm{MT}$, equating to $\sim 19.6 \mathrm{~m}^{3}$ if only $50 \%$ packing fraction is achieved in a number of small containers.

Table 3. Estimated mass and volume of PBMR pebbles to be diverted for recovery of one significant quantity (1 SQ) of plutonium as a function of recirculation pass

\begin{tabular}{|c|c|c|c|c|}
\hline $\begin{array}{c}\text { Recirculation } \\
\text { pass completed }\end{array}$ & $\begin{array}{c}\text { Number of } \\
\text { pebbles required } \\
\text { to be diverted for } \\
\text { 1 SQ Pu (8 kg) }\end{array}$ & $\begin{array}{c}\text { Total mass of } \\
\text { material to } \\
\text { be diverted } \\
\text { (MT) }\end{array}$ & $\begin{array}{c}\text { Total volume } \\
\text { of material to } \\
\text { be diverted } \\
\mathbf{( m}^{\mathbf{3}} \mathbf{a}^{\mathbf{a}}\end{array}$ & $\begin{array}{c}\text { Plutonium } \\
\text { dilution (g/MT or } \\
\mathbf{p p m} \text { in the used } \\
\text { fuel }\end{array}$ \\
\hline 1st & 170,213 & 34.0 & 46.6 & $\sim 235$ \\
\hline 2nd & 108,108 & 21.6 & 29.4 & $\sim 370$ \\
\hline 3rd & 88,889 & 17.8 & 24.2 & $\sim 449$ \\
\hline 4th & 80,000 & 16.0 & 21.8 & $\sim 500$ \\
\hline 5th & 72,727 & 14.5 & 19.8 & $\sim 552$ \\
\hline 6th & 69,565 & 13.9 & 18.9 & $\sim 575^{b}$ \\
\hline
\end{tabular}

${ }^{a}$ Assumes $50 \%$ packing fraction in multiple small containers; in one large container, the packing fraction may increase up to a random packing of $64 \%$, thereby reducing the quoted volume by a factor of $\sim 0.78$.

${ }^{b}$ This value of $575 \mathrm{ppm}$ differs from the $570 \mathrm{ppm}$ in Table 1 due to the round-off in the different steps in making the respective calculations.

While the quantitative tabulations were not incorporated into the final report, the key conclusion from the ORNL unincorporated information was included in Reference [1], and the final edited version of this conclusion from Reference [1] is quoted as follows.

Since each fresh fuel pebble contains only 9 grams of low enriched uranium in a spherical fuel pebble having a mass of 200 grams, keeping track of thousands of pebbles appears at first blush to be impractical; however, when the special nuclear material (SNM) content of the fresh and irradiated pebble is examined, the mass and volume of material that must be diverted become evident and the problem of diversion becomes one of being able to hide the diversion of metric tons and cubic meters of graphite. The SNM content of irradiated pebbles has been calculated by the designer and several other independent analysts and is consistent with the estimates shown in Table 5.7. The abrupt diversion of 1 SQ of LEU in the form of fresh fuel would require 
a container, or multiple containers, having a total volume between of 20 $25 \mathrm{~m}^{3}$. This is equivalent to between five and six standard-sized dump trucks in the United States - a very large movement of bulk material and one that should be detectable with effective safeguards measures. For the diversion of one SQ plutonium in the form of spent fuel, the diverter would require two to four standard sized dump trucks. Additionally, the spent fuel would need to be packed in shipping casks, because of the high radiation, which would make the material movement bulkier and easier to detect. By comparison with a typical light water reactor, a single fresh PWR fuel assembly contains an average of 1/4 SQ of LEU. A fully irradiated PWR fuel subassembly (at $55 \mathrm{GWd} / \mathrm{t}$ ) contains $1 / 2 \mathrm{SQ}$ of plutonium. In all cases for the PWR the nuclear material content of a given volume of PWR vs. PBMR fuel is ten times greater, or more.

Also not incorporated in the final report [1] was the suggestion from ORNL that the Nuclear Material Identification System (NMIS) should be considered for further testing and development for application in measuring the fissile content for NMC\&A of the PBMR used-fuel storage tanks. Instead, Reference [1] suggests the development of an anti-neutrino detector, which, as currently developed and used by physicists as instrumentation in such experimental work as the Large Hadron Collider in Switzerland, tends to be a large device requiring extensive shielding (under hundreds of meters of earth or granite) to avoid undesired interactions with cosmic rays and is not very sensitive to the particle it is supposed to detect. Exactly how the anti-neutrino detectors would be employed for PBMR safeguards is not fully addressed in Reference [1] including whether such detectors would be used merely to infer burnup of the mix of pebbles in the operating PBMR or to perform surveillance on the spent fuel storage. However, within the last decade, tests have been performed on small (cubic meter) detectors set close ( 25 $\mathrm{m})$ to an operating nuclear reactor core where the anti-neutrino flux from both fissions and the $\beta$-decay of fission products is extremely high [27-29]. These smaller detectors have been shown to be sufficiently sensitive to detect reactor power variations including variations in the anti-neutrino flux resulting from refueling of the reactor, at which times spent fuel diversion might occur. How such detectors could be demonstrated to be effective in observing the fissions of plutonium versus uranium isotopes from subcritical multiplication with the source neutrons generated by spontaneous fissions of primarily the ${ }^{240} \mathrm{Pu}$ in spent fuel storage canisters is unclear since the fission rates would be something like ten orders of magnitude lower, if not more, than in the operating reactor. In addition, since spent fuel storage for the PBMR is located adjacent to the reactor inside the reactor building to promote physical protection, it is not clear how such a detector would distinguish between the extremely low subcritical fission rates in the spent fuel storage versus the dominating anti-neutrino flux from the operating reactor. The implication is that the anti-neutrino detectors are going to have to be either very much larger (and more expensive) or very much more sensitive than those currently being tested on reactors but either way implying a time-consuming and expensive development effort. On the other hand, NMIS has been used to identify and quantify both uranium and plutonium in various storage configurations. 
With regard to the safeguards for PBMR used fuel, Reference [1] defers to an evaluation by Idaho National Laboratory (INL) [4] of fully burned PBMR-400 spent fuel. The INL evaluation focuses on plutonium and refers without quantification to the IAEA Safeguards Manual and to the manual's tabulation in Policy 2.14 of the dilution limits for plutonium-bearing discards in the wastes from fuel reprocessing but fails to provide a quantitative comparison of the unquoted limit values to the dilution of SNM in PBMR spent fuel. Focusing only on direct-use plutonium, the only quantitative comparison in Reference [4] is made for the fraction or percentage of ${ }^{238} \mathrm{Pu}$ in the spent fuel, which is much less than the IAEA limit of a minimum of $80 \mathrm{wt} \%$, leading to the conclusion in the INL evaluation that the fuel does not qualify for termination of safeguards without further elaboration of the significance of the degree of dilution of the residual SNM. The INL evaluation does not provide an evaluation of the practical impact of the dilution of the SNM residual in the spent fuel on the economics and technical difficulty of recovery versus possibly more direct and less expensive alternatives such as constructing a covert production reactor and PUREX-based reprocessing facility. The INL evaluation [4], without a substantive review of the history of the technology development, reached the following conclusions about the practicality of reprocessing coated-particle fuel.

The recovery of the plutonium could be expensive but not necessarily prohibitive. The plutonium contained in the PBMR-400 spent fuel cannot be considered to be irretrievable. Furthermore, the $\mathrm{Pu}-239$ content of the spent fuel, though small, is sufficient to be of interest to a would-be proliferant, especially in the case of an outright diversion of large numbers of spent fuel pebbles.

Therefore, the INL evaluation [4] does not attempt to elaborate on nor quantify how the verbiage "cannot be considered to be irretrievable" equates to the verbiage "practicably irrecoverable" in the IAEA requirements for termination of safeguards $[13,14]$ beyond the following statements.

The strict adherence to the $80 \%{ }^{238} \mathrm{Pu}$ content requirement for termination of safeguards has been criticized by many authors. Proponents of a lower limit have put forward defensible arguments in favor of such a lesser limit as well as arguments in favor of a criterion that takes into account the mix of all plutonium isotopes in formulating a condition for termination of safeguards. Despite those advocates of a different limit, the present works adheres strictly to the criterion of a ${ }^{238} \mathrm{Pu}$ content for termination of safeguards. This choice is made in order to be most responsive to the needs of the IAEA and because there could be significant physics reasons for even this criterion to be insufficiently conservative, although the details underlying this remark are beyond the scope of this project.

The INL evaluation [4] also tacitly equates the termination of safeguards to the termination of NMC\&A without differentiating between NMC\&A and the physical protection aspect/requirements for maintaining safeguards. 


\section{DISCUSSION OF THE REFERENCED PBMR BURNUP ANALYSES [2-4]}

As noted in Section 1, the INL burnup analysis [4] is compared to the PBMR (Pty) Ltd. burnup analysis [2,3] in Appendix A. The conclusion of the comparison in Appendix A is that the INL analysis yielded the following.

- A burnup that is $\sim 24 \%$ higher than the target burnup used in the PBMR (Pty) Ltd. analysis, that is, $\sim 113 \mathrm{GWD} / \mathrm{MT}$ compared to $90.8 \mathrm{GWD} / \mathrm{MT}$, equating to $\sim 1.5$ additional passes for pebble recirculation beyond the target number of 6 passes in the PBMR (Pty) Ltd. analysis

- An $\sim 23 \%$ higher amount of plutonium in the discharged pebble that, while linear with the excess burnup, seems to be on the high side and inconsistent with the projected plutonium build-in trajectory calculated and plotted by PBMR (Pty) Ltd. This amount, obtained by visual inspection/projection of plotted results from the PBMR (Pty) Ltd. analysis, was estimated to be $\sim 0.120 \mathrm{~g} /$ pebble at the higher burnup ( $\sim 13 \mathrm{GWD} / \mathrm{MT})$ achieved in the INL analysis."

In addition, the comparison in Appendix A indicates that the discharge enrichment of

${ }^{235} \mathrm{U}$ in a LEU pebble achieving the target burnup of $90.8 \mathrm{GWD} / \mathrm{MT}$ is estimated to be $\sim 3.8 \mathrm{wt} \%$ in uranium, equating to $\sim 1,560 \mathrm{ppm}$ of SNM in the pebble. As discussed in the following section, the IAEA limit of the provisional criteria for termination of safeguards on uranium-bearing unconditioned waste is for LEU ( $<20 \%$ enriched) or natural uranium and does not further address the ${ }^{235} \mathrm{U}$ enrichment. Also, the presentation of the IAEA provisional criteria based on consensus does not provide a limit for LEU in conditioned (stabilized) waste forms. From Appendix A, the estimated total LEU diluted content of a discharged pebble at a burnup of $90.8 \mathrm{GWD} / \mathrm{MT}$ would be $\sim 41,015 \mathrm{ppm}$ or $\sim 4.1 \mathrm{wt} \%$ for LEU in the discharged pebble.

In addition, the analyses reported in References [2] through [4] do not quantify the discharge quantities of either ${ }^{232} \mathrm{U}$ or ${ }^{236} \mathrm{U}$ that impact the attractiveness from a radiological risk standpoint, the detectability of attempted covert reprocessing, and the utility of the potentially recoverable LEU in PBMR used fuel. Instead, Section 3.4 of Reference [4] states, without acknowledging, due to the reactivity penalty from ${ }^{236} \mathrm{U}$, the need for blending with natural uranium and re-enrichment to the higher enrichments required to achieve the same burnup for current light water reactor fuel cycles [7-10].

All of these fissile materials contents predicted for the spent fuel have roughly the same magnitude as the fissile content of fresh light water reactor fuel. As a consequence, with a small amount of processing the PBMR-400 spent fuel could be used as source of fuel for another reactor, albeit not another PBMR.

\footnotetext{
* As discussed in Appendix A, the analysis by INL reports a value of $\sim 0.14 \mathrm{~g}$ of plutonium per pebble (or $\sim 700 \mathrm{ppm}$ or $0.07 \mathrm{wt} \%$ ) but does not quote a burnup for the analyses performed; however, it can be inferred from the mass balances of uranium and plutonium that the burnup in the analysis was likely closer to $>\sim 113 \mathrm{GWD} / \mathrm{MT}$ or $\sim 7.5$ pebble recirculations as opposed to 6 . By similar inference/extrapolation from the analysis by PBMR (Pty) Ltd., the plutonium content for an equivalent 7.5 recirculation passes would be about $0.12 \mathrm{~g}$.
} 
The supplemental analysis provided in Appendix A uses other sources and techniques to provide estimates of the key isotopic data that are not reported in the referenced analyses [2-4] but that may provide a useful basis for assessing associated proliferation risks. 


\section{DISCUSSION OF THE IAEA PROVISIONAL CRITERIA FOR TERMINATION OF SAFEGUARDS [13-18]}

The IAEA provisional criteria are based on non-binding international consensus guidance [15-18] subject to implementation in a state with IAEA approval so as to meet the intent of agreements with the IAEA under an IAEA-approved safeguards system $[13,14]$ that provides for the following.

The Agreement should provide that safeguards shall terminate on nuclear material subject to safeguards thereunder upon determination by the Agency that it has been consumed, or has been diluted in such a way that it is no longer usable for any nuclear activity relevant from the point of view of safeguards, or has become practicably irrecoverable.

The guidance issued in References [15] through [18] relates to waste forms of measured discards from nuclear fuel fabrication and reprocessing activities where spent fuel is understood to remain subject to safeguards for purposes of physical protection if not NMC\&A at least until final disposal in a geologic repository wherein continued monitoring will be required to ensure that no subsequent access is made to the disposed spent fuel or nuclear material-bearing wastes in the geologic repository. However, the guidance is used here to assess the relative dilution of plutonium and uranium in the PBMR used fuel with respect to the need for continued NMC\&A of the highly diluted plutonium. Proposed methods to demonstrate how PBMR used fuel can be asserted to meet the IAEA definition for a "measured discard" under Paragraph 107(b)(iv) of Reference [14] are addressed later in Section 8.2 of this report.

\subsection{Analysis of the IAEA Provisional Criteria for Termination of Safeguards as a Basis for Termination of NMC\&A on Plutonium in Discharged LEU Pebbles}

Table 4 is based on the IAEA provisional criteria for termination of safeguards for plutonium diluted in "conditioned waste." Conditioned waste is understood from context but not specifically defined by IAEA to mean "stabilized" in terms of not allowing for or resisting the leakage or leaching of the enclosed nuclear material or similarly resisting access to remove external nuclear material contamination on the surfaces of the enclosed contaminated material. In this sense, the enclosure of coated particles in graphitized carbon or graphite has been recognized by technical experts in both Germany and the United States as sufficiently stabilized for disposal in a repository with no additional steps required beyond canning, with or without an interstitial mix of non-soluble material in the can, where canning is primarily required to facilitate handling of multiple fuel elements [30-34].

As noted in Table 4, the minimum criterion for termination of safeguards on plutoniumbearing conditioned wastes is a dilution limit of $\sim 500 \mathrm{~g} / \mathrm{MT}$ or $500 \mathrm{ppm}$ by mass. This value is for surface-contaminated fuel clad hulls diluted in normal-density concrete at $1,200 \mathrm{~g} / \mathrm{m}^{3}$. As summarized from various tables in Reference [15], the data presented in

Table 1, page 206, Reference [17] and in Table E1, page 78, Reference [18] are both 
given in terms of ppm of weight/volume or $\mathrm{g} / \mathrm{m}^{3}$. Only, the assessment in Table 1 of Reference [16] provides a mass-to-mass ratio-based interpretation of this criterion that requires knowledge of or an assumption about the density of the diluting material.

The $500 \mathrm{~g} / \mathrm{MT}$ is the same value quoted in Footnote "a" of Table 1 of Reference [16], which footnote also states that "Termination criteria based on IAEA-proposed value of $500 \mathrm{~g} \mathrm{Pu} / \mathrm{MT}$ solids ( 0.042 critical mass/MT solids where the critical mass is calculated from a mixture of isotopes for the actinide element)." This footnoted statement is not discussed elsewhere in official IAEA documentation but is understood from discussions

Table 4. Conversion of STR-251 (Rev 2) [15] plutonium concentrations in conditioned waste forms from $\mathrm{g} / \mathrm{m}^{3}$ (as presented) to equivalent parts per million (ppm or $\mathrm{g} / \mathrm{MT}$ )

\begin{tabular}{|c|c|c|c|c|c|c|}
\hline $\begin{array}{l}\text { Plutonium- } \\
\text { bearing waste } \\
\text { form }\end{array}$ & \multicolumn{2}{|c|}{$\begin{array}{c}\text { Maximum } \\
\text { concentration of } \\
\text { plutonium in a batch } \\
\text { of waste conditioned } \\
\text { in glass (vitrified) }^{a}\end{array}$} & \multicolumn{2}{|c|}{$\begin{array}{c}\text { Maximum concentration } \\
\text { of plutonium in a batch } \\
\text { of waste conditioned in } \\
\text { cement }\end{array}$} & \multicolumn{2}{|c|}{$\begin{array}{c}\text { Concentration of } \\
\text { plutonium in a } \\
\text { batch of waste } \\
\text { conditioned in } \\
\text { bitumen }\end{array}$} \\
\hline $\begin{array}{l}\text { Density of } \\
\text { diluent in waste } \\
\text { form }\end{array}$ & $\begin{array}{r}\text { Nor } \\
2.4 \text { to } \\
\text { Lea } \\
3.1\end{array}$ & $\begin{array}{l}1 \text { glass: } \\
8 \mathrm{MT} / \mathrm{m}^{3} \\
\text { glass: } \\
\text { IT } / \mathrm{m}^{3}\end{array}$ & $\begin{array}{l}\text { Cem } \\
\text { low dens } \\
\text { normal d }\end{array}$ & $\begin{array}{l}\text { concrete: }^{b} \\
1.75 \mathrm{MT} / \mathrm{m}^{3 ;} \\
\text { ty } 2.4 \mathrm{MT} / \mathrm{m}^{3}\end{array}$ & $\begin{array}{r}\mathrm{Bi} \\
\sim 1 .\end{array}$ & iT $:^{c} \mathrm{~m}^{3}$ \\
\hline Concentration & $g / m^{3}$ & $\begin{array}{c}\text { g/MT or } \\
\text { ppm }\end{array}$ & $\mathrm{g} / \mathrm{m}^{3}$ & $\begin{array}{c}\text { g/MT or } \\
\text { ppm }\end{array}$ & $\mathrm{g} / \mathrm{m}^{3}$ & $\begin{array}{l}\text { g/MT } \\
\text { or ppm }\end{array}$ \\
\hline $\begin{array}{l}\text { Hulls (externally } \\
\text { contaminated } \\
\text { with plutonium) }\end{array}$ & & & $1,200^{d}$ & $\begin{array}{c}500 \text { (normal) } \\
\text { to } 686 \text { (low } \\
\text { density) }\end{array}$ & & \\
\hline $\begin{array}{l}\text { Fixed } \\
\text { clarification } \\
\text { sludges }\end{array}$ & $2,500^{d}$ & $\begin{array}{c}645 \\
\text { (leaded) to } \\
1,042 \\
\text { (normal } \\
\text { lowest } \\
\text { density) }\end{array}$ & $2,000^{d}$ & 833 to 1,143 & & \\
\hline $\begin{array}{l}\text { High active } \\
\text { liquid }\end{array}$ & $2,500^{d}$ & $\begin{array}{l}645 \text { to } \\
1,042\end{array}$ & & & & \\
\hline $\begin{array}{l}\text { Medium active } \\
\text { liquid }\end{array}$ & & & $1,600^{d}$ & 667 to 914 & $600^{d}$ & 600 \\
\hline
\end{tabular}

${ }^{a}$ Densities of glasses from http://hypertextbook.com/facts/2004/ShayeStorm.shtml

${ }^{b}$ Densities of concretes from http://hypertextbook.com/facts/1999/KatrinaJones.shtml

${ }^{c}$ Density of bitumen from http://wiki.answers.com/Q/What is the density of bitumen

${ }^{d}$ By comparison on a volumetric basis, $0.114 \mathrm{~g}$ of plutonium per pebble divided by a net volume (including surrounding void) of $0.0001527 \mathrm{~m}^{3}$ per pebble when optimally packed (highest density) in a large container is $747 \mathrm{~g} / \mathrm{m}^{3}$. At random packing $\left(0.0001767 \mathrm{~m}^{3}\right)$ in a large container, this value reduces to $645 \mathrm{~g} / \mathrm{m}^{3}$. In a small container at $50 \%$ packing $\left(0.0002262 \mathrm{~m}^{3}\right)$, this value reduces to $504 \mathrm{~g} / \mathrm{m}^{3}$. In a single pebble (packing fraction of 1.0), the maximum value becomes $1007 \mathrm{~g} / \mathrm{m}^{3}$.

with the principal author of Reference [16] to represent an internal U.S. expert assessment technique that was based on correlating the IAEA 500g/MT in nuclear waste with a bare critical mass of $11.9 \mathrm{~kg}$ of unspecified plutonium isotopics. Since the principal author of Reference [16] was unable to recall exactly how the critical mass was 
established, the following assessment of this technique was made to correlate the dilution of actinide content in a stabilized waste form with its minimum bare metallic critical mass as an index of its utility in a nuclear weapon if the actinide material were to be recovered from the waste form.

\subsubsection{Calculating the critical mass of a bare sphere with a homogeneous loading of plutonium recovered from spent fuel or nuclear waste}

Using transport-theory analytical tools and appropriate data for both material densities and neutron cross sections available in various data libraries, the critical mass of a bare sphere with various actinide nuclides or mixtures can be performed with the tools available, as described in Reference [35]. Reference [35] also provides a correlation between the calculated critical mass $(\mathrm{kg})$ and the fission-spectrum-averaged fissionmicroscopic cross section for each actinide isotope, but this correlation, which only applies to a single isotope in the set of actinide isotopes correlated, does not need to be repeated here but may be a useful tool for others. Finally, Reference [35] also provides the most recent crystallographic data for fissionable actinide isotopic densities where it is noted that the plutonium isotopes do have an isotopic-dependent variation in the densest $\alpha$-phase.

If a detailed analytical model is not used to calculate the bare sphere critical mass, then there are sufficient data to use correlated approximations. It can be shown from transporttheory-adjusted one-group diffusion theory, applied to a bare sphere of homogenous fissile material (especially applicable for fast neutron critical configurations), by solving for the critical radius, $r_{c}$, of the sphere, that the value of the critical radius is

$$
\mathrm{r}_{\mathrm{c}}=\left(\pi /\left[3 \Sigma_{\mathrm{tr}}\left(\mathrm{v} \Sigma_{\mathrm{f}}-\Sigma_{\mathrm{a}}\right)\right]^{1 / 2}\right)-\left(2.13 / 3 \Sigma_{\mathrm{tr}}\right) .
$$

Since the various macroscopic neutron cross sections $(\Sigma)$ are directly proportional to the homogeneous density, $\rho$, of the nuclear material, the sphere critical radius, $r_{c}$, is inversely proportional to the homogeneous density, $\rho$; that is,

$$
r_{c} \propto \rho^{-1} \text {. }
$$

The mass of a homogeneously loaded sphere varies directly with the volume that in turn varies with the cube of the radius:

$$
\mathrm{M}=\rho \mathrm{V}=\rho\left(4 \pi \mathrm{r}^{3} / 3\right)
$$

Therefore, for homogeneous fissile material, the bare critical mass varies as follows:

$$
M_{c} \propto \rho^{-2} .
$$

The relationship between the critical mass, $\mathrm{M}_{\mathrm{c}}$, for a bare sphere and the homogenous density of contained fissile material is described in Appendix C (pages 21-22), "Explanation of the $m_{\text {critical }} \propto \rho^{-1.6}$ Relationship" as applied to a reflected sphere in comparison to a bare sphere, of Reference [36] as being

$$
M_{2}=M_{1}\left(\rho_{1} / \rho_{2}\right)^{2}
$$


This Los Alamos correlation for estimating bare critical masses based on the inverse proportionality to the change in homogeneous density can be applied to the Los Alamos re-evaluated critical masses for the Los Alamos bare homogeneous plutonium critical spheres JEZEBEL and JEZEBEL-240, as described in Table 1 of Reference [37]. These experimental critical mass data are based on the lower near $\delta$-phase densities of the plutonium used in the critical experiments. The above correlation can be used to adjust the measured critical mass data for the $\delta$-phase plutonium metal to estimate the bare critical mass of the denser $\alpha$-phase with a density of $\sim 19.8 \mathrm{~g} / \mathrm{cm}^{3}$ (that would exist in the limit at the center of a plutonium pit during a nuclear implosion-detonation) from Table II of Reference [38]. " Using this technique, the highest density bare-sphere critical masses for JEZEBEL and JEZEBEL-240 plutonium isotopics can be estimated as given in Table 5.

Table 5. Adjusted $\alpha$-phase density bare-sphere critical masses from near $\delta$-phase density plutonium bare-sphere critical experiments

\begin{tabular}{|c|c|c|c|c|c|c|c|}
\hline \multirow[b]{2}{*}{$\begin{array}{c}\text { Critical } \\
\text { Experiment }\end{array}$} & \multicolumn{4}{|c|}{ Plutonium isotopic mass fractions } & \multirow{2}{*}{$\begin{array}{c}\text { Re-evaluated } \\
\text { plutonium } \\
\text { density } \\
\delta \text {-phase } \\
\left(\mathrm{g} / \mathrm{cm}^{3}\right)\end{array}$} & \multirow{2}{*}{$\begin{array}{c}\text { Re-evaluated } \\
\text { critical mass } \\
\delta \text {-phase } \\
(\mathrm{kg})\end{array}$} & \multirow{2}{*}{$\begin{array}{c}\text { Critical mass } \\
\text { adjusted to } \\
\alpha-p h a s e \\
{ }^{a} \\
\text { (kg) }\end{array}$} \\
\hline & ${ }^{239} \mathrm{Pu}$ & ${ }^{240} \mathrm{Pu}$ & ${ }^{241} \mathrm{Pu}$ & ${ }^{242} \mathrm{Pu}$ & & & \\
\hline JEZEBEL & 0.952 & & 0.00 & --- & 15.61 & 17.02 & $\sim 10.6$ \\
\hline JEZEBEL-240 & 0.764 & 0.201 & 0.031 & 0.004 & 15.73 & 19.46 & $\sim 12.3$ \\
\hline
\end{tabular}

${ }^{a}$ For the $\beta$-phase (density equals $17.8 \mathrm{~g} / \mathrm{cm}^{3}$ ), the adjusted critical masses would be $\sim 13.1 \mathrm{~kg}$ for JEZEBEL and $\sim 15.2 \mathrm{~kg}$ for JEZEBEL-240.

Thus, the estimated $\alpha$-phase critical masses for JEZEBEL and JEEZEBEL-240 bracket the $11.9 \mathrm{~kg}$ upon which the 0.042 multiplier is based to correlate bare critical mass (in grams) with the $500 \mathrm{~g} / \mathrm{MT}$ minimum IAEA provisional criterion for dilution in plutonium-bearing waste. The multiplying factor of 0.042 has not been endorsed by the IAEA but rather reflects an independent assessment methodology derived by informed American staff familiar with the IAEA consultant's assessment $[15,16]$. By comparison, the factors to correlate, respectively, the JEZEBEL critical mass for weapon-grade plutonium and the JEZEBEL-240 critical mass for the late 1950s or early 1960s reactorgrade plutonium isotopics with the IAEA minimum provisional criterion of $500 \mathrm{~g} / \mathrm{MT}$ in plutonium-bearing waste would be $\sim 0.047$ for weapon-grade isotopics used in JEZEBEL and $\sim 0.041$ for the older reactor-grade isotopics used in JEZEBEL-240.

Therefore, the factor of 0.042 times the critical mass will continue to be used in the current analysis documented in this report as a basis for estimating the acceptable plutonium dilution in waste forms in spite of the facts that (1) this factor lacks official status of acceptance by the IAEA (all such analysis is subject to IAEA approval under References [13] and [14]) and (2) the exact basis for the assumed $11.9 \mathrm{~kg}$ critical mass in Reference [16] could not be asserted by the principal author of Reference [16], as noted above. However, the above analysis indicates that the factor is a reasonably based method

\footnotetext{
* By comparison, Reference [35] indicates that the most recent crystallographic data shows an average plutonium metal $\alpha$-phase density of $19.851 \mathrm{~g} / \mathrm{cm}^{3}$, which would reduce the adjusted masses in Table 5 by $\sim 0.08 \mathrm{~kg}$.
} 
to correlate the bare-sphere critical mass with the minimum acceptable plutonium dilution limit in a conditioned/stabilized waste form.

However, the estimation technique requires confirmation for the calculation referred to in the statement "where the critical mass is calculated from a mixture of isotopes for the actinide element." Rather than actually calculating the critical mass with a neutron transport-theory analytical tool with a given data set of neutron cross section data, an approximation recognized in a criticality safety consensus standard will be used to demonstrate the conservative utility of the estimation process. Table 6 compares the JEZEBEL and JEZEBEL-240 $\alpha$-phase critical masses to estimates that are based on using the generally accepted criticality-safety Rule of Fractions (ROF) from the standard ANSI/ANS-8.15 [39]. The ROF has been validated conditionally for homogeneous mixtures of fissile-fissile metals as discussed in Reference [40] at least for compositions of two fissile metals. Since the ROF is primarily used to assess the subcritical multiplication factor $\left(\mathrm{k}_{\mathrm{eff}}\right)$ to ensure continued subcriticality in the safe handling and transport of fissionable nuclear materials and since the ROF may vary significantly for complicated mixtures of fast and thermal neutron-fissionable materials, the French regulator, Institut de Radioprotection et de Sûreté Nucléaire (IRSN), has proposed a conservative method for estimating acceptably subcritical masses designated as the Criticality Safety Index (CSI) [41]. However, the CSI biases the estimation process in an overly conservative manner so that the use of the ROF is more appropriate for the estimation of the bare sphere critical mass for plutonium metal isotopic mixtures. Derivation of the critical mass estimation process is given as follows using the IRSN nomenclatures from Section 4.1.3 (pages 29-30) of Reference [41] applied to a presumed critical system $\left(\mathrm{k}_{\mathrm{eff}}=1.0\right)$, where $\mathrm{FCM}_{i}$ is the Fraction of Critical Mass for isotope $i$ summed over the set of isotopes $i$ :

and

$$
\Sigma_{i} \mathrm{FCM}_{i} \approx 1.0
$$

$$
\Sigma_{i}\left(\mathrm{~m}_{i} / \mathrm{M}_{c i}\right) \approx 1.0
$$

where $\mathrm{m}_{i}$ is the mass of isotope $i$ and $\mathrm{M}_{c i}$ is the bare critical mass of isotope $i$.

$$
\begin{gathered}
\Sigma_{i}\left(\left[(\text { mass fraction })_{i} \times \mathrm{M}_{\text {total }}\right] / \mathrm{M}_{\mathrm{ci}}\right) \approx 1.0 . \\
\Sigma_{i}\left(\left[(\text { mass fraction })_{i}\right] / \mathrm{M}_{c i}\right) \approx 1.0 / \mathrm{M}_{\text {total }} . \\
\mathrm{M}_{\text {total }} \approx 1 / \Sigma_{i}\left(\left[(\text { mass fraction })_{i}\right] / \mathrm{M}_{c i}\right) .
\end{gathered}
$$

The ROF correlation to estimate the total critical mass of the mixture $\left(\mathrm{M}_{\text {total }}\right)$ compared to the adjusted $\alpha$-phase critical mass of the JEZEBEL and JEZEBEL-240 critical experiments is presented in Table 6 using the metal plutonium isotopic bare critical mass data $\left(\mathrm{M}_{c i}\right)$ quoted for assessing the proliferation attributes of spent fuel in Table 1 of Reference [42]. 
Table 6. Critical mass estimates for JEZEBEL and JEZEBEL-240 using the ROF technique

\begin{tabular}{|c|c|c|c|}
\hline \multirow[b]{2}{*}{ Plutonium isotope } & \multirow{2}{*}{$\begin{array}{l}\text { Bare-sphere critical } \\
\text { mass (kg) }[42]\end{array}$} & \multirow{2}{*}{$\begin{array}{c}\text { JEZEBEL } \\
\begin{array}{l}\text { Isotopic mass } \\
\text { fraction }\end{array}\end{array}$} & \multirow{2}{*}{$\begin{array}{c}\text { JEZEBEL-240 } \\
\begin{array}{c}\text { Isotopic mass } \\
\text { fraction }\end{array} \\
\end{array}$} \\
\hline & & & \\
\hline${ }^{239} \mathrm{Pu}$ & 10 & 0.952 & 0.764 \\
\hline${ }^{240} \mathrm{Pu}$ & 36 & 0.045 & 0.201 \\
\hline${ }^{241} \mathrm{Pu}$ & 13 & 0.003 & 0.031 \\
\hline${ }^{242} \mathrm{Pu}$ & 92 & --- & 0.004 \\
\hline \multicolumn{2}{|c|}{ Estimated bare-sphere critical mass $(\mathrm{kg})$} & $\sim 10.3$ & $\sim 11.8$ \\
\hline \multicolumn{2}{|c|}{$\alpha$-phase-adjusted bare-sphere critical mass $(\mathrm{kg})$} & $\sim 10.6$ & $\sim 12.3$ \\
\hline \multicolumn{2}{|c|}{ Ratio of adjusted-to-estimated critical mass } & $\sim 1.03$ & $\sim 1.04$ \\
\hline
\end{tabular}

Table 6 illustrates that the ROF method is conservatively low for estimating the $\alpha$-phase critical mass for the plutonium isotopic mixtures in JEZEBEL and JEZEBEL-240 and presumably will remain conservatively low as the non-fissile but fast-neutron-fissionable concentrations of ${ }^{240} \mathrm{Pu}$ and ${ }^{242} \mathrm{Pu}$ increase with used-fuel burnup. Therefore, rather than doing precise calculations with transport-theory analytical models, the ROF method will be used to estimate the critical mass for the PBMR used-fuel isotopics.

Based on the value $(11.8 \mathrm{~kg})$ in Table 6 for the estimated $\alpha$-phase bare-sphere critical mass for JEZEBEL-240 using the ROF, it may be that the $11.9 \mathrm{~kg}$ reportedly used in Footnote "a" to Table 1 of Reference [16] was derived in a similar manner to be representative of reactor-grade plutonium for the isotopic fractions of spent fuel in the early 1960s.

\subsubsection{Basis for terminating NMC\&A on plutonium in PBMR used fuel based on IAEA "provisional" criteria for termination of safeguards as presented in Table 4}

Assuming that the pebble with coated particles represents a conditioned/stabilized form, the assessment of the Table 4 criteria for the considered waste forms compared to the graphitized-carbon pebble leads to a conclusion that an acceptable criteria for termination of safeguards for NMC\&A due to plutonium dilution in the pebble and inside coated particles can be argued to be closer to $\sim 1,000 \mathrm{~g} / \mathrm{MT}$ or $\sim 1,000 \mathrm{ppm}$.

One of course can counter-argue that the pebble can be ground, burned, and leached with acids just as breakage or grinding can be applied to the conditioned/stabilized waste forms cited in Table 4 where hydrofluoric acid can be applied to vitrified waste forms and other acids to cemented concrete to recover plutonium. This argument would be analogous to that presented by INL in Reference [4] that "the plutonium contained in the PBMR-400 spent fuel cannot be considered to be irretrievable." This argument is also analogous to the Russian-interpreted results of Russian testing of the U.S.-proposed glass or ceramic forms for the immobilization of weapon-grade plutonium [25(b), 25(c)] where the Russian analysts' conclusion from testing of small specimens is quoted as follows. 
The investigation performed should have provided the answer to the question of whether plutonium incorporation into vitreous or ceramic compositions could create an additional barrier in the nonproliferation system...The results reported have shown that plutonium incorporation into the studied compositions is a poor obstacle against its unauthorized use.

The quoted Russian conclusion is based on laboratory-scale testing of unirradiated specimens and does not account for the time and expense required to convert a laboratory-scale test into an engineered and implemented pilot-scale or industrial-scale operating facility capable of recovering one to multiple significant quantities of plutonium. Of course, the referenced work was for the immobilization of weapon-grade plutonium in a massive can-in-canister configuration with ${ }^{137} \mathrm{Cs}$ in glass inside the canister enclosing the cans, where each can was to contain up to $5 \mathrm{wt} \%$ plutonium in glass or $15 \mathrm{wt} \%$ plutonium in a ceramic. The barriers provided by mass and radiation were also not considered in the Russian analysis, which focused merely on the resistance to chemical processing of small samples of the glass and ceramic. Diversion and reprocessing of this proposed immobilized form for weapon-grade plutonium would be analogous to diverting several metric tons of irradiated pebbles in an attempt to recover less-than-weapon-grade plutonium.

\subsubsection{Basis for terminating NMC\&A on plutonium in PBMR used fuel by applying the criterion given in Footnote " $a$ " in Table 1 of Reference [16]}

As derived in Section 4.1.1 above, Footnote "a" quoted above from Table 1 in Reference [16] provides another methodology beyond simple comparison to the g/MT or ppm limits given in Table 4 to assess the acceptability of the dilution of isotopically degraded plutonium in the discharged pebble. As discussed in Section 4.1.1, this criterion is 0.042 critical mass/MT solids where the critical mass is calculated from a mixture of isotopes for the actinide element. Also discussed in Section 4.1.1, the ROF can be used to estimate with some confidence the bare minimum critical mass from a mixture of isotopes for the residual plutonium without performing a separate transport-theory calculational analysis.

From Figure 8 of Reference [2] as quantified in Appendix A of this report, the predicted plutonium isotopic fractions of the $90.8 \mathrm{GWD} / \mathrm{MT}$ discharged pebble are known. With this information, the $\alpha$-phase bare-sphere critical mass using recovered plutonium can be estimated using the ROF method. The resulting estimated bare-sphere critical mass is presented in Table 7.

For a critical mass of $16 \mathrm{~kg}$ ( or 16,000 $\mathrm{g}$ ) from Table 7, the results of applying the criterion in Footnote "a" of Table 1 to Reference [16] is 16,000 $\mathrm{g} \times 0.042=672 \mathrm{~g} / \mathrm{MT}$ or $672 \mathrm{ppm}$.

At $0.114 \mathrm{~g}$ of plutonium in a $200 \mathrm{~g}(0.0002 \mathrm{MT})$ pebble, the dilution of the plutonium in the pebble corresponds to $570 \mathrm{ppm}$ by mass. Thus, the dilution of the plutonium in the pebble corresponds to $570 \mathrm{ppm}$ and is therefore below both the inferred 1,000 ppm criterion from equivalent waste forms as discussed in Section 4.1.2 above from Table 4 
Table 7. Estimated minimum critical mass of plutonium isotopic mix in a discharged pebble at a burnup of $90.8 \mathrm{GWD} / \mathrm{MT}$

\begin{tabular}{|c|c|c|c|}
\hline Plutonium isotope & $\begin{array}{c}\text { Mass in discharged } \\
\text { pebble (g) [9] }\end{array}$ & Mass fraction & $\begin{array}{c}\text { Minimum critical } \\
\text { mass (kg) (bare } \\
\text { sphere) [21] }\end{array}$ \\
\hline${ }^{239} \mathrm{Pu}$ & $\sim 0.044$ & 0.386 & 10 \\
\hline${ }^{240} \mathrm{Pu}$ & $\sim 0.027$ & 0.237 & 36 \\
\hline${ }^{241} \mathrm{Pu}$ & $\sim 0.023$ & 0.202 & 13 \\
\hline${ }^{242} \mathrm{Pu}$ & $\sim 0.020$ & 0.175 & 92 \\
\hline Estimated TOTAL & $\sim 0.114$ & 1.000 & $\sim 16.0$ \\
\hline
\end{tabular}

and the inferred $672 \mathrm{ppm}$ criterion using the approach applied in the Footnote "a" in Table 1 of Reference [16]. Similarly, as noted above in Footnote " $d$ " in Table 4, the volumetric dilution of residual plutonium in the discharged pebble is between $\sim 747 \mathrm{~g} / \mathrm{m}^{3}$ and $504 \mathrm{~g} / \mathrm{m}^{3}$ (or less than $1007 \mathrm{~g} / \mathrm{m}^{3}$ for a solid single pebble, ignoring packing fraction), depending upon packing fraction of the pebbles in a container, but this range of volumetric dilution values is also less than each of the volumetric dilution criteria in Table 4 taken from STR-251 (Rev 2) [15] as presented in Table 1 of Reference [17] and in Table E1 of Reference [18] except for medium active liquid waste conditioned/ stabilized in bitumen. Therefore, whether in terms of dilution by $\mathrm{g} / \mathrm{MT}$ (or ppm) or $\mathrm{g} / \mathrm{m}^{3}$, the plutonium in the pebble is less than the IAEA provisional criterion for termination of safeguards and should be sufficient to terminate NMC\&A on the plutonium in PBMR used fuel as a measured discard. The technical approach or methodology that can be used to define each discharged pebble to be a measured discard with regard to its plutonium content is described in Section 8.2.

\subsection{Analysis of the IAEA Provisional Criteria for Termination of Safeguards on Uranium in Discharged LEU Pebbles}

Table 8 is based on the IAEA provisional criteria for termination of safeguards for plutonium dilution in packaged but unconditioned (that is, unstabilized) waste forms, and the data in Table 8 can be compared to that in Table 4 for plutonium in a conditioned waste form to infer a multiplication factor accounting for the difference between the plutonium content in a conditioned or stabilized waste form versus that in an unconditioned waste form. Such a factor is needed to assess the uranium dilution in conditioned/stabilized uranium-bearing wastes since the IAEA provisional criteria for uranium is provided only for unconditioned (i.e., unstabilized) waste forms as presented in Table 9.

In comparing the data in Tables 4 and 8 for plutonium-bearing conditioned/stabilized waste forms versus unconditioned/unstabilized waste forms, attention is drawn to the base data $\left(\mathrm{g} / \mathrm{m}^{3}\right)$ in Table 4 for conditioned waste forms for fixed clarification sludges and high active liquid in vitrified form since the dispersion of nuclear material in the waste form is most like that of coated particles in the graphitized carbon of a pebble fuel element. The graphitized carbon in the pebble will have a density of between 1.5 and $1.7 \mathrm{MT} / \mathrm{m}^{3}$ (with $1.69 \mathrm{MT} / \mathrm{m}^{3}$ being that inferred for a $200 \mathrm{~g}, 60 \mathrm{~mm}$ diameter pebble less $9 \mathrm{~g}$ of uranium) compared to normal glass with a density of 2.4 to $2.8 \mathrm{MT} / \mathrm{m}^{3}$. The net 
density in a packed bed of pebbles depends on the packing fraction, which depends in turn on the volume of the container.

The methods to recover nuclear material from pebbles versus vitrified waste would also be similar with some combination of grinding, burning, and leaching with nitric acid for graphitized-carbon forms and a combination of breaking by smashing or grinding followed by leaching with hydrofluoric acid for the vitrified forms. The relevant data for the provisional criteria for termination of safeguards in conditioned/stabilized plutoniumbearing waste forms from Table 4 are $2500 \mathrm{~g} / \mathrm{m}^{3}$ for the waste forms that are most similar to irradiated pebbles and are therefore of most relevant interest for comparison.

For the IAEA provisional criteria for termination of safeguards for unconditioned/ unstabilized plutonium-bearing waste forms in Table 8, the base concentrations for feed clarification sludges (using the reduced level adopted after Reference [15] was issued) and highly active waste is $500 \mathrm{~g} / \mathrm{m}^{3}$. Thus, there is a factor five difference between the IAEA-recommended provisional concentration limit for plutonium in a conditioned/stabilized waste form $\left(2500 \mathrm{~g} / \mathrm{m}^{3}\right)$ and that for plutonium in an unconditioned/unstabilized waste form $\left(500 \mathrm{~g} / \mathrm{m}^{3}\right)$. By applying this factor of five to the most similar unconditioned/unstabilized waste form for uranium in Table 9 , the resulting provisional limit for uranium in a pebble would be 7,635 ppm $(1,527 \mathrm{ppm} \times 5)$ of uranium (normalized to the maximum density in a packed bed of pebbles). However, the estimated uranium dilution in a discharged pebble from Appendix A is 41,015 ppm (normalized to a single pebble) so that the uranium dilution is not sufficiently low to meet the IAEA provisional criteria for termination of safeguards with respect to NMC\&A.

It is further noted that if the reprocessing technique used for the pebble nuclear material recovery were that of electrolytic disintegration/dissolution in nitric acid [43-46], the intermediate step in that process would yield a carbon-based sludge very similar to the feed clarification sludges so by analogy the reprocessing of pebbles would resemble the steps for uranium recovery from a conditioned/stabilized waste form.

Finally, it should be noted that for LEU with an enrichment below $5 \mathrm{wt} \%$, as is the case for the discharged LEU pebble, the criterion in the Footnote "a" to Table 1 of Reference [9] (namely, " 0.042 critical mass/MT solids where the critical mass is calculated from a mixture of isotopes for the actinide element") is difficult to apply since the bare critical mass of LEU metal at $5 \mathrm{wt} \%$ enriched goes to infinity, implying an infinite limit (or in effect no limit) on the amount of LEU ( $<5 \mathrm{wt} \%$ enriched) per metric ton. However, if, instead of applying the criterion to direct-use material as is done for plutonium, this criterion were applied to one significant quantity of $75 \mathrm{~kg}$ of indirect-use ${ }^{235} \mathrm{U}$ (less than $20 \mathrm{wt} \%$ enriched) from Table II of the IAEA Safeguards Glossary [47] at the discharge enrichment inferred from Appendix A $(\sim 3.8 \mathrm{wt} \%)$, the implied limit would be $[(75,000 \mathrm{~g} / 0.038) \times 0.042]=82,895 \mathrm{~g} / \mathrm{MT}$ or $82,895 \mathrm{ppm}$, which is both much higher than the 7,635 ppm of uranium inferred above from the tables in STR-251 (Rev 2) [15] and would adequately cover the 41,015 ppm of diluted uranium in the pebble from the estimate in Appendix A. This interpretation would still require IAEA review and acceptance under the provisions of Reference [13] or [14]. 
Table 8. Conversion of STR-251 (Rev 2) [15] plutonium concentrations ${ }^{a}$ in unconditioned waste forms $\mathrm{s}^{b}$ from $\mathrm{g} / \mathrm{m}^{3}$ (as presented) to equivalent parts per million (ppm) in an assumed waste form of a $200 \mathrm{~g}$ graphitized carbon pebble with a net volume (including surrounding voids) in highest density storage $e^{c}$ of $0.0001527 \mathrm{~m}^{3}$ per pebble

\begin{tabular}{|c|c|c|c|}
\hline $\begin{array}{l}\text { Plutonium-bearing } \\
\text { unconditioned waste } \\
\text { form }\end{array}$ & $\begin{array}{c}\text { Maximum } \\
\text { concentration }\left(\mathrm{g} / \mathrm{m}^{3}\right) \\
\text { of plutonium in a } \\
\text { batch of } \\
\text { unconditioned waste }\end{array}$ & $\begin{array}{l}\text { Maximum parts per } \\
\text { million (ppm) for a } \\
\text { packaged } \\
\text { unconditioned waste } \\
\text { form (assumed } \\
\text { diluent densities } \\
\text { noted below) }\end{array}$ & $\begin{array}{l}\text { Maximum parts per } \\
\text { million (ppm) for a } \\
\text { packed pebble bed } \\
\text { with an average } \\
\text { density of } \\
\sim 1.31 \mathrm{MT} / \mathrm{m}^{3}\end{array}$ \\
\hline $\begin{array}{l}\text { Hulls (surface } \\
\text { contaminated) }\end{array}$ & 200 & $\begin{array}{c}36 \text { (assuming } \\
\text { crushed/packed } \\
\text { Zircaloy-4 hulls at } \\
\sim 85 \% \text { dense of } 6.55 \\
\left.\mathrm{MT} / \mathrm{m}^{3}\right)^{e}\end{array}$ & $\begin{array}{l}153 \text { (judged to be not } \\
\text { applicable to PBMR } \\
\text { used fuel with no } \\
\text { internal surface } \\
\text { contamination) }\end{array}$ \\
\hline $\begin{array}{l}\text { Feed clarification } \\
\text { sludges }\end{array}$ & $5,000(500)^{f}$ & $\begin{array}{c}3,333(333) \text { (for } \\
\text { Magnox reprocessing } \\
\left.\text { sludge }^{g} 1.5 \mathrm{MT} / \mathrm{m}^{3}\right) \text { to } \\
5,000(500) \text { for water } \\
\text { with no solid } \\
\text { suspensions } \\
\left(1.0 \mathrm{MT} / \mathrm{m}^{3}\right) \\
\end{array}$ & $3,817(382)^{f}$ \\
\hline Highly active waste & $\begin{array}{c}500 \text { (fraction of } \\
\text { solids) }\end{array}$ & 500 (water) & 382 \\
\hline Medium active waste & $\begin{array}{c}500 \text { (fraction of } \\
\text { solids) }\end{array}$ & 500 (water) & 382 \\
\hline
\end{tabular}

${ }^{a}$ As presented in Table E2, page 79, Reference [18], unless otherwise modified as noted.

${ }^{b}$ The terminology "unconditioned waste form" essentially means unstabilized.

${ }^{c}$ A more realistic volume estimate, especially for smaller containers, would be between $0.0001767 \mathrm{~m}^{3}$ (maximum random packing) and $0.0002262 \mathrm{~m}^{3}$ (low-density random packing) or $\sim 0.0002 \mathrm{~m}^{3}$.

${ }^{d}$ The pebble density is $\left[(0.0002 \mathrm{MT}) /\left(0.001131 \mathrm{~m}^{3}\right)\right]=\sim 1.77 \mathrm{~g} / \mathrm{m}^{3}$ (including the heavy metal loading), but the average density is the solid pebble density multiplied by the packing fraction ( $\sim 0.74$ for the maximum possible in a large container).

${ }^{e}$ TECHNICAL DATA SHEET: Reactor Grade Zirconium Alloys for Nuclear Waste Disposal, ATI

Wah Chang, Allegheny Technologies, http://www.wahchang.com/pages/products/data/pdf/Zr_Alloys $\% 20$ for $\% 20$ Nuclear $\% 20$ Waste $\% 20 \mathrm{Dspsl} . \mathrm{pdf}$

${ }^{t}$ The value shown is as it appears in Table 3 of STR-251 (Rev.2). In the recorded comments by the United States on Table 3 in the Annex to STR-251, the suggested value is $650 \mathrm{~g} / \mathrm{m}^{3}$. Table 1, page 206, in Reference [17] and Table E1, page 79, in Reference [18] list $500 \mathrm{~g} / \mathrm{m}^{3}$, which would equate to $382 \mathrm{ppm}$ in the last column.

${ }^{g}$ From "Plasma Solution to Waste Streams including Wet ILW," Commercial Nuclear Waste Strategies, 21-22 May 2007, United Kingdom. 
Table 9. Conversion of STR-251 (Rev 2) [15] low-enriched or natural uranium concentrations ${ }^{a}$ in unconditioned waste ${ }^{b}$ from $\mathrm{g} / \mathrm{m}^{3}$ (as presented) to equivalent parts per million (ppm) in an assumed waste form of a $200 \mathrm{~g}$ graphitized carbon pebble with a net volume (including surrounding voids) in highest density storage ${ }^{c}$ of $0.0001527 \mathrm{~m}^{3}$ per pebble

\begin{tabular}{|c|c|c|c|}
\hline $\begin{array}{l}\text { Uranium-bearing } \\
\text { unconditioned waste } \\
\text { form }\end{array}$ & $\begin{array}{c}\text { Maximum } \\
\text { concentration } \\
\left(\mathrm{g} / \mathrm{m}^{3}\right) \text { of uranium } \\
\text { in a batch of } \\
\text { unconditioned } \\
\text { waste }\end{array}$ & $\begin{array}{l}\text { Maximum parts per } \\
\text { million (ppm) for a } \\
\text { packaged } \\
\text { unconditioned waste } \\
\text { form (assumed } \\
\text { densities noted below) }\end{array}$ & $\begin{array}{c}\text { Maximum parts per } \\
\text { million (ppm) for a } \\
\text { packed pebble bed } \\
\text { with an average } \\
\text { density of } \\
\sim 1.31 \mathrm{MT} / \mathrm{m}^{3}\end{array}$ \\
\hline $\begin{array}{l}\text { Final extraction } \\
\text { residuals }\end{array}$ & 2,000 & $\begin{array}{l}1,333(\text { Magnox sludge } \\
\left.\text { at } 1.5 \mathrm{MT} / \mathrm{m}^{3}\right) \text { to } 2,000 \\
\left(\text { water at } 1.0 \mathrm{MT} / \mathrm{m}^{3} \text { ) }\right.\end{array}$ & 1,527 \\
\hline $\begin{array}{l}\text { Combustible waste } \\
\text { (such as paper and } \\
\text { plastics) }\end{array}$ & 200 & $\begin{array}{c}266(\text { compacted paper } \\
\left.\text { at } 0.75 \mathrm{MT} / \mathrm{m}^{3}\right) \text { to } 182 \\
\left(\text { compacted plastics }^{e} \text { at }\right. \\
\left.1.1 \mathrm{MT} / \mathrm{m}^{3}\right)\end{array}$ & $\begin{array}{l}153 \text { (judged to be not } \\
\text { applicable to PBMR } \\
\text { used fuel since } \\
\text { graphitized carbon in } \\
\text { solid form is not } \\
\text { combustible per se } \\
\text { without grinding) }\end{array}$ \\
\hline $\begin{array}{l}\text { Incombustible waste } \\
\text { (such as surface } \\
\text { contamination on } \\
\text { metal tools, Zircaloy, } \\
\text { ceramic bricks, etc.) }\end{array}$ & 200 & $\begin{array}{c}36 \text { (assuming } \\
\text { crushed/packed } \\
\text { Zircaloy-4 scrap at } \\
\sim 85 \% \text { dense of } \\
\left.6.55 \mathrm{MT} / \mathrm{m}^{3}\right)\end{array}$ & $\begin{array}{l}153 \text { (judged to be not } \\
\text { applicable to PBMR } \\
\text { used fuel with no } \\
\text { internal surface } \\
\text { contamination) }\end{array}$ \\
\hline
\end{tabular}

${ }^{a}$ As presented in Table E2, page 79, Reference [18].

${ }^{b}$ The terminology "unconditioned waste form" is as defined in the footnote to Table 4.

${ }^{c}$ A more realistic volume estimate, especially for smaller containers, would be between $0.0001767 \mathrm{~m}^{3}$ (maximum random packing) and $0.0002262 \mathrm{~m}^{3}$ (low density random packing), or $\sim 0.0002 \mathrm{~m}^{3}$.

${ }^{d}$ http://www.paperonweb.com/density.htm

${ }^{e}$ http://www.machinist-materials.com/comparison_table_for_plastics.htm

\subsection{Analysis of Other Aspects of Uranium in Discharged LEU Pebbles Not Considered in the IAEA Provisional Criteria for Termination of Safeguards}

\subsubsection{Impact of PBMR used-fuel uranium isotopic degradation on its potential reuse}

The IAEA provisional criteria for termination of safeguards does not address the isotopic degradation of either plutonium or uranium in the dilution limits quoted above for waste forms. For plutonium, Annex II, "Categorization of Nuclear Material," to the International Conventions on the Physical Protection of Nuclear Materials [47] acknowledges that plutonium containing greater than $80 \%{ }^{238} \mathrm{Pu}$ does not warrant physical protection for purposes of safeguards for NMC\&A, since the alpha-decay heating would be sufficient to preclude the use of such plutonium in a nuclear weapon However, the report does not address the continued need for physical protection required 
for purposes of preventing radiological sabotage by using plutonium with greater than $80 \%{ }^{238} \mathrm{Pu}$ in a radiological dispersal device.

There is no equivalent exemption for uranium containing ${ }^{232} \mathrm{U},{ }^{233} \mathrm{U},{ }^{234} \mathrm{U},{ }^{236} \mathrm{U}$, or ${ }^{237} \mathrm{U}$, but there are economic and radiological considerations that impact the use of reprocessed uranium. Typically, the impact of the minor uranium isotopes is assessed after reprocessing that is assumed to take place following 5 years of spent fuel cooling and decay of the precursors to some of these minor uranium isotopes. The concentrations of the isotopes of ${ }^{232} \mathrm{U},{ }^{233} \mathrm{U}$, and ${ }^{234} \mathrm{U}$ depend upon the decay of other actinides (principally, ${ }^{237} \mathrm{~Np},{ }^{236} \mathrm{Pu}$, and ${ }^{238} \mathrm{Pu}$ that primarily originate from the ${ }^{235} \mathrm{U}$ transmutation chain that starts with ${ }^{236} \mathrm{U}$ ), as discussed in Section 2.1.3 of Reference [7]. The concentration of these uranium isotopes increases during fuel cooling after discharge from the reactor as illustrated in Figures 9 through 13 in Reference [7]. In Appendix A, the reported results or data from References [2], [4], and [7] were used to develop concentration estimates for the minor uranium isotopes since such information was not reported in Reference [2] or [4]. A comparison of these estimates to the limits for acceptable reprocessed uranium without requiring blending to produce acceptable LEU for reactor use is taken from the standard specification in ASTM C787 as quoted in Section 4.1.2.1 (page 29) of Reference [7]. A comparison of the isotopic estimates from Appendix A with the ASTM C787 standard specification limits is given in Table 10.

Table 10. Comparison of the estimated PBMR used fuel uranium isotopics at 90.8 GWD/MT and cooled for 5 years to the limits in the reprocessed uranium specification in ASTM C787

\begin{tabular}{|c|c|c|c|}
\hline \multirow{2}{*}{$\begin{array}{c}\text { Uranium minor } \\
\text { isotope }\end{array}$} & \multicolumn{2}{|c|}{ ASTM C787 (reprocessed uranium) } & $\begin{array}{c}\text { PBMR used fuel } \\
\text { (Appendix A) }\end{array}$ \\
\cline { 2 - 4 } & $\boldsymbol{\mu g} / \mathbf{g U}$ & $\mathbf{g} / \mathbf{M T}$ & $\mathbf{g} / \mathbf{M T}$ \\
\hline${ }^{232} \mathbf{U}$ & 0.005 & 0.005 & 0.018 \\
\hline${ }^{234} \mathbf{U}$ & 480 & 480 & 430 \\
\hline${ }^{236} \mathbf{U}$ & 8,400 & 8,400 & 12,560 \\
\hline
\end{tabular}

Although these standard limits specifically apply to uranium hexafluoride, the isotope limits given in these specifications are accepted as the reference in the standard specifications for reprocessed uranium in other chemical forms. Based on the estimates from Appendix A, which must still be confirmed by calculations with appropriate analytical tools, the values for both ${ }^{232} \mathrm{U}$ and ${ }^{236} \mathrm{U}$ exceed the acceptable standard specification for safe handling of reprocessed uranium. Compared to light-water-reactor spent fuels as described in Table 7 of Reference [7] and Tables 4 through 6 of Reference [10], the ${ }^{236} \mathrm{U}$ content of the PBMR used fuel is more than a factor of two greater than it is in discharged light water reactor fuel originally enriched from natural uranium and irradiated to burnups of $60 \mathrm{GWD} / \mathrm{MT}$ and then, in the case of Reference [7], cooled for up to 5 years. Cooling impacts the ${ }^{232} \mathrm{U}$ content but does not affect the ${ }^{236} \mathrm{U}$ content, which remains unchanged from the time of fuel discharge. Per Table 4 of Reference [10], the ${ }^{236} \mathrm{U}$ content in spent fuel from light water reactors would only approach that of the PBMR used fuel after three recyclings of spent fuel with blending and re-enrichment at the end of each preceding cycle to reduce the loaded ${ }^{236} U$ at the beginning of the next cycle. Similarly, the estimated ${ }^{232} \mathrm{U}$ content in the cooled PBMR used fuel is nearly a 
factor of five greater than light water reactor spent fuel from Table 7 of Reference [7]. This implies that more blending will be required for reprocessed uranium from PBMR used fuel than is assumed needed for reprocessed light water reactor fuel in the referenced analyses $[10,11]$ in order to meet the specification limits of the ASTM C787 standard.

For CANDU reactors, the assertion is made that "because of the softer neutron spectrum in a CANDU reactor, the absorption worth of the ${ }^{236} \mathrm{U}$ is an order of magnitude lower in a CANDU than in a PWR" [11(c)]. However, conflicting assertions are also made one paragraph apart in Reference [11(a)], which states the following.

It should also be recognized that because the CANDU route does not require re-enrichment of the ${ }^{235} \mathrm{U}$ there is no consequential re-enrichment of ${ }^{236} \mathrm{U}$ and

${ }^{232} \mathrm{U}$. Thus the dose level associated with the handling of RU [reprocessed uranium] for CANDU is greatly reduced compared with the routes that require re-enrichment.

For BNFL to supply RU into the Canadian CANDU market it will be necessary to supply $\mathrm{UO}_{2}$ powder of a specific enrichment value to a CANDU fuel manufacturer and thus conversion to a ceramic-grade $\mathrm{UO}_{2}$ powder is required. Furthermore, the enrichment value chosen must take account of the neutron absorbing property o the ${ }^{236} \mathrm{U}$ content and can be considered an equivalent ${ }^{235} \mathrm{U}$ enrichment....

From Table 1 of Reference [11(a)], the desired isotopic fractions $\left({ }^{232} \mathrm{U}\right.$ not included) for CANDU use of reprocessed uranium (RU) and slightly enriched uranium (SEU) are compared as follows.

\begin{tabular}{llc}
\multicolumn{3}{l}{ CANDU Fresh Fuel Isotopic } \\
${$\cline { 1 - 1 }$} }$ & ${ }^{234} \mathrm{U}$ & 0.016 \\
& ${ }^{235} \mathrm{U}$ & 0.956 \\
& ${ }^{236} \mathrm{U}$ & 0.275 \\
& ${ }^{238} \mathrm{U}$ & 98.750 \\
$\underline{0.90 \% \mathrm{SEU}}$ & ${ }^{235} \mathrm{U}$ & 0.90 \\
& ${ }^{238} \mathrm{U}$ & 99.10
\end{tabular}

As indicated by the above comparison, the CANDU does require an $\sim 6 \%$ increase in enrichment in order to achieve the same burnup with a ${ }^{236} \mathrm{U}$ content equivalent to that of ${ }^{235} \mathrm{U}$ in enrichment tails ( $\left.\sim 0.2-0.3 \mathrm{wt} \%\right)$. Hence, while no enrichment of spent fuel is to be used for the CANDU, blending with enriched uranium derived from natural uranium is required to meet the specification used in the analyses reported in Reference [11(a)]. For PBMR used fuel to be used in a CANDU reactor with the fresh fuel meeting the above specification, substantial blending would also be required at a ratio of $\sim 12$ to 1 for blending with natural uranium and $\sim 5$ to 1 for blending with enrichment tails at $\sim 0.3 \%$ ${ }^{235} \mathrm{U}$. In both cases, the residual ${ }^{236} \mathrm{U}$ content after blending would meet the CANDU fuel specification for reprocessed uranium usage. However, if the reprocessed uranium from the PBMR used fuel were blended with reprocessed uranium from light-water-reactor 
spent fuel with $\sim 0.8 \%{ }^{235} \mathrm{U}$ and $\sim 0.5 \%{ }^{236} \mathrm{U}$ estimated from Table 7 of Reference [7] for 55 GWD/MT burnup, the resulting ${ }^{236} \mathrm{U}$ percentage will be $\sim 0.55 \%$ or twice that of the CANDU specification. Thus, the use of reprocessed PBMR used fuel in a standard CANDU cycle would not be a logical choice since it either would require extensive blending with either natural uranium or enrichment tails without ${ }^{236} \mathrm{U}$ or would negatively impact either the achievable power level or burnup or both with the negative reactivity penalty, but these facts would not preclude its use in a covert non-standard fuel cycle where inspector detection of the presence of substantial quantities of ${ }^{236} \mathrm{U}$ and ${ }^{232} \mathrm{U}$ could provide indicators of such usage.

In Russia, the graphite-moderated, light-water-cooled RBMK is known to use reprocessed spent fuel from both the BN-600 fast reactor and the VVER-440 light water reactors. The enrichment of the RBMK fresh fuel is between $1.8 \mathrm{wt} \%{ }^{235} \mathrm{U}$ and $2 \mathrm{wt} \%$ ${ }^{235} \mathrm{U}$ [12] when using LEU enriched from natural uranium but is between $2.65 \mathrm{wt} \%$ and 2.87 wt $\%{ }^{23} 5 \mathrm{U}$ with $0.42 \mathrm{wt} \%{ }^{236} \mathrm{U}$ and 1.2 parts per billion (ppb) ${ }^{232} \mathrm{U}$ when using reprocessed uranium (Section 4.3.4, page 48, of Reference [7]). The uranium isotopics for BN-600 spent fuel $\left(15-17 \%{ }^{235} \mathrm{U}\right.$ with $\left.1.5 \%{ }^{236} \mathrm{U}\right)$ are recognized to be those given in Table 13 of Reference [7], and it can be assumed that the uranium isotopics of the VVER-400 spent fuel $\left(\sim 0.8-1.0 \%{ }^{235} \mathrm{U}\right.$ and $\left.\sim 0.4-0.55 \%{ }^{236} \mathrm{U}\right)$ would be bracketed by the light-water-reactor spent fuel isotopics in the first row of Table 5 in Reference [10] and the first column of Table 7 in Reference [7]. As a result, the blending of the reprocessed uranium from the two spent fuels to the desired ${ }^{235} \mathrm{U}$ enrichment would yield a ${ }^{236} \mathrm{U}$ content of $\sim 0.4-0.5 \mathrm{wt} \%$, or almost twice the standard for CANDU reactors. Downblending reprocessed PBMR used fuel with reprocessed VVER-440 spent fuel would require less mixing to achieve the desired ${ }^{235} \mathrm{U}$ enrichment than blending with BN-600 reprocessed spent fuel but would also substantially increase the ${ }^{236} U$ content and the resulting reactivity penalty. This would negatively impact either the achievable power level or burnup or both in the RBMK; however, this fact would not preclude its use in a covert non-standard fuel cycle in a covert graphite-moderated production reactor where inspector detection of the presence of substantial quantities of ${ }^{236} U$ and ${ }^{232} U$ could provide indicators of such usage.

Thus far, the analysis in this section has shown why the high concentration of ${ }^{236} \mathrm{U}$ in PBMR used fuel would discourage its first choice for use as reprocessed uranium as fuel in light water reactors, CANDU reactors, and RBMKs. This may not always be the case in the future for commercial applications if the availability of natural uranium becomes limited. Limiting the reactivity penalty of ${ }^{236} \mathrm{U}$ means from a strictly economic viewpoint that re-enrichment with blends of reprocessed uranium and natural or enrichment tails uranium will be the second choice to the enrichment of natural uranium and that the use of re-enriched uranium from reprocessed fuels from light water reactors with lower ${ }^{236} \mathrm{U}$ content will be the third choice before turning to the use of reprocessed PBMR used fuel. Such economic considerations may not dissuade a would-be proliferant nation, but the technical complexity, cost, and detectability of reprocessing such fuel using a technology that has only been tested on a laboratory-scale must also be addressed by the would-be proliferant state in assessing the practicability of uranium recovery from PBMR used fuel. 
Finally, the presence of a substantial quantity of ${ }^{236} \mathrm{U}$ in the PBMR used fuel also hinders and complicates attempts to produce HEU by re-enrichment of post-reprocessed uranium. One reported value from the Soviet era is that the content of ${ }^{236} \mathrm{U}$ in HEU re-enriched from spent production reactor fuel was as high as $25 \%$ [12], implying that the limit on the ${ }^{235} \mathrm{U}$ content in HEU from such reprocessed fuel is likely to be no more than $\sim 70 \%$ or so without going to much higher separative work units (SWUs) than what would be needed for $90 \%$ enrichment from natural uranium. Of course, the content of the ${ }^{236} \mathrm{U}$ in the Soviet spent production reactor fuel is not known, but that of U.S. weapon-grade plutonium production targets using natural uranium and yielding $\sim 94 \%{ }^{239} \mathrm{Pu}$ at $600 \mathrm{MWD} / \mathrm{MT}$ burnup would have been $\sim 0.016 \%{ }^{236} \mathrm{U}$ and $0.65 \%{ }^{235} \mathrm{U}$ in the discharged targets. The content of ${ }^{236} \mathrm{U}$ in SEU driver fuel would have been higher. Therefore, the used fuel from irradiation in the PBMR would not be the most desirable indirect-use nuclear material due to the high level of ${ }^{236} \mathrm{U}$ concentration and to the detectable radiation hazard posed by the presence of ${ }^{232} \mathrm{U}$.

\subsubsection{Radiological aspects of PBMR used-fuel uranium isotopic degradation on its potential reuse}

The relative radiological penalties need to be addressed for reprocessing and reusing PBMR used fuel compared to reusing reprocessed fuel from light water reactors. For such a comparative analysis, the IAEA assessment methodology will be used for the likely exposure or dose resulting from a "medium" accident occurring during the transport of the reprocessed uranium as radioactive material in a dispersible form. The safety of the transport of reprocessed uranium is used here for a quantitative comparison since a review if the IAEA safety standards at http://www-ns.iaea.org/standards/ indicates that only the standards for safe transport of radioactive materials provide a technical basis for a quantitative comparison that is not otherwise found in the IAEA safety standards for radiation protection in facilities.

The technical history and basis (exposure assumptions) for this methodology are explained in Appendix I, "The Q System for the Calculation and Application of the $\mathrm{A}_{1}$ and $A_{2}$ Values," of Reference [48], where the $A_{2}$ method is applicable to the dispersible forms of transported radioactive material. The $A_{2}$ value is expressed in terms of disintegrations per second or Becquerel (symbol Bq) where the quantity for $\mathrm{A}_{2}$ has been normalized for each radioactive isotope to the effective dose limit to an exposed individual or individual body part so as to provide a measure of dose limit equivalence among isotopes for the transport accident condition assumed for dispersible isotopes, as explained in Appendix I of Reference [48]. An example of using the isotopic values for $\mathrm{A}_{2}$ to assess the transportation safety of mixtures of reprocessed and re-enriched uranium isotopes is given in Table IX, Appendix VIII of Reference [5] using the equation from page 11 of Reference [5], which equation also appears in paragraph 404 in Reference [49] that updates and replaces IAEA Safety Series No. 6 cited in Reference [5]. In paragraph 404 in Reference [49], the equation for $X_{m}$ for a mixture of radioactive isotopes is the same as the equation for $\mathrm{A}_{2}$ of a mixture of radioactive isotopes in Reference [5]. It is noted that the uranium isotope-dependent values for $\mathrm{A}_{2}$ are now different in Table 1 of Reference [49] compared to those used in Reference [5] where the 
new values provided in Table 1 of Reference [49] account both for the chemical form of the uranium and for its rate of lung absorption. Thus the values for $\mathrm{A}_{2}$ are representative of inhalation exposure limits but not ingestion exposure limits nor contamination exposure limits into the bloodstream through cuts in the skin of an individual.

For the $\mathrm{A}_{2}$ analyses below, the specific activity $(\mathrm{Bq} / \mathrm{g})$ of each isotope is taken from the IAEA-specified values in Table II.1, Appendix II of Reference [48], and the isotopic values for $\mathrm{A}_{2}$ are taken from the IAEA regulations in Table 1 of Reference [49]. As in Table IX, Appendix VIII of Reference [5], the daughter-product isotope ${ }^{228} \mathrm{Th}$ is assumed to be in equilibrium with ${ }^{232} \mathrm{U}$, but unlike Table X, Appendix IX of Reference [5], there is no accounting for the uranium-adherent technetium fission product ${ }^{99} \mathrm{Tc}$ since there are no data for this in the analyses being used as sources of the isotopic information. It is unknown of course whether the would-be proliferant nation would add the extra chemical processing steps to PUREX needed to remove ${ }^{99} \mathrm{Tc}$ from the reprocessed uranium. This is important since ${ }^{99} \mathrm{Tc}$ can raise the effective dose by an order of magnitude in reprocessed, re-enriched uranium as noted in Reference [5]. In addition, plutonium contamination of reprocessed uranium can also impacts it radiological hazard and may be a significant consideration in covert reprocessing where chemical purity of the uranium product may not be a primary consideration by would-be proliferators especially if the intent is to use the covertly-reprocessed uranium as driver fuel for a covert production reactor.

The radiological penalty difference between reprocessed PBMR used fuel with a $3.8 \mathrm{wt}$ $\%{ }^{235} \mathrm{U}$ discharge enrichment using the isotopic data estimates from Appendix A and reprocessed light-water-reactor fuel using the data from Table 7 of Reference [7] is calculated using the following equation and the data set in Table 11.

where

$$
\mathrm{A}_{2} \text { or } \mathrm{X}_{\mathrm{m}} \text { for a uranium mixture }=\left[\Sigma_{i}\left[\mathrm{f}(\mathrm{i}) / \mathrm{A}_{2}(i)\right]\right]^{-1},
$$

$\mathrm{f}(i)=$ the fraction of activity of nuclide $i$ in the mixture, $\mathrm{A}_{2}(i)=$ the appropriate $\mathrm{A}_{2}$ value for the nuclide $i$. 
Table 11. Reprocessed uranium contained isotopics: specific activities and $\mathbf{A}_{2}$ values

\begin{tabular}{|c|c|c|c|c|}
\hline Isotope & $\begin{array}{l}\text { Specific activity } \\
(\mathrm{Bq} / \mathrm{g})[48]\end{array}$ & $\begin{array}{c}\text { Fast lung } \\
\text { absorption } \\
\text { (FLA) } \mathbf{A}_{2}(\mathbf{B q}) \\
{[49]}\end{array}$ & $\begin{array}{c}\text { Medium lung } \\
\text { absorption } \\
\text { (MLA) } \mathbf{A}_{2}(\mathbf{B q}) \\
{[49]}\end{array}$ & $\begin{array}{c}\text { Slow lung } \\
\text { absorption } \\
\text { (SLA) } \mathbf{A}_{2}(\mathbf{B q}) \\
{[49]}\end{array}$ \\
\hline${ }^{99} \mathrm{Tc}$ & $6.286 \times 10^{8}$ & \multicolumn{3}{|c|}{$9 \times 10^{8}$} \\
\hline${ }^{228} \mathrm{Th}$ & $3.039 \times 10^{13}$ & \multicolumn{3}{|c|}{$1 \times 10^{6}$} \\
\hline${ }^{232} \mathrm{U}$ & $7.935 \times 10^{11}$ & $1 \times 10^{7}$ & $7 \times 10^{6}$ & $1 \times 10^{6}$ \\
\hline${ }^{233} \mathrm{U}$ & $3.589 \times 10^{8}$ & $9 \times 10^{7}$ & $2 \times 10^{7}$ & $6 \times 10^{6}$ \\
\hline${ }^{234} \mathrm{U}$ & $2.317 \times 10^{8}$ & $9 \times 10^{7}$ & $2 \times 10^{7}$ & $6 \times 10^{6}$ \\
\hline${ }^{235} \mathrm{U}$ & $8.014 \times 10^{4}$ & Unlimited & Unlimited & Unlimited \\
\hline${ }^{236} \mathrm{U}$ & $2.399 \times 10^{6}$ & Unlimited & $2 \times 10^{7}$ & $6 \times 10^{6}$ \\
\hline${ }^{238} \mathrm{U}$ & $1.246 \times 10^{4}$ & Unlimited & Unlimited & Unlimited \\
\hline${ }^{239} \mathrm{Pu}$ & $2.305 \times 10^{9}$ & \multicolumn{3}{|c|}{$1 \times 10^{6}$} \\
\hline${ }^{240} \mathrm{Pu}$ & $8.449 \times 10^{9}$ & \multicolumn{3}{|c|}{$1 \times 10^{6}$} \\
\hline${ }^{241} \mathrm{Pu}$ & $3.819 \times 10^{12}$ & \multicolumn{3}{|c|}{$6 \times 10^{7}$} \\
\hline${ }^{242} \mathrm{Pu}$ & $1.456 \times 10^{8}$ & \multicolumn{3}{|c|}{$1 \times 10^{6}$} \\
\hline
\end{tabular}

Using the isotopic dependent values of both the specific activity and $A_{2}$ from Table 11 , the total specific activity and the $\mathrm{A}_{2}$ value of the mixture of isotopes can be calculated for reprocessed uranium.

In Table 12, the values for both the specific activity and $A_{2}$ limit of the uranium-isotopic mixture from reprocessed PBMR used fuel are presented without accounting for the possible presence of either ${ }^{99} \mathrm{Tc}$ or plutonium contamination since these data were not provided in the previous analyses $[2,4]$ and depend upon the effectiveness of the reprocessing technology employed. The inferred specific activity and $\mathrm{A}_{2}$ value from reprocessed PBMR used fuel in Table 12 can be compared to the specific activity and $\mathrm{A}_{2}$ calculated using the reprocessed-uranium isotopic data for light water reactors as taken from Table 7 of Reference [7] for 4.5\% enriched LEU irradiated to $48 \mathrm{GWD} / \mathrm{MT}$ as given in Table 13 and for 4.1\% LEU irradiated to $60 \mathrm{GWD} / \mathrm{MT}$ as given in Table 14. Since the isotopic mass values in Table 7 of Reference [7] are given in grams per the initial or loaded metric ton of uranium, the mass fractions had to be renormalized to their discharged values after irradiation as given in Tables 13 and 14.

By comparing Tables 12 and 13, it can be seen that the total activity of uranium from reprocessed PBMR used fuel at a burnup of $90.8 \mathrm{GWD} / \mathrm{MT}$ and reprocessed light-waterreactor spent fuel at a burnup of $48 \mathrm{GWD} / \mathrm{MT}$ is a factor of two difference with PBMR reprocessed uranium having the higher specific activity. However, the PBMR-to-LWR dose-normalized radiological hazard limit ratio from the release of a dispersible form of the reprocessed uranium is `2.5 for fast lung absorption, 18.4 for medium lung absorption, and $\sim 1.54$ for slow lung absorption. Hence, while the radiological hazard potential of reprocessed uranium from PBMR used fuel is greater than that from spent fuel from light water reactors leading to more restrictive limits on safe transport under IAEA regulations, the difference may not dissuade covert reprocessing for use of the recovered uranium as fuel in a covert production reactor. 
Table 12. $A_{2}$ for reprocessed uranium (Rep-U) from PBMR used fuel $(9.6 \%$ initial ${ }^{235} \mathrm{U}$ enrichment) at a burnup of $90.8 \mathrm{GWD} / \mathrm{MT}$ and cooled for 5 years with an assumed equilibrium of ${ }^{228} \mathrm{Th}$ and ${ }^{232} \mathrm{U}$ and without ${ }^{99} \mathrm{Tc}$ and plutonium

\begin{tabular}{|c|c|c|c|c|c|c|c|c|c|}
\hline Isotope & $\begin{array}{c}\text { Uranium } \\
\text { mass } \\
\text { fraction }\end{array}$ & $\begin{array}{c}\text { Rep-U } \\
\text { activity } \\
\text { (Bq/g U) }\end{array}$ & $\begin{array}{c}\text { Activity } \\
\text { fraction } \\
\text { f(i) }\end{array}$ & $\begin{array}{l}\text { FLA } \\
\mathbf{A}_{2}(\mathbf{i})\end{array}$ & $\begin{array}{l}\text { FLA } \\
\frac{f(i)}{A_{2}(i)}\end{array}$ & $\begin{array}{c}\text { MLA } \\
\mathbf{A}_{2}(\mathbf{i})\end{array}$ & $\begin{array}{l}\text { MLA } \\
\frac{\mathbf{f}(i)}{A_{2}(i)}\end{array}$ & $\begin{array}{l}\text { SLA } \\
\mathbf{A}_{2}(\boldsymbol{i})\end{array}$ & $\begin{array}{l}\text { SLA } \\
\frac{f(i)}{A_{2}(i)}\end{array}$ \\
\hline${ }^{228} \mathrm{Th}$ & -- & $1.43 \times 10^{4}$ & 0.082 & $\begin{array}{l}1 \times \\
10^{6}\end{array}$ & $\begin{array}{c}8.2 \times \\
10^{-8}\end{array}$ & $\begin{array}{l}1 \times \\
10^{6}\end{array}$ & $\begin{array}{c}8.2 \times \\
10^{-8}\end{array}$ & $\begin{array}{l}1 \times \\
10^{6}\end{array}$ & $\begin{array}{c}8.2 \times \\
10^{-8}\end{array}$ \\
\hline${ }^{232} \mathrm{U}$ & $1.8 \times 10^{-8}$ & $1.43 \times 10^{4}$ & 0.082 & $\begin{array}{l}1 \times \\
10^{7} \\
\end{array}$ & $\begin{array}{c}8.2 \times \\
10^{-9} \\
\end{array}$ & $\begin{array}{l}7 \times \\
10^{6} \\
\end{array}$ & $\begin{array}{r}1.17 \\
\times 10^{-8} \\
\end{array}$ & $\begin{array}{l}1 \times \\
10^{6} \\
\end{array}$ & $\begin{array}{c}8.2 \times \\
10^{-8} \\
\end{array}$ \\
\hline${ }^{233} \mathrm{U}$ & $7 \times 10^{-9}$ & 2.51 & $\begin{array}{c}1.45 \times \\
10^{-5}\end{array}$ & $\begin{array}{l}9 \times \\
10^{7}\end{array}$ & $\begin{array}{l}1.6 \times \\
10^{-13}\end{array}$ & $\begin{array}{l}2 \times \\
10^{7}\end{array}$ & $\begin{array}{l}7.3 \times \\
10^{-13}\end{array}$ & $\begin{array}{l}6 \times \\
10^{6}\end{array}$ & $\begin{array}{l}2.4 \times \\
10^{-12}\end{array}$ \\
\hline${ }^{234} \mathrm{U}$ & 0.00043 & $9.96 \times 10^{4}$ & 0.574 & $\begin{array}{l}9 \times \\
10^{7}\end{array}$ & $\begin{array}{c}6.38 \times \\
10^{-9}\end{array}$ & $\begin{array}{l}2 \times \\
10^{7}\end{array}$ & $\begin{array}{c}2.87 \\
\times 10^{-8}\end{array}$ & $\begin{array}{l}6 \times \\
10^{6}\end{array}$ & $\begin{array}{l}9.57 \\
\times 10^{-8}\end{array}$ \\
\hline${ }^{235} \mathrm{U}$ & 0.038 & $3.05 \times 10^{3}$ & 0.018 & Unl & 0 & Unl & 0 & Unl & 0 \\
\hline${ }^{236} \mathrm{U}$ & 0.013 & $3.12 \times 10^{4}$ & 0.180 & Unl & 0 & $\begin{array}{l}2 \times \\
10^{7} \\
\end{array}$ & $\begin{array}{l}9 \times \\
10^{-9} \\
\end{array}$ & $\begin{array}{l}6 \times \\
10^{6} \\
\end{array}$ & $\begin{array}{l}3 \times \\
10^{-8} \\
\end{array}$ \\
\hline${ }^{238} \mathrm{U}$ & 0.945 & $1.18 \times 10^{4}$ & 0.068 & Unl & 0 & Unl & 0 & Unl & 0 \\
\hline SUM & 1.00 & $1.74 \times 10^{5}$ & $\sim 1.00$ & -- & $\begin{array}{c}9.66 \times \\
10^{-8}\end{array}$ & -- & $\begin{array}{l}1.31 \\
\times 10^{-7} \\
\end{array}$ & -- & $\begin{array}{c}2.9 \times \\
10^{-7} \\
\end{array}$ \\
\hline \multicolumn{4}{|c|}{$\begin{array}{l}A_{2} \text { for uranium mixture }= \\
{\left[\Sigma_{i}\left[\mathbf{f}(i) / \mathbf{A}_{2}(i)\right]\right]^{-1}}\end{array}$} & \multicolumn{2}{|c|}{$\mathrm{A}_{2}=1.04 \times 10^{7}$} & \multicolumn{2}{|c|}{$\mathrm{A}_{2}=7.6 \times 10^{6}$} & \multicolumn{2}{|c|}{$\begin{array}{c}\mathrm{A}_{2}=3.45 \times \\
10^{6}\end{array}$} \\
\hline
\end{tabular}

Table 13. $A_{2}$ for reprocessed uranium (Rep-U) from a LWR (4.5\% initial ${ }^{235} \mathrm{U}$ enrichment) at a burnup of $48 \mathrm{GWD} / \mathrm{MT}$ and cooled for 5 years [7] with an assumed equilibrium of ${ }^{228} \mathrm{Th}$ and ${ }^{232} \mathrm{U}$ and without ${ }^{99} \mathrm{Tc}$ and plutonium

\begin{tabular}{|c|c|c|c|c|c|c|c|c|c|}
\hline Isotope & $\begin{array}{c}\text { Uranium } \\
\text { mass } \\
\text { fraction }\end{array}$ & $\begin{array}{c}\text { Rep-U } \\
\text { activity } \\
(\text { Bq/g U) }\end{array}$ & $\begin{array}{c}\text { Activity } \\
\text { fraction } \\
\text { f(i) }\end{array}$ & $\begin{array}{l}\text { FLA } \\
\mathbf{A}_{2}(\mathbf{i})\end{array}$ & $\begin{array}{l}\text { FLA } \\
\underline{\mathbf{f}(\boldsymbol{i})} \\
\underline{\mathrm{A}_{2}(\boldsymbol{i})}\end{array}$ & $\begin{array}{c}\text { MLA } \\
\mathbf{A}_{2}(i)\end{array}$ & $\begin{array}{l}\text { MLA } \\
\frac{\mathbf{f}(\boldsymbol{i})}{\mathbf{A}_{2}(\boldsymbol{i})}\end{array}$ & $\begin{array}{l}\text { SLA } \\
\mathbf{A}_{2}(i)\end{array}$ & $\begin{array}{l}\text { SLA } \\
\frac{f(i)}{A_{2}(i)}\end{array}$ \\
\hline${ }^{228} \mathrm{Th}$ & -- & $\begin{array}{c}2.42 \times \\
10^{3} \\
\end{array}$ & 0.028 & $\begin{array}{l}1 \times \\
10^{6} \\
\end{array}$ & $\begin{array}{r}2.8 \times \\
10^{-8} \\
\end{array}$ & $\begin{array}{l}1 \times \\
10^{6} \\
\end{array}$ & $\begin{array}{c}2.8 \times \\
10^{-8} \\
\end{array}$ & $\begin{array}{l}1 \times \\
10^{6} \\
\end{array}$ & $\begin{array}{c}2.8 \times \\
10^{-8} \\
\end{array}$ \\
\hline${ }^{232} \mathrm{U}$ & $3.05 \times 10^{-9}$ & $\begin{array}{c}2.42 \times \\
10^{3} \\
\end{array}$ & 0.028 & $\begin{array}{l}1 \times \\
10^{7} \\
\end{array}$ & $\begin{array}{c}2.8 \times \\
10^{-9} \\
\end{array}$ & $\begin{array}{l}7 \times \\
10^{6} \\
\end{array}$ & $\begin{array}{c}4 \times \\
10^{-9} \\
\end{array}$ & $\begin{array}{l}1 \times \\
10^{6} \\
\end{array}$ & $\begin{array}{c}2.8 \times \\
10^{-8} \\
\end{array}$ \\
\hline${ }^{233} \mathrm{U}$ & $4.06 \times 10^{-9}$ & 1.46 & $\begin{array}{c}1.68 \times \\
10^{-5}\end{array}$ & $\begin{array}{l}9 \times \\
10^{7}\end{array}$ & $\begin{array}{c}1.28 \times \\
10^{-13}\end{array}$ & $\begin{array}{l}2 \times \\
10^{7}\end{array}$ & $\begin{array}{c}5.75 \\
\times \\
10^{-13}\end{array}$ & $\begin{array}{l}6 \times \\
10^{6}\end{array}$ & $\begin{array}{c}1.92 \\
\times \\
10^{-12}\end{array}$ \\
\hline${ }^{234} \mathrm{U}$ & $2.34 \times 10^{-4}$ & $\begin{array}{c}5.42 \times \\
10^{4} \\
\end{array}$ & 0.623 & $\begin{array}{l}9 \times \\
10^{7} \\
\end{array}$ & $\begin{array}{c}6.92 \times \\
10^{-9} \\
\end{array}$ & $\begin{array}{l}2 \times \\
10^{7} \\
\end{array}$ & $\begin{array}{l}3.115 \\
\times 10^{-8} \\
\end{array}$ & $\begin{array}{l}6 \times \\
10^{6} \\
\end{array}$ & $\begin{array}{l}1.04 \\
\times 10^{-7} \\
\end{array}$ \\
\hline${ }^{235} \mathrm{U}$ & 0.011 & 882 & 0.0101 & Unl & 0 & Unl & 0 & Unl & 0 \\
\hline${ }^{236} \mathrm{U}$ & 0.0062 & $\begin{array}{c}1.49 \times \\
10^{4}\end{array}$ & 0.164 & Unl & 0 & $\begin{array}{l}2 \times \\
10^{7}\end{array}$ & $\begin{array}{l}8.55 \\
\times 10^{-9}\end{array}$ & $\begin{array}{l}6 \times \\
10^{6}\end{array}$ & $\begin{array}{l}2.85 \\
\times 10^{-8}\end{array}$ \\
\hline${ }^{238} \mathrm{U}$ & 0.9826 & $\begin{array}{c}1.224 \times \\
10^{4}\end{array}$ & 0.141 & Unl & 0 & Unl & 0 & Unl & 0 \\
\hline SUM & 1.00 & $\begin{array}{c}8.706 \times \\
10^{4} \\
\end{array}$ & $\sim 1.00$ & -- & $\begin{array}{c}3.77 \times \\
10^{-8} \\
\end{array}$ & -- & $\begin{array}{c}7.17 \mathrm{x} \\
10^{-8} \\
\end{array}$ & -- & $\begin{array}{l}1.885 \\
\times 10^{-7} \\
\end{array}$ \\
\hline \multicolumn{4}{|c|}{$\begin{array}{l}A_{2} \text { for uranium mixture }= \\
{\left[\Sigma_{i}\left[\mathbf{f}(i) / \mathbf{A}_{2}(i)\right]\right]^{-1}}\end{array}$} & \multicolumn{2}{|c|}{$\begin{array}{c}\mathrm{A}_{2}=2.65 \times \\
10^{7}\end{array}$} & \multicolumn{2}{|c|}{$\begin{array}{c}\mathrm{A}_{2}=1.395 \times \\
10^{7}\end{array}$} & \multicolumn{2}{|c|}{$\begin{array}{c}\mathrm{A}_{2}=5.305 \times \\
10^{6}\end{array}$} \\
\hline
\end{tabular}


While the PBMR-to-LWR dose-normalized radiological hazard limit ratio from the release of a dispersible form of the reprocessed uranium is a factor of $\sim 2.5$ for fast lung absorption, the technology for reprocessing used by a would-be proliferant would be important to the quantification of the results, particularly when the potential radiological effects of ${ }^{99} \mathrm{Tc}$ and plutonium contamination are not included and the sophistication of the covert reprocessing technology is an unknown.

An important question is how clean the reprocessed uranium will be with regard to both ${ }^{99} \mathrm{Tc}$ and plutonium contamination that could significantly lower the radiological hazard limit for dispersible forms of the reprocessed fuel. The fission product content of ${ }^{99} \mathrm{Tc}$ would be expected to be higher in the reprocessed uranium from PBMR used fuel due to its higher burnup and higher fissioning of ${ }^{235} \mathrm{U}$. Commercial reprocessing would likely produce very low plutonium contamination in the recovered uranium, whereas covert reprocessing may be expected to produce less clean uranium. The lack of favorable economic incentives for reprocessing PBMR used fuel to recover uranium has been addressed in the previous section where the incentives for would-be proliferators to recover uranium were gauged with regard to its potential use as driver fuel in a covert production reactor. Covert reprocessing for uranium to use in a covert production reactor and the covert reprocessing of the production reactor targets/fuels would provide increased radiological signatures and indicators than using indirect-use natural uranium or SEU alone as driver fuel for a covert production reactor.

A check of the relative PBMR used fuel reprocessed-uranium radiological hazard potential is given for comparison as follows in Table 14 based on light-water-reactor spent fuel data from Table 7 of Reference [7] for 4.1\%-enriched LEU irradiated to $60 \mathrm{GWD} / \mathrm{MT}$. Comparing Tables 12 sand 14 indicates that the specific activities of the mixture of reprocessed uranium differ by a factor of $\sim 2.3$ between uranium recovered from discharged PBMR used fuel and uranium recovered from discharged light-waterreactor fuel irradiated to $60 \mathrm{GWD} / \mathrm{MT}$. The PBMR-to-LWR dose-normalized radiological hazard limit ratios from the release of a dispersible form of the reprocessed uranium are $\sim 1.62$ for fast lung absorption, $\sim 1.64$ for medium lung absorption, and only $\sim 1.71$ for slow lung absorption. These results indicate (1) that reprocessed uranium from PBMR used fuel is more hazardous than that from high-burnup light-water-reactor fuel based on the lower safe transport limits for PBMR used fuel derived from IAEA regulations and (2) that accounting for the presence of ${ }^{99} \mathrm{Tc}$ and plutonium would be important to quantifying the radiological hazard limit in such assessment since LWR reprocessed uranium from a commercial reprocessing plant would be expected to be cleaner (less contamination) than that from a covert reprocessing plant.. 
Table 14. $A_{2}$ for reprocessed uranium (Rep-U) from a $\operatorname{LWR}\left(4.1 \%\right.$ initial ${ }^{235} U$ enrichment) at a burnup of $60 \mathrm{GWD} / \mathrm{MT}$ and cooling for 5 years [7] with an assumed equilibrium of ${ }^{228} \mathrm{Th}$ and ${ }^{232} \mathrm{U}$ and without ${ }^{99} \mathrm{Tc}$ or plutonium

\begin{tabular}{|c|c|c|c|c|c|c|c|c|c|}
\hline Isotope & $\begin{array}{c}\text { Uranium } \\
\text { mass } \\
\text { fraction }\end{array}$ & $\begin{array}{c}\text { Rep-U } \\
\text { activity } \\
(\mathrm{Bq} / \mathrm{g} \mathbf{U})\end{array}$ & $\begin{array}{c}\text { Activity } \\
\text { fraction } \\
\text { f(i) }\end{array}$ & $\begin{array}{l}\text { FLA } \\
\mathbf{A}_{2}(\mathbf{i})\end{array}$ & $\begin{array}{l}\text { FLA } \\
\frac{f(i)}{A_{2}(i)}\end{array}$ & $\begin{array}{l}\text { MLA } \\
\mathbf{A}_{2}(\mathbf{i})\end{array}$ & $\begin{array}{l}\text { MLA } \\
\frac{\mathbf{f}(\mathbf{i})}{\mathbf{A}_{2}(i)}\end{array}$ & $\begin{array}{l}\text { SLA } \\
\mathbf{A}_{2}(i)\end{array}$ & $\begin{array}{l}\text { SLA } \\
\frac{f(i)}{A_{2}(i)}\end{array}$ \\
\hline${ }^{228} \mathrm{Th}$ & -- & $\begin{array}{c}3 . .666 \times \\
10^{3}\end{array}$ & 0.0484 & $\begin{array}{l}1 \times \\
10^{6}\end{array}$ & $\begin{array}{c}4.84 \times \\
10^{-8}\end{array}$ & $\begin{array}{l}1 \times \\
10^{6}\end{array}$ & $\begin{array}{r}4.84 \\
\times 10^{-8} \\
\end{array}$ & $\begin{array}{l}1 \times \\
10^{6}\end{array}$ & $\begin{aligned} 4.84 \\
\times 10^{-8} \\
\end{aligned}$ \\
\hline${ }^{232} \mathrm{U}$ & $4.62 \times 10^{-9}$ & $\begin{array}{c}3 . .666 \times \\
10^{3}\end{array}$ & 0.0484 & $\begin{array}{l}1 \times \\
10^{7} \\
\end{array}$ & $\begin{array}{c}4.84 \times \\
10^{-9}\end{array}$ & $\begin{array}{l}7 \times \\
10^{6} \\
\end{array}$ & $\begin{array}{r}4.84 \\
\times 10^{-9} \\
\end{array}$ & $\begin{array}{l}1 \times \\
10^{6}\end{array}$ & $\begin{aligned} 4.84 \\
\times 10^{-9} \\
\end{aligned}$ \\
\hline${ }^{233} \mathrm{U}$ & $3.82 \times 10^{-9}$ & 1.37 & $\begin{array}{l}1.81 \times \\
10^{-5}\end{array}$ & $\begin{array}{l}9 \times \\
10^{7}\end{array}$ & $\begin{array}{c}2.01 \times \\
10^{-13}\end{array}$ & $\begin{array}{l}2 \times \\
10^{7}\end{array}$ & $\begin{array}{c}9.05 \\
\times \\
10^{-13} \\
\end{array}$ & $\begin{array}{l}6 \times \\
10^{6}\end{array}$ & $\begin{array}{c}3.02 \\
\times \\
10^{-12}\end{array}$ \\
\hline${ }^{234} \mathrm{U}$ & 0.0001765 & $\begin{array}{c}4.09 \times \\
10^{4} \\
\end{array}$ & 0.54 & $\begin{array}{l}9 \times \\
10^{7} \\
\end{array}$ & $\begin{array}{l}6 \times \\
10^{-9} \\
\end{array}$ & $\begin{array}{l}2 \times \\
10^{7} \\
\end{array}$ & $\begin{array}{c}2.7 \times \\
10^{-8} \\
\end{array}$ & $\begin{array}{l}6 \times \\
10^{6} \\
\end{array}$ & $\begin{array}{l}9 \times \\
10^{-8} \\
\end{array}$ \\
\hline${ }^{235} \mathrm{U}$ & 0.00533 & 427.1 & 0.0056 & Unl & 0 & Unl & 0 & Unl & 0 \\
\hline${ }^{236} \mathrm{U}$ & 0.00615 & $\begin{array}{c}1.475 \times \\
10^{4}\end{array}$ & 0.195 & Unl & 0 & $\begin{array}{l}2 x \\
10^{7}\end{array}$ & $\begin{array}{l}9.75 \\
\times 10^{-9}\end{array}$ & $\begin{array}{l}6 \times \\
10^{6}\end{array}$ & $\begin{array}{l}3.25 \\
\times 10^{-8}\end{array}$ \\
\hline${ }^{238} \mathrm{U}$ & 0.98835 & $\begin{array}{c}1.231 \times \\
10^{4} \\
\end{array}$ & 0.163 & Unl & 0 & Unl & 0 & Unl & 0 \\
\hline SUM & $\sim 1.00$ & $\begin{array}{c}7.572 \times \\
10^{4}\end{array}$ & $\sim 1.00$ & -- & $\begin{array}{c}5.92 \times \\
10^{-8}\end{array}$ & -- & $\begin{array}{l}8.031 \\
\times 10^{-8} \\
\end{array}$ & -- & $\begin{array}{l}1.757 \\
\times 10^{-7}\end{array}$ \\
\hline \multicolumn{4}{|c|}{$\begin{array}{l}\mathrm{A}_{2} \text { for uranium mixture }= \\
{\left[\Sigma_{i}\left[\mathrm{f}(i) / \mathrm{A}_{2}(i)\right]\right]^{-1}}\end{array}$} & \multicolumn{2}{|c|}{$\begin{array}{c}\mathrm{A}_{2}=1.689 \times \\
10^{7}\end{array}$} & \multicolumn{2}{|c|}{$\begin{array}{c}\mathrm{A}_{2}=1.245 \times \\
10^{7}\end{array}$} & \multicolumn{2}{|c|}{$\begin{array}{c}\mathrm{A}_{2}=5.69 \times \\
10^{6}\end{array}$} \\
\hline
\end{tabular}

\subsection{Comparative Analysis of Applying the IAEA Provisional Criteria for Termination of Safeguards on Irradiated Uranium to the Unirradiated Uranium Dilution in Fresh LEU Pebbles}

The PBMR fresh fuel loading is $9 \mathrm{~g}$ of uranium with ${ }^{235} \mathrm{U}$ enrichment in the fresh fuel that varies from the equilibrium-core fresh fuel with $9.6 \mathrm{wt} \%$ enrichment to the initialcore-loading fresh fuel with $\sim 5.7 \mathrm{wt} \%$ enrichment.

To make an estimate of allowable criteria merely for comparative purposes, recognizing that there is no basis for termination of safeguards on fresh/unirradiated uranium fuel under any circumstance, the most applicable data for such a comparison from STR-251 (Rev2) [15] are the values for low-activity plutonium-bearing and uranium-bearing wastes from Tables E1 and E2 of Reference [18]. Low-activity uranium-bearing waste would be the closest approximation to fresh/unirradiated uranium fuel.

By applying the factor of eight that can be derived from the ratio of conditioned to unconditioned waste form limits for low-activity plutonium-bearing wastes as shown in Table 15, the estimate for unirradiated uranium in the pebble is $\sim 1,224 \mathrm{~g} / \mathrm{MT}$ or ppm interpreted as being the low-activity dilution limit for uranium in a stabilized form (specifically as a graphitized-carbon pebble). 
Table 15. Selected IAEA provisional criteria for safeguards termination on uranium-bearing low-activity waste

\begin{tabular}{|l|c|c|}
\hline \multicolumn{1}{|c|}{ Type of low-activity waste } & $\begin{array}{c}\text { Concentration limit } \\
\left(\mathbf{g} / \mathbf{m}^{\mathbf{3}}\right)\end{array}$ & $\begin{array}{c}\text { Estimated g/MT or ppm for a } \\
\text { packed pebble bed with a } \\
\text { density of } \mathbf{1 . 3 1} \mathbf{M T} / \mathbf{m}^{\mathbf{3}}\end{array}$ \\
\hline $\begin{array}{l}\text { Plutonium-bearing } \\
\text { conditioned/stabilized in } \\
\text { cement concrete }\end{array}$ & 160 & N/A \\
\hline $\begin{array}{l}\text { Unconditioned/unstabilized } \\
\text { plutonium-bearing residual } \\
\text { solids from reprocessing }\end{array}$ & 20 & N/A \\
\hline $\begin{array}{l}\text { Unconditioned/unstabilized } \\
\text { uranium chemical residues }\end{array}$ & 200 & 153 \\
\hline
\end{tabular}

However, using the same logic from Footnote "a" to Table 1 of Reference [16] and the indirect-use one significant quantity of ${ }^{235} \mathrm{U}$ in LEU from Table II of Reference [50], the predicted dilution limits for termination of safeguards on PBMR fresh fuel loadings may also be estimated for both the equilibrium fresh fuel (9.6 wt \% enrichment) and initial core loading fresh fuel ( $\sim 5.7 \mathrm{wt} \%$ enrichment) as follows:

Equilibrium core fresh fuel: $[((75,000 \mathrm{~g}) /(0.096)) \times(0.042)]=32,813 \mathrm{~g} / \mathrm{MT}($ or ppm $)$ Initial core load fresh fuel: $[((75,000 \mathrm{~g}) /(0.057)) \times(0.042)]=55,263 \mathrm{~g} / \mathrm{MT}($ or ppm)

The actual dilution of uranium in fresh PBMR fuel is $(9 \mathrm{~g} / 0.0002 \mathrm{MT})=45,000 \mathrm{~g} / \mathrm{MT}$ or ppm in a single pebble. Thus, the dilution of uranium in the fresh pebble for the equilibrium core would not meet the low-activity-waste limit of 1,224 ppm nor, except for the initial core load fresh pebble, the higher inferred limit of 32,813 ppm for the equilibrium-core fresh pebble.

Finally, the ${ }^{235} \mathrm{U}$ concentrations of the fresh pebbles would be between $\sim 2,565 \mathrm{ppm}$ for the initial core load fresh pebble and 4,320 ppm for the equilibrium core fresh pebble, but the IAEA criteria does not specifically provide a limit on ${ }^{235} \mathrm{U}$. Such a limit may be inferred by multiplying the enrichment fraction times the inferred uranium limit $(\sim 1,224 \mathrm{~g} / \mathrm{MT}$ from Table 15 or the values inferred above by using the multiplier from Footnote "a" to Table 1 of Reference [16] times $75,000 \mathrm{~g}$ of ${ }^{235} \mathrm{U}$ ) to yield a value. For the latter, this would be $(75,000 \mathrm{~g}) \times 0.042=\sim 3,150 \mathrm{~g} / \mathrm{MT}$ or ppm. For the former, this would be the $\sim 1,224 \mathrm{~g} / \mathrm{MT}$ derived above for stabilized uranium-bearing low-level-waste forms times the upper enrichment limit allowed of 0.2 for the data used in the tabulations in STR-251 (Rev2) [15] or $\sim 225 \mathrm{~g} / \mathrm{MT}$. By comparison, the actual dilution of ${ }^{235} \mathrm{U}$ in fresh pebbles is either $(9 \mathrm{~g} \times 0.096) / 0.0002 \mathrm{MT} /$ pebble $=4,320 \mathrm{~g} / \mathrm{MT}$ or ppm for a fresh equilibrium core pebble or $(9 \mathrm{~g} \times 0.057) / 0.0002 \mathrm{MT} / \mathrm{pebble}=2,565 \mathrm{~g} / \mathrm{MT}$ or $\mathrm{ppm}$ for the initial core fresh pebble. As would be expected since enrichment is simply a multiplier on both the numerator and denominator of a ratio, the results are analogous to those for total uranium, as noted in the preceding paragraph. Therefore, there is no basis for termination of safeguards including NMC\&A on fresh PBMR fuel. 


\section{THE DOE ECONOMIC DISCARD LIMIT (EDL) FOR TERMINATION OF SAFEGUARDS ON DOE-OWNED SPECIAL NUCLEAR MATERIAL (SNM) [21-24]}

The DOE EDL for termination of safeguards on SNM in waste is provided in the DOE Manual DOE M 470.4-6 Chg 1, Nuclear Material Control and Accountability [21]. The EDL is selected for plutonium production based on the relative cost of chemical processing for further recovery of plutonium from reprocessing discharge waste versus the additional cost of building a new production reactor balanced against the cost of the need to continue NMC\&A on the discarded material. The EDL does not mean that termination of safeguards for physical protection is allowed since that need is based on the radiation hazard posed by the discarded material and its potential for use in radiological sabotage.

Per Table I-1 of DOE M 470.4-6 Chg 1, a gram quantity of either enriched uranium or plutonium (i.e., SNM) is considered to be a "reportable quantity" subject to the provisions of the manual, but, per Table I-2, the "Attractiveness Level E Criteria of SNM," the maximum SNM concentration (wt \%) for NMC\&A termination is, for discards of SNM-contaminated graphite parts, $0.2 \mathrm{wt} \%$ or $2000 \mathrm{ppm}$ by mass. This EDL is higher than the inferred IAEA provisional criteria for termination of safeguards on plutonium (a minimum of $500 \mathrm{ppm}$ for fuel element hulls encapsulated in cement concrete and as high as 1,143 ppm in fixed clarification sludges in cement concrete), and the IAEA has no such provisional criteria specifically for HEU or ${ }^{235} \mathrm{U}$ alone.

By comparison also to the IAEA provisional criteria for termination of safeguards on plutonium in bitumen-stabilized waste forms (i.e., $600 \mathrm{ppm}$ for bitumen-stabilized low activity liquid waste), Table I-2 of the DOE manual allows up to $1.0 \mathrm{wt} \%$ or $10,000 \mathrm{ppm}$ for "SNM microencapsulated in refractory compounds or in solid-dilution" such as bitumen.

Thus, the DOE EDL is generally less restrictive than the IAEA provisional criteria for termination of safeguards for plutonium-bearing wastes $(2,000 \mathrm{ppm}$ for the DOE EDL versus 500 to $1,000 \mathrm{ppm}$ for the IAEA provisional criteria).

A review of preceding DOE reports [22-24] indicates that, in the past, the site EDLs were often higher than the EDL in the current manual. These reports also indicate that the post-processing of plutonium-bearing graphite parts was generally done based primarily on surface contamination that was ground off the surface of the contaminated graphite part then burned with the ashes from the graphite burn further leached by nitric acid so that whole components (equivalent to a whole PBMR pebble) were not handled in the recovery operations - only the surface grinding residues. From Table 1, "RFP [Rocky Flats Plant] Residue Feed Stream Summary," in Reference [24], it is noted that plutonium contamination on graphite components recommended for a crush/burn/nitric acid leach at Rocky Flats varied from $46,125 \mathrm{ppm}$ down to 1,253 ppm, while the plutonium concentration on graphite components recommended for crush/burn/grout for disposal was $200 \mathrm{ppm}$. However, the purpose of Reference [24] was not to decide on what materials should be recovered but rather what materials should be processed in what 
manner for disposal in a vitrified or other more stable waste form as opposed to grouting as was done for the low-level contamination. Reference [24] provides no information on the proposed termination of safeguards for these waste forms except to imply in context that the planned disposition path is for waste forms suitable for disposal in the Waste Isolation Pilot Project (WIPP) in New Mexico.

The burning of uranium-contaminated graphite forms has also been used to recover uranium contamination starting in the 1940s at the Y-12 Plant [51]. The method used was grinding of the surface of the graphite component, burning the graphite, and applying nitric acid to the residue. From Table 2 of Reference [51], the residual discarded uranium appears to be $7.3 \mathrm{~g}$ per 5,000 $\mathrm{g}$ of carbon processed or $\sim 1,460 \mathrm{ppm}$. However, this application was for the recovery of all uranium (enriched and tails) from graphite components in calutrons at a time when the amount of uranium in the earth's crust was still not known and all uranium was considered to be potentially valuable to the developing nuclear weapons program in the United States. This value is also higher than the IAEA provisional criteria $(200 \mathrm{ppm})$ both for unconditioned/unstabilized burnable waste forms and for noncombustible waste forms such as ash, which would most closely resemble the residuals from the Y-12 Plant's burned graphite that were post-processed by nitric acid dissolution. As noted in DOE M470.4-6, the current DOE EDL for HEU (i.e., uranium as SNM) is 2,000 ppm. ${ }^{*}$ As times change, the acceptable investments to meet needs also change. In the late 1940s, there was great uncertainty in how much uranium there was in the earth's crust. At that time 1,460 ppm was the acceptable cutoff for recovering any uranium left on graphite parts from the Y-12 calutrons, but, by today's standards, 2,000 ppm of HEU is an acceptable DOE limit for cutoff of HEU recovery from HEU-bearing waste forms.

As illustrated in Table 1, both the plutonium and ${ }^{235} \mathrm{U}$ residual contents in a discharged pebble meet the current DOE EDL, but the EDL of a would-be proliferant nation could be much lower. Although the plutonium content meets and the uranium content marginally meets the IAEA provisional criteria for termination of safeguards for the PBMR used fuel, bulk accounting of the overall fissile content of the used fuel in spent fuel storage containers is likely still the best option without the need for specific quantitative accounting of the residual plutonium in the used fuel in storage.

\footnotetext{
* The DOE SNM EDL was developed for plutonium in DOE weapons programs and for HEU used in DOE weapons, naval reactors, and research reactors programs. For LEU, the current DOE EDL may not be relevant except for DOE waste disposal decisions.
} 


\section{FORMER SOVIET UNION EDL FOR PRODUCTION OF WEAPON-GRADE PLUTONIUM [25(a)]}

From Reference [25(a)], the EDL for the former Soviet Union weapons plutonium production program was $200 \mathrm{~g} / \mathrm{MT}$ in discharged solid wastes. The analogous liquid waste discharge limit was $<50-100 \mu \mathrm{g}$ of plutonium per liter of liquid waste, which, assuming the density of water at room temperature, is a factor of 1,000 lower than that for DOE liquid wastes $(0.1 \mathrm{wt} \%$ or $1,000 \mathrm{ppm})$ from Table I-2 in Reference [21].

The Soviet EDL solid waste criteria were those used to justify recovery of weapon-grade plutonium ${ }^{*}$ from actinide-bearing solid wastes from production activities as opposed to investing in constructing a new production reactor as the means to make more weapongrade plutonium available for use in nuclear weapons. The processing used to achieve the Soviet EDL for contaminated solids was apparently different at the Tomsk site and at the Mayak site. Tomsk used a series of caustic and acid leach process recovery steps for their solid production wastes. Mayak likely used an incinerator for combustible contaminated solids (such as plastic and paper) and then used a caustic fusion process step to produce "pellets" of solid sodium hydroxide $(\mathrm{NaOH})$ containing "soluble" plutonium; the $\mathrm{NaOH}$ pellets were then dissolved and processed to recover the plutonium.

The Soviet recovery technologies for weapon-grade plutonium generated large volumes of liquid and sludge wastes. The discharged liquid wastes from the reprocessing of irradiated fuel targets and recovery of weapon-grade plutonium at Tomsk and Krasnoyarsk for further use in Soviet weapons work at Mayak and Tomsk were chemically adjusted and then injected into deep boreholes in clay formations at Krasnoyarsk and Tomsk. The chemical wastes at Mayak were stored in tanks or discharged into holding ponds or lakes at the Mayak site. The production infrastructure was backed up by a large research, development, and architect-engineering establishment both at the production sites and at such institutes as the A. A. Bochvar All-Soviet Research and Development Institute of Inorganic Materials (VNIINM) in Moscow, the Khlopin Radium Institute in St. Petersburg, the All-Soviet Science Research and Design Institute of Power Engineering Technology (VNIPIET) in St. Petersburg, and the AllSoviet Design and Research Institute of Industrial Technology (VNIPIPT) in Moscow. Achieving the $200 \mathrm{ppm}$ EDL for solids represented a huge national investment but was part of the past Soviet Cold War methodology where current-day technologies for generating and handling secondary wastes and environmental cleanup legacies would not likely be the same.

A would-be proliferant nation with a strong incentive to generate multiple significant quantities of plutonium and who would seek to achieve an equivalent $200 \mathrm{ppm}$ EDL without detection would face an extremely expensive endeavor that would have to be

\footnotetext{
* The isotopic content of Soviet weapon-grade plutonium is considered to be a classified number by the Russian Federation; however, it is known that the plutonium oxide used by the Research Institute of Atomic Reactors (NIIAR) in Dimitrovgrad to fabricate mixed oxide vibrationally compacted test fuel for irradiation in BOR-60, BN-350, and BN-600 came from Mayak and that the plutonium for at least one BN-600 test assembly had a ${ }^{239} \mathrm{Pu}$ content of $96.5 \mathrm{wt} \%$ or near super-grade. Whether this plutonium came from production reactor stock or another source is not known.
} 
balanced against the expense and detectability of building a covert production reactor and reprocessing facility or a covert, large uranium enrichment facility. A billion dollar plus investment in one to two PBMR modules under IAEA safeguards with a likely contract to return spent fuel to the vendor's country is judged not likely to be a primary choice given the extensive dilution of low-grade plutonium in the used fuel that makes the undetected diversion of significant quantities very difficult to execute.

The dilution of recoverable plutonium in the PBMR discharged pebble is already only a factor of $\sim 2.7$ above the former Soviet EDL assuming that the effective recovery fraction previously demonstrated in laboratory-scale reprocessing testing in the United States [20] remains at $\sim 95 \%$ of the nuclear material in the pebble. If the $200 \mathrm{~g} / \mathrm{MT}$ or $200 \mathrm{ppm}$ from the Soviet EDL is taken as the lower limit for being practically irrecoverable, then the plutonium content in the unprocessed PBMR used-fuel pebble sits just above that limit of being practically irrecoverable.

By comparison to the $200 \mathrm{~g} / \mathrm{MT}$ Soviet EDL, an $\sim 710 \mathrm{~kg}$ VVER-1000* fuel assembly with $\sim 435 \mathrm{~kg}$ of LEU at a burnup of $\sim 50 \mathrm{GWD} / \mathrm{MT}$ will contain $\sim 4 \mathrm{~kg}$ of plutonium (half of one significant quantity) with a comparable dilution of over 5,600 g/MT, and once all the solid metal parts are cut away, the plutonium dilution in the residual actinide oxide would be about $8,500 \mathrm{~g} / \mathrm{MT}$.

\footnotetext{
${ }^{*}$ http://www.elemash.ru/en/production/Products/NFCP/VVER1000/
} 


\section{REPROCESSING OF GRAPHITE-ENCASED COATED-PARTICLE FUELS}

As noted previously, the INL evaluation [4] of the IAEA criteria for termination of safeguards, which states that the safeguards on "nuclear material subject to safeguards [under a s state safeguards agreement can be terminated] upon determination by the Agency that it has been consumed, or has been diluted in such a way that it is no longer usable for any nuclear activity relevant from the point of view of safeguards, or has become practicably irrecoverable," cannot be met by PBMR spent fuel because, although "the recovery of the plutonium could be expensive but not necessarily prohibitive," "the plutonium contained in the PBMR-400 spent fuel cannot be considered to be irretrievable." As demonstrated in the previous sections, the plutonium concentration in the PBMR used fuel is sufficiently dilute to meet, without further conditioning, the IAEA provisional criteria for termination of safeguards on stabilized waste forms. This section will further address the practicably irrecoverable aspect for a fuel (coated particles encased in graphitized carbon) for which no demonstrated pilot-scale or industrial-scale precedent has ever existed to support a "not necessarily prohibitive" and therefore a not practicably "irretrievable" determination.

The reprocessing of graphite-based fuels including that of pebble bed reactors has been studied extensively starting in the United States in the mid-1940s [52, 53]. The reprocessing of HEU/Th coated-particle fuel has been studied extensively on a laboratory scale with an excellent bibliography of this past work contained in Appendix A of Reference [54]. However, when it comes down to near pilot-scale but still mostly laboratory-scale work, there are only two relevant precedents that have moved somewhat beyond laboratory-based work only:

- the recovery of HEU/Th in TRISO-coated particles from unirradiated Fort St. Vrain fuel sticks and German pebbles ( $7 \mathrm{~g}$ of fuel per pebble with a thoriumto-HEU ratio of $\sim 5$ ) in the cold test line at General Atomic Company in the early 1980s $[19,20]$ and

- the recovery of HEU from dispersed uncoated or pyro-carbon-coated (BISO) HEU carbide particles in niobium carbide-coated fuel elements from unirradiated and lightly irradiated ROVER rocket fuel elements at the Idaho Chemical Processing Plant in the early 1980s [55].

Both of these near-pilot-scale (but still mostly laboratory-scale) test activities used a combustion-acid leach dissolution process for recovering HEU/Th or HEU from graphitematrix fuels. Although limited engineering flow-sheets exist for these test lines (but not completely in the open literature) and burner designs have been published for this early1980s and earlier research work, these efforts constitute separate equipment tests or primarily the arrangement of test equipment for the head-end processing and must be supplemented/complemented with a PUREX/THOREX plant on the back-end. To date with only a few dated exceptions [56-58]", no current engineering cost estimates have

\footnotetext{
* The cost estimate by the Ralph M. Parsons Company (RMP) architect-engineering firm from the mid1970s for the HTGR Fuel Reprocessing Facility proposed to be co-located with the Idaho Chemical Processing Plant to reprocess HEU/Th coated particle fuels from DOE-owned HTGR fuels may exist with
} 
been made for the development and construction of a coated-particle fuel reprocessing plant. It is understood that the DOE Office of Nuclear Energy plans to develop such an estimate in the future for sustainability assessments of the Next Generation Nuclear Plant (NGNP) and possibly for the deep-burn actinide-fueled coated particle type system, but the work on the cost estimates has not yet been undertaken and the deep-burn option may rely only on reprocessing of light water reactor fuel.

Once a consensus cost estimate baseline is developed for a coated-particle-fuel reprocessing facility, it will be possible to estimate the cost of various diversion and covert reprocessing scenarios as has been done in assessing the economic aspects of being practicably irrecoverable for material discards from light-water-reactor fuel reprocessing waste following termination of safeguards $[60,61]$. The references $[60,61]$ address the investments and operating costs estimated as of 1991 to recover plutonium or uranium [60] from various heavy-metal-bearing liquid and solid waste forms generated by light-water-reactor fuel fabrication and reprocessing facilities as a basis for confirming or otherwise requiring changes to the IAEA provisional criteria for termination of safeguards. Some key conclusions from References [60] and [61] that may be most relevant to the covert recovery of material form PBMR used fuel include the following:

- LEU (less than $5 \%{ }^{235} \mathrm{U}$ ) from Section 3.3, "Diversion Approaches for the Recovery of Nuclear Material," pages 21-22 of Reference [60]: "Nuclear material discards presented as final extraction residues that had not undergone acid leaching and contained $2000 \mathrm{gU} / \mathrm{MT}$ of discard material potentially could contain recoverable uranium; however, recovery of the uranium contained in these discards would exceed a factor of 10 greater effort (i.e., relative cost) than the production of equivalent material from uranium ore." The IAEA provisional criteria limits for final extraction residues (see Table 4-6, second column, second row as taken from STR-251 (Rev 2) [15]) are the solid suspensions in liquids or sludges, that is, uranium-bearing unconditioned waste forms, from reprocessing given in units of $2,000 \mathrm{~g} / \mathrm{m}^{3}$ that are apparently assumed in Reference [60] to have a density of $\sim 1.0 \mathrm{MT} / \mathrm{m}^{3}$, or that of water at room temperature, to yield the value of $2000 \mathrm{~g} \mathrm{U} / \mathrm{MT}$. These solid suspensions in liquids or sludges are unconditioned/unstabilized waste forms that are directly amenable to further chemical post-processing. As discussed in Section 4.2 of this supplemental report, the ratio in allowable concentrations between conditioned and unconditioned plutonium-bearing discards is a factor of five, from which it was inferred that, for a LEU-fueled pebble discharged at a burnup of $90.8 \mathrm{GWD} / \mathrm{MT}$, the limiting uranium concentration in a packed bed would be $\sim 7,635 \mathrm{~g} / \mathrm{MT}$ compared to the actual estimated residual of 41, $015 \mathrm{~g} / \mathrm{MT}$ from Appendix A. Thus, by comparison to the economic assessment of recovery costs in Reference [60], it is inferred that recovery of the uranium contained in PBMR used-fuel discards would exceed a factor of $\sim 10 / 5=\sim 2$ greater effort (i.e., relative cost) than the production of equivalent material from uranium ore. However, as discussed in Section 4.3 of this supplemental report, the high contents of ${ }^{232} U$ and ${ }^{236} U$ in the

the system design descriptions in the Idaho National Laboratory archives for High Level Waste, but its existence has not been confirmed [59]. 
recoverable uranium from PBMR used fuel will (1) require extensive blending with natural uranium to meet the ASTM C787 specification limits for these isotopes for reuse in standard fuel cycles or (2) impose reactivity, radiological, and detectability penalties on attempted covert reprocessing and reuse as driver fuel for a covert production reactor where any attempt to re-enrich to HEU would be impeded by the high concentrations of light uranium isotopes $\left({ }^{232} \mathrm{U},{ }^{234} \mathrm{U}\right.$, and $\left.{ }^{236} \mathrm{U}\right)$. Each of these aspects adds time, effort, and cost to both commercial and attempted covert reprocessing and reuse of uranium from PBMR used fuel. As discussed further in the next bullet on recovery of a single significant quantity of plutonium, there is another factor 2 in effort and/or cost associated with performing recovery in a laboratory hot cell as opposed to a dedicated reprocessing facility, and since there is a factor of nearly 10 difference between a significant quantity of plutonium and that of LEU (i.e., 75/8), it can be inferred by similar scaling that small-scale recovery of indirect-use uranium from PBMR used fuel will require a factor of at least 4 greater effort (i.e., relative cost). Whether the head-end processing of PBMR used fuel would increase this cost and effort by another factor of 3 to 5 so that the net exceeds "a factor of 10 greater effort (i.e., relative cost) than the production of equivalent material from uranium ore" requires access to the yet-to-be-developed consensus, optimized flow sheets and cost estimate for coated particle fuel reprocessing.

- Plutonium: From Section 1.3, "Assessment of Consultants' Recommendations," page 3 of Reference [60], the concern is expressed that "the cost of recovery of plutonium from the discards on which safeguards could be terminated (assuming termination of all wastes at the maximum quantity and/or concentration limits and treatment of all nuclear material discards on which safeguards was terminated) was estimated to be less that a factor of 3 greater than the cost to commercially produce the plutonium." From Section 3.3, page 21 of Reference [60], "Costs for the recovery of one significant quantity of plutonium from the reprocessing plant discards at a research laboratory hot cell facility would be at least a factor of 2 greater than the costs at the recovery facility described in the previous paragraphs." The facility being referred to in Reference [60] is one that would process unconditioned plutonium-bearing waste forms that are more amenable to chemical post-processing without the need for the head-end preprocessing required to recover heavy metal from PBMR used fuel for which current cost estimates are not available. In effect, one would have to preprocess PBMR used fuel with the graphite-encased coated-particle-fuel head-end reprocessing technology and leach the residues with nitric acid to get to the point being physically and chemically like the suspended solids in light-water-reactor reprocessed fuel waste sludge. From Table 4 of Reference [60], the estimated cost of recovering one significant quantity of plutonium from such sludge (at a concentration at the IAEA provisional criteria limit for termination of safeguards) in a dedicated reprocessing facility would be $\$ 30.9$ million in 1991 dollars. The cost of doing so in a research laboratory was estimated to be twice that amount, as noted above, and likely where the cost of the required head-end processing of PBMR used fuel would increase the total recovery cost substantially. While Reference [60] focused on the estimated costs of material recovery from 
unconditioned wastes, Reference [61] was focused on the costs aspects of "safeguards termination criteria ... developed for conditioned plutonium-bearing wastes from reprocessing plants." As discussed in Section 4.1 of this report, the dilution of plutonium in the discharged pebble of PBMR used fuel is most similar to that of plutonium-bearing conditioned sludge waste forms in glass or cement, both of which are addressed in Reference [61]. While Reference [61] does not provide a cost number per se for plutonium recovered from measured discards in conditioned waste, the references does provide some guidelines quoted as follows from page 334 of Reference [61]:

To deter clandestine recovery of nuclear material from discards on which safeguards have been terminated, the combined risk of detection and costs required for the recovery of nuclear material from the discard must be greater than the combined risks and costs required (1) to produce nuclear material from source material or (2) to divert product nuclear material from a safeguarded facility. A minimum factor of 10 increase in the resources and effort required to recover nuclear material from discards on which safeguards have been terminated over the costs required to produce equivalent nuclear material from source material is estimated to be necessary to achieve this deterrence. The effort and resources are increased by a factor of 10 by reducing the nuclear material concentration in the discard. Reducing the concentration increases not only the effort and resources required for recovery of the nuclear material, but also the risk of detection because more or larger processing facilities are required.

To date, current optimized consensus flow sheets and cost estimates for coated particle reprocessing have not been developed, so the type evaluation given in References [60] and [61] cannot be completed. As noted in Section 5 of Reference [2], the proponent of the PBMR states the following.

The difficulties of reprocessing of HTR spent fuel are mainly associated with the nature of its constituents. The graphite and the silicon carbide are practically chemical inert compounds, and few chemical reagents are capable of dissolving them quantitatively and effectively [1]. Methods for reprocessing HTR spent fuel elements have been developed in the past. These methods incorporated combinations of thermal, chemical and mechanical processes. However, none of these processes has ever reached a large-scale (commercial) status, both for political and economical reasons. Since reprocessing is technically feasible, it could become the method of choice in case of limited supply of uranium and thorium.

Thus currently, there is no demonstrated engineering basis to believe that, from a standpoint of cost and engineering considerations, the reprocessing of LEU coated-

\footnotetext{
* The paper's Reference [1] is D. Greneche and P. Brossard, "The Reprocessing Issue for HTR Spent Fuels," Proceedings of ICAPP 04, Pittsburgh, Pennsylvania, June 13-17, 2004.
} 
particle fuel to recover only the highly diluted low-grade plutonium is "practicable" in comparison to the cost of building a covert, small natural-uranium-metal-fueled, graphitemoderated, air-cooled or water-cooled production reactor, using long-recognized and demonstrated off-the-shelf technologies [63-66], coupled to a small PUREX plant, as has been done by every nuclear weapons state to date except for those with access to heavywater reactor technology. This does not mean that this finding alone justifies termination of safeguards but only that the lack of practicability in potential recovery of material should be considered in the context of the IAEA provisional criteria for acceptable concentrations in diluted waste forms. The INL evaluation [4] seems to be based on the same premise as the Russian logic [25(b)] in discounting the acceptability of U.S.proposed immobilization of weapon-grade plutonium [68]. For example, if recovery is technically doable on a laboratory scale, it follows that it is "practicable" on an engineering scale without due consideration of any of the other intervening complexities in terms of time, cost, and development effort or past experience that has yet to lead to a practicable implementation on an industrial scale. The fact that in theory something may be hypothetically possible does not necessarily equate to "practicable," especially in a third world country. One can argue that the rest of the world was surprised that Iraq covertly and without detection developed the unclassified calutron designs for purposes of uranium enrichment. This surprise has led to the need to implement the Additional Protocol for safeguards agreements with the IAEA. However, if the Iraqi leadership and technical community had devoted its funding and expertise to replicating protonaccelerating cyclotrons of the type to smash $200 \mathrm{MeV}$ protons onto lead or uranium targets so as to drive natural-uranium-metal-fueled light-water-moderated subcritical production reactors [67], the covert production of weapon-grade plutonium might have been both less expensive and more achievable than the attempted uranium enrichment. The need for a monitoring regime under extrinsic safeguards, including monitoring the exports and imports of "Trigger List" [69,70] and "Dual Use List" [71] items, does not go away but also may not justify developing expensive and technically exotic techniques to execute facility surveillance for items with sufficiently diluted waste forms that satisfy the IAEA provisional criteria for termination of safeguards.

With regard to the equipment items on the "Trigger List" $[69,70]$ and "Dual Use List" [71], these lists do not currently include the types of equipment that would be used in head-end reprocessing of graphitized-carbon-encased coated-particle fuels, that is, grinders, burners, and/or electrolytic disintegration/dissolution devices as described in References [19-20], [43-44], and [45-46]. For that matter, while not relevant to the issue of recovering either uranium or plutonium from spent coated-particle fuels, the current "Trigger List" [69, 70] and "Dual Use List" [71] do not even cover the types of equipment that would be used in fabricating coated-particle fuels such as solutiongelation kernel formers, coating furnaces, and coating gas supply controllers. These aspects reflect the lack of attention that comes with the lack of maturity of the coated particle-fuel technologies not being applied on an industrial scale. The fact that neither the Zangger Committee nor the Nuclear Suppliers Group (NSG) has addressed the types of equipment required for the head-end reprocessing of graphite-encased coated particles fuels is itself generally indicative of the perceived lack of practicability of such reprocessing technology. 


\section{DETERMINING THE PLUTONIUM CONTENT OF PBMR PEBBLES BEING DISCHARGED AND APPLYING A NMIS-TYPE SURVEILLANCE TO PBMR USED FUEL IN STORAGE}

\subsection{The Limitations of Anti-Neutrino Detection for NMC\&A of Spent Fuel Storage}

The discussion of IAEA safeguards for the PBMR from Section 4.6.3, "Anti-Neutrino Detectors as a Safeguards Tool for the Future," of Reference [1] indicates (1) that the IAEA is interested in the possible future application of anti-neutrino detectors to monitor nuclear power plants and (2) that some combination of intrinsic and extrinsic safeguards such as those currently used for CANDU reactors will be applicable to the PBMR with the possible use of non-intrusive, unattended, remotely monitored inspection technologies such as anti-neutrino detectors to allow the IAEA "to conduct infrequent short-notice random inspections (SNRI) to confirm that the safeguards systems are operational and that the reactor remains properly safeguarded." To date, the testing of small anti-neutrino detectors has been limited primarily to monitoring the power level of operating reactors [27-29], since the reaction cross sections for anti-neutrinos with matter are exceedingly small (on the order of $10^{-40}$ ) and require a high flux of anti-neutrinos to be effective at detecting a source such as a multi-megawatt research reactor or power reactor core operating at power. In theory and to a lesser extent in practice, anti-neutrino detectors can be used to monitor reactor power levels and, by distinguishing between the anti-neutrino spectra from ${ }^{235} \mathrm{U}$ and ${ }^{239} \mathrm{Pu}$ fissions and the different spectra from the $\beta$-decay of the different fission product chains, to infer the reactor burnup. For a PBMR on an equilibrium fuel cycle of reloaded/recirculated pebbles, the anti-neutrino spectra should equilibrate and thus provide an indicator of a major change in power level or the fuel cycle loading. It is doubtful, however, that such a detector would be very sensitive to the respective fissioning of various fissile isotopes occurring as the result of subcritical multiplication induced by the spontaneous fission of plutonium isotopes such as ${ }^{240} \mathrm{Pu}$ in a spent fuel storage container so as to provide remote indication/detection of the removal of a large quantity of irradiated pebbles. The anti-neutrino signature would simply be too small compared to that of the adjacent operating reactor. The investment cost of developing, validating, and deploying anti-neutrino detectors for used fuel monitoring may also be too high for the technical advantage gained if any over other monitoring technologies.

\subsection{A Feasible Option for PBMR Used Fuel Surveillance}

The surveillance of PBMR used fuel in the facility's spent fuel storage tanks may be limited to the total fissile content without specific regard to the diluted plutonium concentration if, for purposes of applying the IAEA provisional criteria for termination of safeguards on NMC\&A of plutonium, the used fuel meets the IAEA definition of a sufficiently diluted measured discard. Under Paragraph 107(b)(iv) of Reference [14] and Section 6.23 of Reference [50], the IAEA defines measured discards as "nuclear material which has been measured, or estimated on the basis of measurements, and disposed of in such a way that it is not suitable for further nuclear use." As described by the PBMR proponent in Reference [2], the burnup of a pebble by nondestructive assay (NDA) to determine if it is to be returned to the core for further irradiation or disposed to the spent 
fuel storage tanks is performed by a "gross gamma activity measurement." However, the use of gross gamma activity measurement alone may not be sufficient to satisfy the IAEA definition of measured, or estimated on the basis of measurements, without the measurement of one or more additional indices.

At a minimum, spectrographic measurements of the gamma ray emissions from a pebble to be discharged could be used to gauge the ratio of concentrations of selected fission products. These measured ratios could be compared against those of standard calculations of fission product ratios correlated with fissile material contents. If the spectrographic measurements fall within a predetermined allowance, the pebble could be discharged to the spent fuel storage containers with confidence that the plutonium content is acceptably below that of the IAEA criteria for termination of safeguards on measured discards. Suspect pebbles that appear to meet the full burnup requirement of $90.8 \mathrm{GWD} / \mathrm{MT}$ by virtue of gross gamma activity measurement but that fail to meet the expected gamma ray ratios of fission products could be diverted to a dedicated temporary storage tank for further analysis or retention for IAEA inspection. Similarly, an arbitrary/random selection process controlled by the IAEA could be used to divert a few pebbles during each irradiation period to a special IAEA surveillance storage tank for subsequent access and confirmatory testing by the IAEA inspector to provide a random confirmation of the plutonium content in discharged pebbles.

However, more advanced measurement techniques, such as passive neutron albedo [73] and uranium and plutonium x-ray fluorescence [62, 72-74], are being developed for high heavy-metal-loaded light-water-reactor fuels and small liquid samples from reprocessing plant sample lines [72]. Such techniques may be adapted and applied after validation by testing and with appropriate modifications to quantify more directly the plutonium content of each pebble before being discharged to the spent fuel storage tanks. In the case of $x$-ray fluorescence, tests need to be performed to demonstrate that the light loading of heavy metals in the pebble is sufficient to allow its use with confidence in the measured result. The use of such detectors for PBMR pebbles requires miniaturization of the scintillater crystals so that a significant multiple of small detectors can be used to speed up the timing of the measurement process that currently takes hours to perform with a single or dual detector arrangement. In addition, if high purity germanium (HPGe) detectors are used, a sophisticated cooling system using liquid nitrogen is needed to reduce signal noise but where a supply of liquid nitrogen is already required for the krypton trap in the PBMR's helium purification system.

Assuming that each pebble discharged to the spent fuel storage containers can be measured to ensure that the plutonium content is below the IAEA provisional criteria for termination of safeguards, the residual uranium content of the pebble may mean that PBMR used fuel cannot be released from the NMC\&A requirements for safeguards under either the IAEA termination-of-safeguards criteria noted above and/or the DOE EDL criteria. In this case, developing and implementing a more realistic and practical NMC\&A system than that proposed [1] can be realized by extending the demonstrated technologies for the Nuclear Material Identification System (NMIS) [26] to the monitoring the fissile content of PBMR used fuel in the storage containers. This is 
justified since the plutonium portion of the highly diluted SNM and/or fissile content of the PBMR used fuel is below the IAEA provisional criteria, as confirmed in the measurements made at discharge, below the EDL criteria used by DOE, and only slightly above (less than a factor of 4 above) the EDL criteria used in the past for recovery of weapon-grade plutonium from production reactor fuel by the Soviet nuclear weapons program. However, NMIS has been demonstrated to measure the content and enrichment of uranium and the content of plutonium or plutonium oxide in various storage configurations in U.S. and Russian nuclear weapons facilities. Adapting a NMIS-type surveillance system to PBMR spent fuel storage containers will require additional development. As described in Section 4.1 of Reference [2], the proponent proposes that each spent fuel storage tank have three access tubes for the insertion of monitoring detectors. Thus both gamma-sensitive and neutron-sensitive detectors as well as a neutron source (fixed or small D-T device) can be inserted separately and simultaneously in the three tubes, providing sufficient flexibility for use of a NMIS-type monitoring system. The primary purpose of such monitoring would be to gauge the overall fissile content of the storage tank sufficient to indicate whether some fraction of a metric ton of used fuel is missing where it would take several metric tons to be diverted to obtain a significant quantity of either direct-use plutonium or indirect use LEU.. 


\section{DISCUSSION OF UNRESOLVED ISSUES IDENTIFIED IN REFERENCE [16] WITH REGARD TO THE IAEA PROVISIONAL CRITERIA FOR TERMINATION OF SAFEGUARDS}

In Reference [16], the authors identified unresolved issues (as of 1994) with regard to the termination of safeguards under the IAEA provisional criteria from Reference [15]. Since these provisional criteria were used in Section 4 of this report to assess the basis for termination of NMC\&A on the plutonium in the PBMR used fuel, it is appropriate to discuss and assess these unresolved issues as they may apply to the PBMR. Each of the issues from Reference [16] is first quoted and then addressed separately as follows for the PBMR.

1. Recoverability of nuclear material from waste is a difficult issue to resolve because of the number of variables that must be considered. These variables include the nature and source of the waste, the size of the recovery facility, and the available recovery technology. The termination criteria recommended by the consultants were based solely on the wastes generated by modern processing facilities [as of 1989]. These criteria are believed by the United States to meet the definition of economically unrecoverable but not necessarily that of "...diluted in such a way that it is no longer usable for any nuclear activity relevant from the point of view of safeguards, or has become practicably irrecoverable."

Assessment for the PBMR: The dilution of the plutonium in the PBMR used fuel is quantified as meeting the IAEA provisional criteria as described in Section 4.1 of this report. Whether the dilution is sufficient to be judged as practicably irrecoverable is problematic. The issues of practicability of recovery are discussed in Section 7 of this report, recognizing the current limitation of not having a consensus set of optimized flow sheets and cost estimates for reprocessing graphite-encased coated-particle fuel so that a cost-and-effort-based evaluation can be performed as has been done for fabrication and reprocessing wastes from light-water-reactor fuels in References [60] and [61].

As discussed in Section 4.1.2 of this report, the Russians concluded that the U.S.proposed immobilized (vitreous and ceramic) forms for weapons-grade plutonium did not provide "an additional barrier in the nonproliferation system" because the Russian laboratory-testing of small samples showed that "plutonium incorporation into the studied compositions is a poor obstacle against its unauthorized use." This Russian assessment ignored the expensive needs to handle and disassemble massive objects (the can-in-canister containers), smash or dissolve the ${ }^{137} \mathrm{Cs}-$ bearing glass radiation barrier enclosing the plutonium-bearing cans, and then finally process the plutonium-bearing immobilized form in each enclosed can [68]. Thus the Russians failed to analyze the cost, time, and effort required to develop and implement an effective recovery facility from the standpoint of engineering practicability given also that the can-in-canisters were supposed to be buried in a bilaterally-monitored geologic repository. Instead, the focus was on the fact that in a laboratory one can use enough acid or caustic to recover plutonium from a small specimen of an immobilized form. The can-in-canister as 
proposed for immobilization of weapon-grade plutonium was to contain 2.5 to 3.5 significant quantities of weapon-grade plutonium in a $2 \mathrm{MT}$ canister. By comparison, the PBMR used fuel is arguably equally if not more acceptable as a disposition mechanism for non-weapon-grade plutonium since, as provided in Table 3, the diversion of single significant quantity of plutonium requires access to $13.9 \mathrm{MT}$ of radioactive pebbles requiring $\sim 19 \mathrm{~m}^{3}$ of. shipping containers plus shielding.

Similarly 30 years ago, as described briefly in Section 7, General Atomic Company used a cold laboratory-scale test line to recover uranium and thorium from unirradiated German pebbles at $\sim 95 \%$ recovery efficiency, and the Idaho Chemical Reprocessing Plant (ICPP) used a small test pilot line to recover HEU (no TRISO particles) from unirradiated and lightly irradiated ROVER fuel. Both laboratory-scale demonstrations used a combination of grind-burn-leach where it is not clear that the grinding machines and furnaces identified as dual-use items in IAEA INFCIRC/254 Part 2 [71] cover the equipment items used in the demonstration tests by General Atomic and the ICPP. This potential shortcoming can be resolved by reviewing the equipment configurations used in previous HTGR fuel reprocessing tests against the current dual-use list and providing an appropriate recommendation to the NSG. However, more generally the mass and volume of material required to be processed to recover one significant quantity of plutonium (Table 3) is very large and substantially larger (by a factor of 7) than that needed to recover 2.5 to 3.5 significant quantities from the U.S.-proposed can-in-canister immobilization of weapon-grade plutonium. None of the HTGR TRISO fuel reprocessing technologies has moved beyond laboratory scale so that there is not available recovery technology that has been demonstrated practicable on an engineering basis. At this juncture the immaturity of coated-particle-fuel reprocessing supports the argument that the nuclear material in PBMR used fuel is practicably irrecoverable.

2. Inert dilution of wastes involves adding a substance to the waste to lower the nuclear material concentration so that the recoverability of the nuclear material is not significantly affected. Resolution of this issue requires establishment of termination criteria based on the ratio of nuclear material content to the quantity of the specific materials from which the nuclear material must be separated and not to the total waste quantity.

Assessment for the PBMR: Nothing has to be added to achieve the dilution of the plutonium in PBMR used fuel. The graphitized carbon of the fuel form satisfies the issue "of termination criteria that are based on the ratio of nuclear material content to the quantity of the specific materials from which the nuclear material must be separated."

3. Resubmission of wastes presents a different concern for the termination of safeguards. Because wastes containing nuclear material on which safeguards have been terminated are no longer subject to IAEA certification, the diverting state 
could represent these materials as new waste. Resubmission of nuclear material in waste could be used to conceal the diversion of more attractive materials from the process through increasing the quantity of nuclear material appearing to be removed in current wastes. This threat exists at any facility producing waste in quantities less than the termination criteria. Whenever safeguards is terminated on the form of the waste material in which it leaves the process, this concern exists.

Assessment for the PBMR: Safeguards on PBMR used fuel must be maintained due to the residual uranium and the physical protection requirements to prevent radiological sabotage. The termination of NMC\&A on the plutonium content with a refocus on the total fissile content of the PBMR used fuel precludes this resubmission concern; however, it is to be recognized that even the residual LEU has such a high content of ${ }^{232} \mathrm{U}$ and ${ }^{236} \mathrm{U}$ as to make it the least attractive option for reuse compared to other spent fuels, as discussed in detail in Section 4.3 of this report.

4. Maximum limit for termination without verification was discussed by the consultants without resolution of differences. This issue was addressed in the U.S. contribution to the IAEA with recommendation of a maximum quantity of 0.01 effective quantity per month. Following review of the issue, the IAEA affirmed this quantity as the limit for safeguards termination without verification.

Assessment for the PBMR: The issue is not applicable to the PBMR since it is not a reprocessing facility; however, feasible methods for verification by appropriate surveillance of the discharged used fuel are discussed in Section 8.2 of this report.

5. Termination criteria for conditioned waste was minimally addressed at the consultants' meeting and in the IAEA-proposed criteria. This issue was investigated by the United States in 1992 and was reported previously. Conditioning places the nuclear materials in the wastes in a form that protects them from environmental release but may not significantly increase the difficulty of nuclear material recovery using established technologies. Termination of safeguards on unconditioned waste is dependent on the defined safeguards termination criteria and the practices of the facility or country generating the waste. Because some forms of unconditioned waste may not be eligible for termination of safeguards until after conditioning, termination criteria also need to be established for conditioned waste. Transuranic wastes generally are required to be conditioned before disposal.

Assessment for the PBMR: As discussed in Section 4 of this report, PBMR used fuel is viewed as being a conditioned waste form which is analogous to the dilution of plutonium in conditioned waste forms meeting the IAEA provisional criteria for termination of safeguards but which is shown to be only marginally acceptable for residual LEU where limits on acceptable conditioned waste forms had to be inferred from the IAEA provisional criteria for plutonium waste forms. In addition to being a conditioned waste form for the residual LEU, the high 
content of ${ }^{232} \mathrm{U}$ and ${ }^{236} \mathrm{U}$ and the lack of a mature reprocessing technology demonstration make uranium recovery the least attractive option for reuse compared to other spent fuels as discussed in detail in Section 4.3; however, the waste form is judged to be very suitable for direct geologic disposal [30-34].

6. Criteria for termination of safeguards on discards exceeding the technical criteria was left to the IAEA's discretion. Guidance for termination of safeguards on these materials is needed and was recommended in U.S. contributions to the IAEA. Batch limits of 0.05 significant quantity and annual limits of 0.2 significant quantity were recommended.

Assessment for the PBMR: The batch limit of 0.05 significant quantity approximates the multiplier of 0.042 minimum critical mass cited in the same Reference [16] and used for the alternative analysis of limits on plutonium and LEU dilution in the PBMR used fuel as a waste form in Section 4 of this report. The batch limits quoted above apply to reprocessing and are not particularly applicable to fuel reloading into large reactors. Similarly the annual limit of 0.02 significant quantity is unrealistic for fuel throughput in a reactor during reactor operation where $\sim 2,936$ pebbles containing less than $\sim 300 \mathrm{~g}$ of build-in plutonium are recirculated each day but could be applied to off-site shipments of used fuel for processing or disposal where, for plutonium, this limit would equate to $\sim 14,035$ used fuel pebbles per shipment. 


\section{RECOMMENDATIONS FOR FUTURE WORK}

Since the data used for the analyses in Section 4 were based on estimates derived in Appendix A drawn from References [2], [4], and [7], a reanalysis is recommended to be performed by the two organizations to the same burnup and for the key fission products (such as ${ }^{99} \mathrm{Tc}$ ), the uranium isotopes and other actinides. The other actinides include plutonium and those that impact the post-shutdown decay to the minor uranium isotopes. A reanalysis of the $A_{2}$ values for reprocessed uranium from PBMR used fuel with an actinide chemistry experts' assessment of the likely ${ }^{99} \mathrm{Tc}$ and plutonium ranges of contamination in the reprocessed uranium would provide a more definitive estimate of the comparative radiological hazard as well as the detectability posed by reuse of covertly reprocessed uranium from PBMR used fuel.

Transport theory calculations of the minimum $\alpha$-phase critical mass of plutonium isotopics recoverable from PBMR used fuel would provide a better basis than the ROF described in Sections 4.1.1 and 4.1.3 for evaluating the plutonium dilution limit using the correlated method discussed in Footnote "a" of Table 1 in Reference [16].

The above-listed efforts would use qualified and validated analytical methods to provide data to replace the estimates for data used in the current analyses presented in this report, which provides an approach for assessment but not a defensible quantification of margins to limits.

Technologies and methods to confirm the plutonium content in discharged pebbles at the time of discharge from the reactor and thereby to qualify the use of such methods to quantify measured discards, as discussed in Section 8.2, require further development and testing to verify that such technologies and methods can be used effectively for both process control and safeguards NMC\&A of PBMR used fuel. In addition, development and testing is required to demonstrate that NMIS-type surveillance systems can be used to establish the fissile content in PBMR used-fuel storage containers given that the plutonium dilution has been shown to meet the IAEA provisional criteria for termination of plutonium-specific NMC\&A at the time of discharge as a measured discard.

Finally, a review of the experimental equipment used previously in laboratory-scale testing of HTGR fuel reprocessing technologies needs to be performed against the "Trigger List" $[69,70]$ and the "Dual Use List" [71] to identify required changes to recommend to the NSG to ensure adequate export controls are in place over key/unique equipment and technologies that could be applied to HTGR fuel reprocessing development, testing, and implementation. 


\section{REFERENCES}

[1] P. C. Durst et al., Nuclear Safeguards Considerations for the Pebble Bed Modular Reactor (PBMR), INL/EXT-09-16782, Idaho National Laboratory, Idaho Falls, ID, October 2009, http://www.inl.gov/technicalpublications/Documents/4374060.pdf.

[2] Johan Slabber, PBMR (Pty) Ltd., "PBMR Nuclear Material Safeguards," Paper No. B14, Proceedings of the Conference on High Temperature Reactors, Beijing, China, September, 22-24, 2004, International Atomic Energy Agency, Vienna (Austria), http://www.iaea.org/inisnkm/nkm/aws/htgr/fulltext/htr2004 b14.pdf.

[3] Johan Slabber, "PBMR Reactor Unit and Main Support Systems," ADAMS Accession Number ML060680079, presentation by PBMR (Pty) Ltd. to the U.S. Nuclear Regulatory Commission in Public Meeting, PBMR Safety and Design Familiarization, February 28-March 3, 2006, http://adamswebsearch2.nrc.gov/idmws/doccontent.dll?library=PU_ADAMS ${ }^{\wedge} \mathrm{PB}$ NTAD01\&ID $=060680165$. [NOTE: Access to this site may sometimes require $\log$-in as "guest."]

[4] A. M. Ougouag, H. D. Gougar, and T. A. Todd, Evaluation of the Strategic Value of Fully Burnt PBMR Spent Fuel, INL/EXT-06-11272, Idaho National Laboratory, Idaho Falls, ID, May 2006, http://www.inl.gov/technicalpublications/Documents/3372140.pdf.

[5] Interim guidance for the safe transport of reprocessed uranium, IAEA-TECDOC750, International Atomic Energy Agency, Vienna (Austria), June 1994, http://www-pub.iaea.org/MTCD/publications/PDF/te 750_prn.pdf.

[6] IAEA SAFETY STANDARDS for protecting people and the environment: Safety of Conversion and Enrichment Facilities, DRAFT SAFETY GUIDE DS 344, Rev. 1, International Atomic Energy Agency, Vienna (Austria), 28 August 2006, http://www-ns.iaea.org/downloads/standards/drafts/ds344.pdf.

[7] Management of Reprocessed Uranium: Current Status and Future Prospects, IAEA-TECDOC-1529, International Atomic Energy Agency, Vienna (Austria), February 2007, http://wwwpub.iaea.org/MTCD/publications/PDF/te_1529_web.pdf.

[8] L. V. Matveev and V. Yu. Rogozhkin, "Compensation for ${ }^{236} \mathrm{U}$ in the fuel of the VVÉR-440," Atomic Energy 66, No. 5, pp. 393-394, May 1989 (translated from Atomnaya Energiya 66 No. 5), available for purchase and downloading at http://www.springerlink.com/content/18n05h487400x501/.

[9] V. N. Proselkov et al., "Analysis of the Possibility of Using Fuel Based on Reclaimed Uranium in VVÉR Reactors," Atomic Energy 95 No. 6, pp. 829-834, December 2003 (Translated from Atomnaya Energiya 95 No. 6), available for purchase and downloading at http://www.springerlink.com/content/p3657vl68p3t1578/.

[10] G. D. Del Cul et al., Analysis of the Reuse of Uranium Recovered from the Reprocessing of Commercial LWR Spent Fuel, ORNL/TM-2007/207 
(ORNL/GNEP/LTR-2008-002), Oak Ridge National Laboratory, Oak Ridge, TN, January 2009, http://apps.ornl.gov/ pts/prod/pubs/1doc14204_ornl_tm_2007_207_final.pdf.

[11] Fuel cycle options for light water reactors and heavy water reactors: Proceedings of a Technical Committee meeting held in Victoria, Canada, 28 April-1 May 1998, IAEA-TECDOC-1122, International Atomic Energy Agency, Vienna (Austria), November 1999, http://wwwpub.iaea.org/MTCD/publications/PDF/te_1122_prn.pdf.

(a) R. J. Page, G. Marsh, M. R.Wash, and W. W. Inch, "Recycled Uranium - An Advanced Fuel for CANDU Reactors," pp. 171-178.

(b) J. V. Donnelly and M. D. D'Antonio, "Fuel Management Simulations for $0.9 \%$ SEU in CANDU 6 Reactors," pp. 179-188.

(c) H. C. Suk, K-S. Sim, J. H. Chung, "CANFLEX-RU Fuel Development Program as One Option of Advanced Fuel Cycles in Korea," pp. 211-219.

[12] E. Lippmaa et al., "Enriched Uranium Technology at the Sillamäe Oil Shale Processing Plant," pp. 275-280, Oil Shale 23 No. 3, Estonian Academy Publishers, 2006, http://www.kirj.ee/public/oilshale/oil-2006-3-8.pdf.

[13] Paragraph 26.c in The Agency's Safeguards System (1965, as Provisionally Extended in 1966 and 1968), INFCIRC/66/Rev.2, International Atomic Energy Agency, Vienna, Austria, 16 September 1968, http://www.iaea.org/Publications/Documents/Infcircs/Others/infcirc66r2.pdf.

[14] Paragraph 11 and Paragraph 107(b)(iv) in The Structure and Content of Agreements between the Agency and States required in connection with the Treaty on the Non-Proliferation of Nuclear Weapons, INFCIRC/153 (Corrected), International Atomic Energy Agency, Vienna, Austria, June 1972, http://www.iaea.org/Publications/Documents/Infcircs/Others/infcirc153.pdf.

[15] Consultants' Report on Meeting for Development of Technical Criteria for Termination of Safeguards for Material Categorized as Measured Discards, STR251 (Rev. 2), International Atomic Energy Agency, Vienna, March 1990.

[16] B. W. Moran and W. M. Murphy, "Unresolved issues concerning the final disposal of nuclear material discards," IAEA Symposium on International Safeguards, Vienna, 14-18 March 1994, IAEA-SM-333/120 (K/NSP-165 or CONF-940307-12), International Atomic Energy Agency, Vienna, March 1994, http://www.osti.gov/energycitations/servlets/purl/10124610-b1p2Kg/native/.

[17] J. A. Larrimore, "Termination of international safeguards on nuclear material discards: An IAEA update," pp. 202-207, Proceedings of the 36th Institute of Nuclear Material Management Annual Meeting, Palm Desert, California, July 912, 1995.

[18] Annex E, "Criteria for termination of safeguards," Guidance for the Application of an Assessment Methodology for Innovative Nuclear Energy Systems INPRO Manual - Proliferation Resistance: Volume 5 of the Final Report of Phase 1 of the International Project on Innovative Nuclear Reactors and Fuel Cycles 
(INPRO), IAEA-TECDOC-1575/Vol. 5, International Atomic Energy Agency, Vienna, July 2007,

http://www.iaea.org/NuclearPower/Downloads/INPRO/Files/5_INPRO\%20PR_m anual $\% 2016-07-2007 \% 20$ pub\%20com.pdf.

[19] N. D. Holder, J. B. Strand, F. A. Schwarz, and H. E. Tischer, Processing of FRG mixed oxide fuel elements at General Atomic under the US/FRG Cooperative Agreement for Spent Fuel Elements, GA-A16111 (CONF-801107-3), General Atomic Company, San Diego, CA, November 1980, http://www.osti.gov/energycitations/servlets/purl/6921670-51sB7O/.

[20] N. D. Holder, J. B. Strand, F. A. Schwarz, and R. N. Drake, Processing of FRG high-temperature gas-cooled reactor fuel elements at General Atomic under the US/FRG Cooperative Agreement for Spent Fuel Elements, GA-A16567 (CONF811103-67), General Atomic Company, San Diego, CA, November 1981, http://www.osti.gov/energycitations/servlets/purl/5817519-VqBYb8/.

[21] Nuclear Material Control and Accountability, DOE M470.4-6 Change 1, U.S. Department of Energy, Washington, D.C., August 14, 2006, https://www.directives.doe.gov/directives/current-directives/470.4-DManual6c1/view.

[22] W. C. White et al., Plutonium removal limit for the disposition of plutoniumbearing materials, WSRC-MS-92-501 (CONF -930205-9) Westinghouse Savannah River Company, Aiken, SC, presented at Waste Management '93,Tucson, AZ (United States),28 February-4 March 1993, December 1992, http://www.osti.gov/energycitations/servlets/purl/10131977-BqGJEL/.

[23] D. C. Christensen and M. A. Robinson, Development and Implementation of Attractiveness Level E Criteria and the Plutonium Disposition Methodology, LA13425-MS, Los Alamos National Laboratory, Los Alamos, NM, March 1998, http://www.osti.gov/energycitations/servlets/purl/653947-d11vRx/webviewable/.

[24] L. Chang, Options for the disposition of current inventory of Rocky Flats Plant residues, UCRL-ID-117455, Lawrence Livermore National Laboratory, Livermore, CA, May 1994, http://www.osti.gov/energycitations/servlets/purl/10177110C66F1O/webviewable/.

[25] L. J. Jardine and G. B. Borisov, Excess Weapons Plutonium Immobilization in Russia: A Review of LLNL Contract Work in Proceedings of the Meeting for Coordination and Review of Work Held in St. Petersburg, Russia, November 1-4, 1999, UCRL-ID-138361, Lawrence Livermore National Laboratory, Livermore, CA, April 15, 2000, https://e-reports-ext.1lnl.gov/pdf/237560.pdf.

(a) G. Borisov, "Approaches and Status of Pu-containing Materials Immobilization in the US and Russia," pp. 3-4.

(b) L. Lazarev et al., "Recovery of Plutonium from Vitreous and Ceramic Materials Used for Waste Immobilization [B344864]," pp. 253-264. 
(c) V. Ilyashenko, V. F. Gorbunov, and O. A. Mansourov, "Study of Recovery of Plutonium from Ceramic and Glass-type Materials [B344863]," pp. 265-270.

[26] J. T. Mihalczo, J. K. Mattingly, J. A. Mullens, and J. S. Seals, NMIS with Gamma Spectrometry for Attributes of Pu and HEU, Explosives and Chemical Agents, Y/LB-16,123, Y-12 National Security Complex, Oak Ridge, TN, May 2002. http://www1.y12.doe.gov/search/library/documents/pdf/ylb-16123-r1.pdf.

[27] N. S. Bowden, "Reactor monitoring and safeguards using antineutrino detectors," The XXIII Conference on Neutrino Physics and Astrophysics, Journal of Physics: Conference Series 136, IOP Publishing, \#022008, 2008, http://www.slac.stanford.edu/econf/C0805263/ProcContrib/bowden_n.pdf.

[28] F. Yermita et al., "The NUCIFER Experiment: reactor monitoring with antineutrinos for non proliferation purpose," Paper 9270, Proceedings of Global 2009, Paris, France, September 6-11, 2009.

[29] M. Fallot et al., "Nuclear Reactor Simulations for Unveiling Diversion Scenarios: capabilities of the antineutrino probe," Paper 9272, Proceedings of Global 2009, Paris, France, September 6-11, 2009.

[30] J. Wolf, Ultimate storage of spent fuel elements from the AVR experimental nuclear power plant in the Asse Salt Mine, GERHTR-147 (translation of JÜL1187), Institut für Chemische Technologie, Kernforschungsanlage Jülich G.m.b.H., Jülich, Germany, February 1975.

[31] H. U. Brinkmann et al., "Contributions towards the Development of a Packaging Concept for the Final Disposal of Spent HTGR Pebble Fuel," Nuclear Engineering and Design 118, pp. 107-113 (1990), North-Holland Publishers.

[32] N. Kirch, H. U. Brinkmann, and P. H. Brücher, "Storage and Final Disposal of Spent HTR Fuel in the Federal republic of Germany," Nuclear Engineering and Design 121, pp. 241-248 (1990), North-Holland Publishers.

[33] D. Niephaus, S. Storch, and S. Halaszovich, "Experience with the interim storage of spent HTR fuel elements and a view to necessary measures for final disposal," Technologies for gas cooled reactor decommissioning, fuel storage and waste disposal, IAEA-TECDOC-1043, Technical committee meeting on technologies for gas cooled reactor decommissioning, fuel storage and waste disposal. Juelich (Germany) 8-10 September 1997, International Atomic Energy Agency, Vienna (Austria), http://www.iaea.org/inisnkm/nkm/aws/htgr/fulltext/29059911.pdf.

[34] Charles W. Forsberg et al., "A New Repository Waste Form: Graphite-Carbon High-Level Waste (HTGR Fuel Processing and Waste Forms)," American Nuclear Society 2003 International High-Level Radioactive Waste Management Conference, Las Vegas, NV, March 30-April 2, 2003, http://www.ornl.gov/ webworks/cppr/y2001/pres/116773.pdf.

[35] R. M. Westfall, S. Golugoglu, and R. Q. Wright, "Critical Masses for Unreflected Metal Spheres," Proceedings of the 2009 Nuclear Criticality Safety Division Topical Meeting on Realism, Robustness and the Nuclear Renaissance, Richland, 
Washington, September 13-17, 2009, American Nuclear Society, La Grange Park, IL (USA), 2009.

[36] R. W. Brewer, Benchmark Critical Experiment of a Water Reflected Alpha-Phase Plutonium Sphere, LA-UR-94-3269 (NEA/NSC/DOC(95)03/I, Volume I, PUMET-FAST-011), Los Alamos National Laboratory, Los Alamos, NM, 1995, http://library.lanl.gov/cgi-bin/getfile?00285686.pdf and http://ftp.fas.org/sgp/othergov/doe/lanl/lib-www/la-pubs/00285686.pdf.

[37] G. E. Hansen and H. C. Paxton, Reevaluated Critical Specifications of Some Los Alamos Fast-Neutron Systems, LA-4208, Los Alamos Scientific Laboratory, Los Alamos, NM, September 1969, http://library.lanl.gov/cgibin/getfile?00368877.pdf.

[38] R. D. Baker, S. S. Hecker, and D. R. Harbur, "Plutonium: A Wartime Nightmare but a Metallurgist's Dream," pp. 142-151, Los Alamos Science Winter/Spring 1983, http://library.lanl.gov/cgi-bin/getfile?07-16.pdf.

[39] Nuclear Criticality Control of Special Actinide Elements, ANSI/ANS-8.15-1981 (Reaffirmed 1987, 1995, and 2005), American Nuclear Society, La Grange Park, IL (USA).

[40] D. R. Finch and T. G. Williamson, Validity of the rule-of-fractions for assuring criticality safety margins, WSRC-TR-91-569 (also WSRC-MS-91-265 and CONF-911107-81), Westinghouse Savannah River Co., Aiken, S.C. October 1991, http://www.osti.gov/energycitations/servlets/purl/10150622-vhpgqd/.

[41] C. Lavarenne, C. D. Mennerdahl, and C. Dean, Evaluation of nuclear criticality safety data and limits for actinides in transport, SEC/T/03.146, Institut de Radioprotection et de Sûreté Nucléaire, Fontenay-aux-Roses (France), May 2003.

[42] D. E. Beller and R. A. Krakowski, Burnup Dependence of Proliferation Attributes of Plutonium from Spent LWR Fuel, LA-UR-99-751, Los Alamos National Laboratory, Los Alamos, N.M., February 24, 2999, http://lib-www.lanl.gov/cgibin/getfile?00326582.pdf.

[43] L. W. Fromm and H. E. Webb, "Recovery of uranium from graphite fuel units," Section III.J, pp. 19-20, Power Pile Divisions Quarterly Report for June, July and August 1948, ORNL-271, Oak Ridge National Laboratory, Oak Ridge, TN, September 1948, http://www.ornl.gov/info/reports/1948/3445603603223.pdf.

[44] L.W. Fromm, Recovering uranium from graphite by electrolytic graphite disintegration in nitric acid, ORNL-238, Oak Ridge National Laboratory, Oak Ridge, TN, February 1949, http://www.ornl.gov/info/reports/1949/3445603603731.pdf.

[45] M. A. Fütterer, H. Bluhm, P. Hoppé, and J. Singer, Head-End Process for the Reprocessing of Reactor Core Material, International Patent WO/2006/087360, European Patent EP1849164, publication date 24 August 2006, http://www.wipo.int/pctdb/en/wo.jsp?wo=2006087360.

[46] J. Paris and J.-R. Costes (Commissariat a I'Energie Atomique), Process for the Treatment of Nuclear Graphite Contaminated with Radioelements by Milling the 
said Graphite in a Liquid Medium, United States Patent US 7,500,623 B2, March 10, 2009, http://patft.uspto.gov/netacgi/nph-

Parser?Sect $1=$ PTO $1 \&$ Sect $2=$ HITOFF $\& d=$ PALL $\& p=1 \& u=\% 2$ Fnetahtm $1 \% 2 F P T O$ $\% 2$ Frchnum.htm $\& \mathrm{r}=1 \& \mathrm{f}=\mathrm{G} \& \mathrm{l}=50 \& \mathrm{~s} 1=7500623 . \mathrm{PN} . \& \mathrm{OS}=\mathrm{PN} / 7500623 \& \mathrm{RS}=\mathrm{P}$ $\mathrm{N} / 7500623$.

[47] The Convention on the Physical Protection of Nuclear Material, INFCIRC/274/Rev.1, International Atomic Energy Agency, Vienna (Austria), May 1980, http://www.iaea.org/Publications/Documents/Infcircs/Others/inf274r1.shtml or http://www.iaea.org/Publications/Documents/Infcircs/Others/infcirc274r1.pdf.

[48] IAEA Safety Standards for protecting people and the environment: Advisory Material for the IAEA Regulations for the Safe Transport of Radioactive Material, Safety Guide No. TS-G-1.1 (Rev. 1), International Atomic Energy Agency, Vienna (Austria), 2008, http://www-pub.iaea.org/MTCD/publications/PDF/Pub1325 web.pdf.

[49] IAEA Safety Standards for protecting people and the environment: Regulations for the Safe Transport of Radioactive Material, 2009 Edition, Safety Requirements No. TS-R-1, International Atomic Energy Agency, Vienna (Austria), 2009, http://wwwpub.iaea.org/MTCD/publications/PDF/Pub1384_web.pdf.

[50] IAEA SAFEGUARDS GLOSSARY, 2001 Edition, INTERNATIONAL NUCLEAR VERIFICATION SERIES No. 3, International Atomic Energy Agency, Vienna (Austria), http://www-pub.iaea.org/MTCD/publications/PDF/nvs-3cd/PDF/NVS3 prn.pdf.

[51] E. D. Shipley and G. H. Clewett, Comparison of various methods for the remvoal of uranium from carbon salvage, Y-352, Y-12 Plant, Oak Ridge, TN, February 1949, http://www.osti.gov/energycitations/servlets/purl/4371197-pUIP61/.

[52] C. R. McCullough et al., Summary report on design and development of high temperature gas-cooled power pile, MonN-383, Clinton Laboratories, Oak Ridge, TN, September 1947, http://www.osti.gov/energycitations/servlets/purl/4359623$\underline{\operatorname{lmW} 9 \mathrm{Je} / .}$.

[53] H. K. Jackson, Preliminary report on the recovery of uranium from spent graphite-uranium fuel material, MonT-320, Clinton Laboratories, Oak Ridge, TN, June 1947, http://www.ornl.gov/info/reports/1947/3445605714885.pdf.

[54] T. Hertzler, Technical and Regulatory Review of the Rover Nuclear Fuel Process for Use on Fort St. Vrain Fuel, EGG-WTD-10550, Science Applications International Corporation, Idaho Falls, Idaho, February 1993, http://www.osti.gov/energycitations/servlets/purl/6420824-pMnptr/ and http://www.osti.gov/energycitations/servlets/purl/10150968-hdtVFe/.

[55] S. Stacey and J. Braun, Historic American Engineering Record, Idaho National Laboratory, Idaho Chemical Processing Plant, Fuel Reprocessing Complex, INL/EXT-06-11969 (HAER No. ID-33-H), Idaho National Laboratory, Idaho 
Falls, ID, December 2006, http://www.inl.gov/technicalpublications/Documents/3551472.pdf.

[56] G. D. C. Short and J. Wharton (U.K.A.E.A. Risley), Preliminary Summary of the Estimated Costs of Reprocessing and Refabrication of Fuels, Dragon Project Report 470, A.E.E. Winfrith, Dorchester, Dorset, England, February 1968.

[57] J. Wharton and G. D. C. Short, H.T.R. Fuel Reprocessing and Refabrication Study, Dragon Project Report 540, United Kingdom Atomic Energy Authority, Risley, Warrington, Lancashire, England, February 1968.

[58] H. Barnert-Wiemer and R. Boehnert, Costs of head-end incineration with respect to Kr separation in the reprocessing of HTR fuel elements, GERHTR-173 (translation of JÜL-1320), Institut für Chemische Technologie, Kernforschungsanlage Jülich G.m.b.H., Jülich, Germany, July 1976.

[59] J. R. Bower and R. T. Struhs (Eds.), Idaho chemical programs annual technical report, fiscal year 1975, ICP-1086, Allied Chemical Corp., Idaho Falls, ID, June 1976, http://www.osti.gov/energycitations/servlets/purl/7268051-ksOdOF/.

[60] B.W. Moran, Safeguards Effectiveness Evaluation of the Proposed Technical Criteria for Termination of Safeguards on Materials Categorized as Measured Discards, K/ITP-295/R1, International Technology Programs Division, Martin Marietta Energy Systems, Inc., Oak Ridge (K-25 Site), TN, January 1991.

[61] B. W. Moran, "Concentration Criteria for the Termination of International Safeguards on Nuclear Material Discards," Proceedings of the 33rd Annual Meeting, Institute of Nuclear Materials Management, Orlando, FL (USA), July 19-22, 1992, pp. 333-338.

[62] A. S. Hoover et al., "Measurement of plutonium in spent nuclear fuel by selfinduced X-ray fluorescence," 50th Institute of Nuclear Materials Management (INMM) Annual Meeting, 12-16 July 2009, Tucson, Arizona.

[63] The Design of Gas-Cooled Graphite-Moderated Reactors, D. R. Poulter, Ed., Oxford University Press, New York, 1963.

[64] Nuclear Graphite, R. E. Nightingale, Ed., Academic Press, New York, 1962.

[65] Fuels Elements Conference, Paris, November 18-23, 1957, TID-7546, Volume 1, Commissariat a l'Energie Atomique, Paris, France, and U.S. Atomic Energy Commission, Washington, DC, http://www.osti.gov/energycitations/servlets/purl/4346314-TuwNpI/native/.

[66] Nuclear reactor fuel elements: metallurgy and fabrication (Prepared under the auspices of the Division of Technical Information, United States Atomic Energy Commission), Albert R. Kaufmann (Ed.), Interscience Publishers, New York, 1962 , available to read page-by-page as image files at http://babel.hathitrust.org/cgi/pt?id=mdp.39015003995118.

[67] C. D. Riendeau, D. L. Moses, and A. P. Olsen, Proliferation Potential of Accelerator-Driven Systems: Feasibility Calculations, K/NSP-778, Lockheed- 
Martin Energy Systems, Oak Ridge, TN, November 1, 1998, http://www.osti.gov/energycitations/servlets/purl/12464-s1ZzJe/webviewable/.

[68] L. W. Gray and J. M. McKibben, The Spent Fuel Standard - Does the Can-inCanister Concept for Plutonium Immobilization Measure Up?, UCRL-JC-134620 (presented at the American Nuclear Society International Conference on Future Nuclear Systems, Jackson Hole, WY, August 29 - September 3, 1999), Lawrence Livermore National Laboratory. Livermore, CA, May 1999, https://e-reportsext.1lnl.gov/pdf/236190.pdf.

[69] Communications of 15 November 1999 Received from Member States Regarding the Export of Nuclear Material and of Certain Other Categories of Equipment and Other Material, IAEA/INFC-209/Rev.2, International Atomic Energy Agency, Vienna (Austria), March 9, 2000, http://www.iaea.org/Publications/Documents/Infcircs/2000/infcirc209r2.pdf as modified and corrected at http://www.iaea.org/Publications/Documents/Infcircs/2009/infcirc209r2c1.pdf.

[70] Communication Received from the Permanent Mission of Brazil regarding Certain Member States' Guidelines for the Export of Nuclear Material, Equipment and Technology, INFCIRC/254/Rev.9/Part 1, International Atomic Energy Agency, Vienna (Austria), 7 November 2007, http://www.iaea.org/Publications/Documents/Infcircs/2007/infcirc254r9p1.pdf or http://www.nuclearsuppliersgroup.org/Leng/PDF/infcirc254r9p1-071107.pdf.

[71] Communications Received from Certain Member States Regarding Guidelines for Transfers of Nuclear-related Dual-use Equipment, Materials, Software and Related Technology, INFCIRC/254/Rev.7/Part 2, International Atomic Energy Agency, Vienna (Austria), March, 20, 2006, http://www.iaea.org/Publications/Documents/Infcircs/2006/infcirc254r7p2.pdf or http://www.nuclearsuppliersgroup.org/Leng/PDF/infcirc254r7p2-060320.pdf.

[72] A. L. Thornton, M. H. Ehinger, S. F. Saavedra, and J. L. Binder, "Reintroduction of hybrid K-edge densitometry to United States fuel reprocessing facilities," 49th Institute of Nuclear Materials Management (INMM) Annual Meeting, Nashville, TN, USA, 13-17 July 2008, http://info.ornl.gov/sites/publications/files/Pub11560.pdf.

[73] S. J. Tobin et al., "Determining plutonium in spent fuel with nondestructive assay techniques," 31st European Safeguards Research and Development Association (ESARDA) Annual Meeting, Vilnius, Lithuania, 26-28 May 2009, http://nsspi.tamu.edu/projects/p19/p19 pub1.pdf.

[74] W. S. Charlton et al., "The use of self-induced XRF to quantify the Pu content in PWR spent nuclear fuel," 31st European Safeguards Research and Development Association (ESARDA) Annual Meeting, Vilnius, Lithuania, 26-28 May 2009, http://nsspi.tamu.edu/projects/p19/p19 pub2.pdf. 
APPENDIX A

PEBBLE BED MODULAR REACTOR (PBMR) BURNUP WORKSHEET COMPARING AND RECONCILING INDEPENDENT ANALYSES BY PBMR (PTY) LTD AND IDAHO NATIONAL LABORATORY (INL) 



\section{Pebble Bed Modular Reactor (PBMR) Burnup Worksheet Comparing and Reconciling Independent Analyses by PBMR (Pty) Ltd and Idaho National Laboratory (INL)}

The purpose of this worksheet is to provide a quantitative comparison and an appropriate reconciliation of the reported results from the two independent analyses of the burnup isotopics for the PBMR-400 as documented in the following:

- Johan Slabber, PBMR (Pty) Ltd., "PBMR Nuclear Material Safeguards," Paper No. B14, Proceedings of the Conference on High Temperature Reactors, Beijing, China, September, 22-24, 2004, International Atomic Energy Agency, Vienna (Austria), http://www.iaea.org/inisnkm/nkm/aws/htgr/fulltext/htr2004_b14.pdf. [2]

- Johan Slabber, "PBMR Reactor Unit and Main Support Systems," ADAMS Accession Number ML060680079, presentation by PBMR (Pty) Ltd. to the U.S. Nuclear Regulatory Commission in Public Meeting, PBMR Safety and Design Familiarization, February 28-March 3, 2006, http://adamswebsearch2.nrc.gov/idmws/doccontent.dll?library=PU ADAMS^PBN $\underline{\mathrm{TAD} 01 \& \mathrm{ID}=060680165}$. [NOTE: Access to this site may sometimes require log-in as "guest."] [3]

- A.M. Ougouag, H. D. Gougar, and T. A. Todd, Evaluation of the Strategic Value of Fully Burnt PBMR Spent Fuel, INL/EXT-06-11272, Idaho National Laboratory, Idaho Falls, ID, May 2006, http://www.inl.gov/technicalpublications/Documents/3372140.pdf. [4]

In addition, this worksheet will use two other documents reporting on light-water-reactor data for the irradiation of LEU fuel and the resulting production of ${ }^{232} \mathrm{U}$ and ${ }^{236} \mathrm{U}$ in order to assist in the estimation process of the other uranium isotopes in the PBMR used fuel:

- Management of Reprocessed Uranium: Current Status and Future Prospects, IAEA-TECDOC-1529, International Atomic Energy Agency, Vienna (Austria), February 2007, http://wwwpub.iaea.org/MTCD/publications/PDF/te 1529 web.pdf. [7]

- G. D. Del Cul et al., Analysis of the Reuse of Uranium Recovered from the Reprocessing of Commercial LWR Spent Fuel, ORNL/TM-2007/207 (ORNL/GNEP/LTR-2008-002), Oak Ridge National Laboratory, Oak Ridge, TN, January 2009, http://apps.ornl.gov/ ppts/prod/pubs/ldoc14204_ornl_tm_2007_207_final.pdf. [10]

The analysis in this worksheet must at times make use of certain assumptions. These assumptions include the following.

- The fission-to-absorption ratio for ${ }^{235} \mathrm{U}$ in the PBMR is approximately the same as the average ratio in an LWR lattice (i.e., $\sim 0.80$ to $\sim 0.85$ ).

- The fraction of LEU fast fissions in the PBMR is the same as in infinite lattices for light-water reactors (i.e., $\sim 0.03$ ).

- The fission contributions to burnup of ${ }^{236} \mathrm{U}$ and ${ }^{237} \mathrm{~Np}$ can be ignored.

- The subsequent fissions in americium and curium after being generated by neutron captures in plutonium are less than $10 \%$ of the isotopes so transmuted. 


\section{$\underline{\text { Assumed Values }}$}

Sensible energy per fission: $200 \mathrm{MeV}$ per fission $=3.70874 \times 10^{-22} \mathrm{MWD}$ per fission Mass conversion: $1 \mathrm{AMU}=1.66054 \times 10^{-24}$ grams

Note: Avogadro's number $\left(A_{n}\right)=6.0221415 \times 10^{23}$ atoms or molecules per gram-mole

END/F-VII (or other recent evaluations that have not changed) cross section data tabulated as a function of neutron energy: http://www.nndc.bnl.gov/exfor/endf00.jsp

Atomic mass of elements and isotopes:

http://physics.nist.gov/cgi-bin/Compositions/stand_alone.pl

\section{$\underline{\text { PBMR (Pty) Ltd Analysis Results }}$}

Total mass per pebble $=200 \mathrm{~g}=0.0002 \mathrm{MT}$

Low Enriched Uranium (LEU) mass per pebble: $9 \mathrm{~g}=9 \times 10^{-6} \mathrm{MT}$

${ }^{235} \mathrm{U}$ enrichment: $9.6 \mathrm{wt} \%$ in fresh equilibrium-cycle fuel (assumed here); $\sim 5.7 \mathrm{wt} \%$ for fresh fuel in initial start-up core loading

Burnup: 90,800 MWD/MT $\times\left(9 \times 10^{-6} \mathrm{MT} /\right.$ pebble $)=0.8172 \mathrm{MWD} /$ pebble for equilibrium cycle

Burnup-equivalent fissions per pebble:

$(0.8172 \mathrm{MWD} /$ pebble $) /\left(3.70874 \times 10^{-22}\right.$ MWD per fission $)=\sim 2.204 \times 10^{21}$ fissions per pebble

Uranium discharge isotopics: Not given

Plutonium discharge isotopics: Given in both cited documents by PBMR (Pty) Ltd. as the following figure 


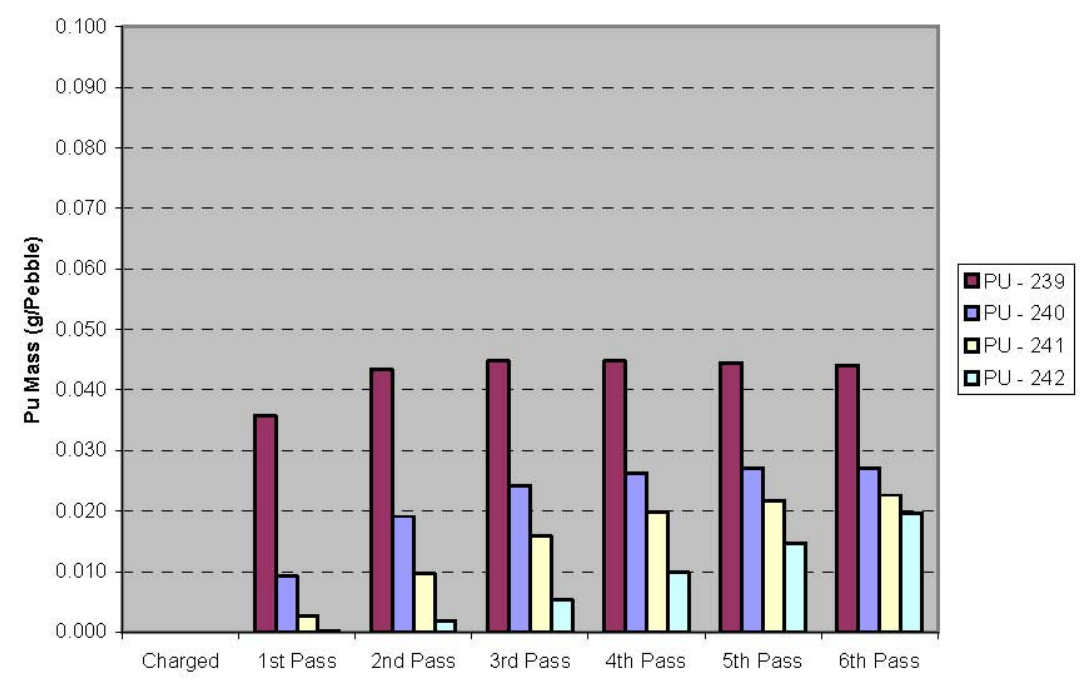

Tabulation of interpreted plutonium isotopics at pebble discharge after the final (sixth) recirculation pass:

Table A-1. PBMR discharged plutonium isotopics from Reference [2]

\begin{tabular}{|c|c|}
\hline Plutonium isotope & Mass per pebble (g) \\
\hline${ }^{239} \mathrm{Pu}$ & $\sim 0.044$ \\
\hline${ }^{240} \mathrm{Pu}$ & $\sim 0.027$ \\
\hline${ }^{241} \mathrm{Pu}$ & $\sim 0.023$ \\
\hline${ }^{243} \mathrm{Pu}$ & $\sim 0.020$ \\
\hline TOTAL & $\sim 0.114$ \\
\hline
\end{tabular}

Therefore, the plutonium content in a discharged pebble at a burnup of $90.8 \mathrm{GWD} / \mathrm{MT}$ is $\{0.114 \mathrm{~g} / \mathrm{pebble}) /(0.0002 \mathrm{MT} /$ pebble $)=570 \mathrm{~g} / \mathrm{MT}=570 \mathrm{ppm}$

\section{$\underline{\text { INL Analysis Results }}$}

Discharge burnup: Not given

Initial and discharge isotopics for uranium (except ${ }^{236} \mathrm{U}$ ) and plutonium 
Table A-2. PBMR-400 fully burnt isotopics from Reference [4]

\begin{tabular}{|l|c|c|c|c|}
\hline \multicolumn{7}{|l|}{$\begin{array}{l}\text { PEBBED-THERMIX-COMBINE Fully Burnt PBMR-400 Spent Fuel Discharge } \\
\text { Isotopics }\end{array}$} \\
\hline
\end{tabular}

Comment on Difference in Results of the Two Independent Analyses

The PBMR (Pty) Ltd. analysis of plutonium mass in pebbles discharged at an average burnup of $90.8 \mathrm{GWD} / \mathrm{MT}$ is $0.114 \mathrm{~g}$ per pebble. The INL analysis of plutonium mass in pebbles discharged at an undefined burnup is $0.14 \mathrm{~g}$ per pebble, that is, $\sim 23 \%$ higher. Therefore, it is necessary to attempt to interpret the burnup in the INL analyses.

\section{Comparison and Reconciliation of Burnup Analyses}

Estimate of uranium fissions and transmutations from the INL analysis results and the effect on the enrichment of discharged pebbles:

${ }^{235} U$ fissions and transmutations:

$\Delta^{235} \mathrm{U}=0.8639 \mathrm{~g}-0.185 \mathrm{~g}=0.6789 \mathrm{~g}$ per pebble

In LEU ( $<5 \%$ enriched) LWR analyses, ${ }^{235} \mathrm{U}$ has a typical (for thermal-neutronreactors) total fission-to-absorption ratio $=\sim 0.8$. This number is likely a lower limit for thermal reactors based on looking at the energy-dependent thermal cross sections and resonance integrals where the contribution of the lower values of the fission-to-absorption ratio in the resonance region are likely suppressed by the resonance shielding of the ${ }^{238} \mathrm{U}$. 
Table A-3. ${ }^{235} \mathrm{U}$ fission-to-absorption ratios for thermal-neutron-energy-dependent point cross sections and lower energy resonance integrals ${ }^{a}(<500 \mathrm{eV})$

\begin{tabular}{|c|c|c|c|}
\hline $\begin{array}{c}\text { Neutron energy, } \\
\mathbf{E}_{\mathbf{n}} \mathbf{( e V )}\end{array}$ & $\begin{array}{c}{ }^{\mathbf{2 3 5}} \mathbf{U} \text { fission cross } \\
\text { section, } \boldsymbol{\sigma}_{\mathbf{f}}(\mathbf{b a r n s})\end{array}$ & $\begin{array}{c}{ }^{\mathbf{2 3 5}} \mathbf{U} \text { capture }<\mathbf{n}, \boldsymbol{\gamma}>\text { cross } \\
\text { section, } \boldsymbol{\sigma}_{\mathbf{c}}(\mathbf{b a r n s})\end{array}$ & $\boldsymbol{\sigma}_{\mathbf{f}} /\left(\boldsymbol{\sigma}_{\mathbf{f}}+\boldsymbol{\sigma}_{\mathbf{c}}\right)$ \\
\hline 0.001 & $\sim 3100$ & $\sim 695$ & $\sim 0.82$ \\
\hline 0.01 & $\sim 956$ & $\sim 175$ & 0.845 \\
\hline 0.0253 & 585.1 & 98.7 & 0.856 \\
\hline 0.05 & $\sim 389$ & $\sim 63$ & 0.861 \\
\hline 0.1 & $\sim 244$ & $\sim 42$ & 0.853 \\
\hline 0.2 & $\sim 174.5$ & $\sim 37.7$ & 0.822 \\
\hline 0.3 & $\sim 190$ & $\sim 43.2$ & 0.815 \\
\hline 0.4 & $\sim 117$ & $\sim 18.3$ & 0.865 \\
\hline 0.5 & $\sim 80$ & $\sim 11$ & 0.879 \\
\hline $0.5-1.0$ & 42.76 & 5.20 & 0.892 \\
\hline $1.0-10.0$ & 75.71 & 43.40 & 0.636 \\
\hline $10.0-100.0$ & 98.88 & 65.30 & 0.602 \\
\hline $100.0-200.0$ & 14.33 & 8.05 & 0.64 \\
\hline $200.0-300.0$ & 8.20 & 3.80 & 0.683 \\
\hline $300.0-400.0$ & 3.74 & 1.571 & 0.704 \\
\hline $400.0-500.0$ & 3.01 & 0.712 & 0.809 \\
\hline
\end{tabular}

${ }^{a}$ Resonance integrals are from an evaluation of preliminary ENDF/B-VI data given in Table 2 from the paper by G. de Saussure, et al, "A new resonance-region evaluation of neutron cross sections for U-235," CONF-880911-2, International Reactor Physics Conference, Jackson Hole, Wyoming (USA), 18 September 1988, http://www.osti.gov/energycitations/servlets/purl/7124306-uY8XmJ/.

The actual resonance integrals for ${ }^{235} \mathrm{U}$ in a coated particle would depend upon the actual energy-dependent neutron flux as opposed to the $1 / E_{n}$ flux shape used to integrate the dilute resonance integrals quoted above, but the values of the inferred fission-to-absorption ratios are likely to be sufficiently representative.

As a check on the assumption made here, a comparison is drawn for the analytical results for light-ware reactors reported in Table 7 of Reference [7], where the data are normalized to the initial metric ton loading, and Table 4 of Reference [10], where the discharge mass fractions are normalized to the discharged loading, using ratios of the changes in mass fractions of ${ }^{236} \mathrm{U}$ to ${ }^{235} \mathrm{U}$.

From Table 7 of Reference [7] for $4.5 \%$ enriched LEU irradiated to 48 GWD/MT:

$$
1.0-\left(\Delta^{236} \mathrm{U} / \Delta^{235} \mathrm{U}\right)=1.0-[0.583 /(4.5-1.03)]=\sim 0.832
$$

From Table 4 of Reference [10] for 4.5\% enriched LEU irradiated to $55 \mathrm{GWD} / \mathrm{MT}$ :

$$
1.0-\left(\Delta^{236} \mathrm{U} / \Delta^{235} \mathrm{U}\right)=1.0-(0.686 /(4.5-0.837))=\sim 0.813
$$

However, this analysis does not take into account the losses to the produced ${ }^{236} \mathrm{U}$ due to either transmutation or fission. If one assumes that this loss is $5 \%$, then the 
numerator in the ratio $\left(\Delta^{236} \mathrm{U} / \Delta^{235} \mathrm{U}\right)$ in the above calculations must be divided by 0.95 so that the results will decrease to $\sim 0.823$ and $\sim 0.803$.

Therefore, assuming that the LWR conditions for the ${ }^{235} \mathrm{U}$ fission-to-absorption ratio approximate those of graphite-moderated thermal-neutron reactors such as the PBMR, the estimated number of ${ }^{235} \mathrm{U}$ fissions per pebble is approximately $\left(\Delta^{235} \mathrm{U} \times 0.8\right)$ grams converted to the number of atoms undergoing fission as follows:

$\left.[(0.6789 \mathrm{~g}) \times(0.8)] /[235.043 \mathrm{AMU} / \mathrm{g}) \times\left(1.66054 \times 10^{-24} \mathrm{~g} / \mathrm{AMU}\right)\right]=$ $\sim 2.05 \times 10^{21}$ fissions of ${ }^{235} \mathrm{U}$ per pebble.

If the fission-to-absorption ratio were higher and closer to $\sim 0.85$, the above estimate of ${ }^{235} \mathrm{U}$ fissions would be proportionally higher, or $\sim 2.18 \times 10^{21}$ fissions of ${ }^{235} \mathrm{U}$ per pebble.

NOTE: As indicated above, 90.8 GWD/MT equates to $2.204 \times 10^{21}$ fissions per pebble for comparison.

${ }^{238} \mathrm{U}$ fissions and transmutations:

$\Delta^{238} \mathrm{U}=8.134 \mathrm{~g}-7.69 \mathrm{~g}=0.444 \mathrm{~g}$ per pebble

In large light water reactors (LWRs), the contribution of fast fissions to the $\mathrm{k}$-effective is $\sim 0.03$ as reflected in the difference in k-effective between using the total neutron fission source spectrum and using the delayed neutron spectrum for an infinite lattice. Given that the neutron yield $(v)$ per fission is approximately the same for ${ }^{235} \mathrm{U}$ and ${ }^{238} \mathrm{U}$, the contribution of ${ }^{238} \mathrm{U}$ relative to ${ }^{235} \mathrm{U}$ to the total number of fast fissions can be expressed as a ratio of the following for each uranium isotope:

Total fission of isotope "i" $=\int \varphi(E) \Sigma_{i, f}(E) d E=N_{i} \int \varphi(E) \sigma_{i, f}(E) d E$ $=\left(M_{i} A_{n} / A_{i}\right) \int \varphi(E) \sigma_{i, f}(E) d E$,

where

$\mathrm{M}_{\mathrm{i}}=$ isotope mass $(\mathrm{g})$ in pebble,

$\mathrm{A}_{\mathrm{n}}=$ Avogadro's number (atoms per gram-mole), and

$\mathrm{A}_{\mathrm{i}}=$ isotope atomic mass (grams per gram-mole), or

Fast fissions $=($ average fast neutron flux $) \times$

(average macroscopic fission cross section)

$=($ average fast neutron flux $) \times$

(average microscopic fission cross section) $\times$ (isotopic number density)

It can be shown that the relative contribution of ${ }^{238} \mathrm{U}$ fast fission to the total fast number of fast fission in uranium is 
$1 /\left[1+\left({ }^{235} \mathrm{U}\right.\right.$ fast fissions $) /\left({ }^{238} \mathrm{U}\right.$ fast fissions $\left.)\right]$, or for the same average flux value,

$1 /\left[1+\left(\left(\sigma_{\mathrm{f}, 235} \times \mathrm{M}_{235}\right) / \mathrm{A}_{238}\right) /\left(\left(\sigma_{\mathrm{f}, 238} \times \mathrm{M}_{238}\right) / \mathrm{A}_{238}\right)\right]$, or

$1 /\left[1+\left(\left(\sigma_{\mathrm{f}, 235} / \sigma_{\mathrm{f}, 238}\right) \times\left(\mathrm{A}_{238} / \mathrm{A}_{235}\right) \times\left(\mathrm{M}_{235} / \mathrm{M}_{238}\right)\right)\right]$

The ratio $\left(\mathrm{A}_{238} / \mathrm{A}_{235}\right)=238.051 / 235.044=\sim 1.028$ is a constant, and the ratio of $\left(\sigma_{f, 235} / \sigma_{f, 238}\right)$ can be estimated approximately on an average basis from the energy-dependent fast fission cross sections (highly variable over neutron energy) as follows.

Table A-4. ${ }^{235} \mathrm{U}$ and ${ }^{238} \mathrm{U}$ fast fission cross section ratios

\begin{tabular}{|c|c|c|c|}
\hline $\begin{array}{c}\text { Neutrom energy } \\
\left(\mathbf{E}_{\mathbf{n}}\right) \text { in MeV }\end{array}$ & $\boldsymbol{\sigma}_{\mathbf{f}, \mathbf{2 3 5}}\left(\mathbf{E}_{\mathbf{n}}\right)$ in barns & $\boldsymbol{\sigma}_{\mathbf{f}, \mathbf{2 3 8}}\left(\mathbf{E}_{\mathbf{n}}\right)$ in barns & $\left(\boldsymbol{\sigma}_{\mathbf{f}, \mathbf{2 3 5}} / \boldsymbol{\sigma}_{\mathbf{f}, \mathbf{2 3 8}}\right)$ \\
\hline 0.8 & 1.11 & 0.004 & 277 \\
\hline 1.0 & 1.20 & 0.014 & 86 \\
\hline 2.0 & 1.28 & 0.53 & 2.42 \\
\hline 3.0 & 1.22 & 0.52 & 2.35 \\
\hline 4.0 & 1.14 & 0.55 & 2.07 \\
\hline 5.0 & 1.07 & 0.55 & 1.95 \\
\hline
\end{tabular}

A rough estimate for the $1 / \mathrm{E}_{\mathrm{n}}$-spectrum-averaged (not fission-sourcespectrum-averaged) value of $\left(\sigma_{\mathrm{f}, 235} / \sigma_{\mathrm{f}, 238}\right)$ would be $\sim 40$ (where the fissionsource-spectrum-averaged value of $\left(\sigma_{\mathrm{f}, 235} / \sigma_{\mathrm{f}, 238}\right)$ would be $\left.\sim 30\right)$.

Assuming the total fraction of fast fissions of the total fissions remains at $\sim 0.03$ for both the LWR and the PBMR, the fraction of ${ }^{238} \mathrm{U}$ fissions can be estimated approximately as follows:

$$
1 /\left[1+\left((40.0) \times(1.028) \times\left(\mathrm{M}_{235} / \mathrm{M}_{238}\right)\right)\right]=1 /\left[1+\left((4.112) \times\left(\mathrm{M}_{235} / \mathrm{M}_{238}\right)\right)\right] .
$$

Therefore for LWRs, the mass ratio is $4 / 96=\sim 0.042$, and, for the PMBR, the mass ratio is $9.6 / 90.4=\sim 0.106$. The PBMR fast neutron fission is $\sim 0.19$ times $\sim 0.03=\sim 0.006$.

Therefore, to first order approximation, the number of ${ }^{238} \mathrm{U}$ fast fissions is $(0.006 / 0.994) \times 2.05 \times 10^{21}=\sim 1.3 \times 10^{19}$ fissions of ${ }^{238} \mathrm{U}$ per pebble.

This number of ${ }^{238} \mathrm{U}$ fast fissions corresponds to a mass loss in ${ }^{238} \mathrm{U}$ due to fast fission of

$\left[1.3 \times 10^{19}\right.$ fissions of $\left.{ }^{238} \mathrm{U}\right] \times\left[(238.050 \mathrm{AMU}) \times\left(1.66054 \times 10^{-24} \mathrm{~g} / \mathrm{AMU}\right)\right]=$ $\sim 0.0 .005 \mathrm{~g}$

The estimated number of grams of ${ }^{238} \mathrm{U}$ transmuted to plutonium by neutron capture will be 
$0.444 \mathrm{~g}-0.005 \mathrm{~g}=\sim 0.439 \mathrm{~g}$

Estimate of ${ }^{236} U$ production and transmutation:

Assuming the same ${ }^{235} \mathrm{U}$ capture-to-absorption ratio used above (i.e., 1.0 minus the assumed fission-to-absorption ratio of $\sim 0.8$ ) is 0.2 (and thereby ignoring other possible transmutation reactions such as $<\mathrm{n}, 2 \mathrm{n}>$ ), the total mass of ${ }^{235} \mathrm{U}$ transmuted to ${ }^{236} \mathrm{U}$ is $\left(\Delta^{235} \mathrm{U} \times 0.2\right)$ grams or $(0.6789 \mathrm{~g}) \times(0.2)=0.136 \mathrm{~g}$.

If the actual ${ }^{235} \mathrm{U}$ capture-to-absorption ratio is lower and around 0.15 (i.e., 1.0 minus a fission-to-absorption ratio of $\sim 0.85$ ), the mass of ${ }^{235} \mathrm{U}$ transmuted to ${ }^{236} \mathrm{U}$ is proportionally lower or $(0.15 / 0.20) \times 0.136 \mathrm{~g}=\sim 0.102 \mathrm{~g}$.

Without a detailed analysis, it is too difficult merely to compare the energydependent capture and fission cross sections of ${ }^{236} \mathrm{U}$ and ${ }^{238} \mathrm{U}$ and make a specific and relative judgment on how much ${ }^{236} \mathrm{U}$ will be consumed by transmutation or fission over the life of the pebble. The ${ }^{238} \mathrm{U}$ non-consumption fraction is $7.69 \mathrm{~g} / 8.134 \mathrm{~g}=\sim 0.95$. Therefore, to first-order approximation, the discharged mass per pebble of ${ }^{236} \mathrm{U}$ is assumed to be $(0.136 \mathrm{~g}) \times(0.95)=\sim 0.129 \mathrm{~g}$ or as low as $0.097 \mathrm{~g}$ assuming a lower value $(0.15)$ for the ${ }^{235} \mathrm{U}$ capture-to-absorption ratio.

For comparison at the PBMR used-fuel discharge burnup of $90.8 \mathrm{GWD} / \mathrm{MT}$, an extrapolation of the LWR curve for ${ }^{236} \mathrm{U}$ build-in in Figure 5 of Reference [7] accounting for the plotted variations in ${ }^{236} \mathrm{U}$ as a function of initial uranium enrichment and burnup would indicate that the ${ }^{236} \mathrm{U}$ in the discharged PBMR fuel element should be $\sim 14,000 \mathrm{~g}$ of ${ }^{236} \mathrm{U}$ per metric ton of discharged uranium. From Table A-2 above, the uranium content in the INL analysis of a fully burnt pebble is $7.875 \mathrm{~g}$ or $7.875 \times 10^{-6}$ MT. Therefore, the estimated ${ }^{236} \mathrm{U}$ content should be

$$
\sim(14,000 \mathrm{~g} / \mathrm{MT}) \times\left(7.875 \times 10^{-6} \mathrm{MT}\right)=\sim 0.110 \mathrm{~g} .
$$

This estimated mass of ${ }^{236} U$ in the discharged pebbles falls within the two values quoted above for high and low values of the ${ }^{235} \mathrm{U}$ fission-to-absorption ratio giving some degree of confidence to the estimation process. Conversely, the $0.129 \mathrm{~g}{ }^{236} \mathrm{U}$ mass per pebble would correspond to a ${ }^{236} \mathrm{U}$ concentration of $\sim 16,400 \mathrm{~g} / \mathrm{MT}$ of discharged uranium. This value is twice the limit of $8,400 \mathrm{~g} / \mathrm{MT}$ of discharged uranium in the reprocessed uranium specification in ASTM C787 as quoted in Section 4.1.2.1 (page 29) of Reference [7].

Estimates for the other uranium isotopes in the PBMR used" fuel, that is, ${ }^{232} U,{ }^{233} U$, ${ }^{234} U$, and ${ }^{237} U$ :

Knowledge of the uranium isotopes in the PBMR used fuel assists in knowing the radiological protection requirements in handling reprocessed fuel and in handling re-enriched fuel produced from the reprocessed fuel. Of these isotopes, only ${ }^{234} \mathrm{U}$ is present in unirradiated uranium enriched from natural uranium, which contains 
$\sim 0.0055 \mathrm{wt} \%{ }^{234} \mathrm{U}$, as indicated in Table s 1 and 5 in Reference [7]. By extrapolated inference from the data on ${ }^{234} \mathrm{U}$ as a function of enrichment in Table 5 of Reference [7], the ${ }^{234} U$ in $9.6 \%$ enriched PBMR fresh LEU should be $\sim 0.09 \mathrm{wt} \%$ to $0.1 \mathrm{wt} \%$. For PBMR used fuel, the concentrations of the isotopes of ${ }^{232} \mathrm{U},{ }^{233} \mathrm{U}$, and ${ }^{234} \mathrm{U}$ depend upon the decay of other actinides as discussed in Section 2.1.3 of Reference [7]. Typically, as given in Reference [7], the concentrations of these isotopes are quoted at 5 years of decay following removal of the fuel from the reactor as opposed to at discharge; this delay corresponds to the typical minimum times allowed for fuel cooling by fission product decay before reprocessing the irradiated fuel. ${ }^{232}$ Uis principally due to the decay of ${ }^{236} \mathrm{Pu} ;{ }^{233} \mathrm{U}$ is principally due to the decay of ${ }^{237} \mathrm{~Np}$; and ${ }^{234} \mathrm{U}$ is due to its initial enrichment less burnup plus the decay of ${ }^{238} \mathrm{Pu}$. In turn each isotope's concentration is principally due to the neutron interactions along the neutron capture chain of ${ }^{235} \mathrm{U} \rightarrow{ }^{236} \mathrm{U} \rightarrow{ }^{237} \mathrm{~Np}$. Therefore, the production of each of these other uranium isotopes should be at first order proportional to the production of ${ }^{236} \mathrm{U}$. The content of the ${ }^{237} \mathrm{U}$ isotope (which has a very short half-life) in the spent fuel is initially in equilibrium with ${ }^{236} \mathrm{U}$ and then steadily diminishes during cooling as shown in Figure 13 of Reference [7]. The basis for estimating the content of each isotope in PBMR used fuel is given as follows:

${ }^{232} \mathrm{U}$ : From page 6 of Reference [7], "The typical concentration of ${ }^{232} \mathrm{U}$ in the RepU is in the range 0.5 to 5 nano-grams ${ }^{232} U$ per gram uranium," based on data from fuel reprocessing of fuel from LWRs and British $\mathrm{CO}_{2}$-cooled reactors. Using Figure 9 in Reference [7] and scaling linearly with comparative burnup (90.8 GWD/MT in the PBMR versus $48 \mathrm{GWD} / \mathrm{MT}$ for the LWR in Figure 9 of Reference [7]), the estimated ${ }^{232} \mathrm{U}$ content just after reactor shutdown would be $\sim 0.0032 \mathrm{~g} / \mathrm{MT}$ of initially load uranium and after 5 years of cooling would be $\sim 0.0055 \mathrm{~g} / \mathrm{MT}$ of initially loaded uranium. Renormalizing to discharge uranium would increase these values by a factor of 1.06 . Using this correlation, the ${ }^{232} \mathrm{U}$ would peak after 10 to 15 years of cooling at $\sim 0.0064 \mathrm{~g} / \mathrm{MT}$ of discharged uranium. However, the ${ }^{232} \mathrm{U}$ content may also be estimated by using the 5-yearcooled LWR spent fuel data in Tables 7 and correlating the PBMR used fuel estimate of ${ }^{236} \mathrm{U}$ concentration $(\sim 16,400 \mathrm{~g} / \mathrm{MT}$ of discharged uranium) times the ratio of the values for ${ }^{232} U$ divided by ${ }^{236} U$ in Table 7 of Reference [7], wherein the normalization of the data from Reference [7] to the initial uranium loading would cancel out (see Table A-5).

From the limited data in Table A-5, it would appear that the extrapolated estimate for ${ }^{232} \mathrm{U}$ is insensitive to the initial enrichment of the LWR fuel but varies linearly with the discharge burnup in GWD/MT; if correct, then the PBMR used fuel ${ }^{232} \mathrm{U}$ content at $90.8 \mathrm{GWD} / \mathrm{MT}$ burnup and after 5 years of cooling could be as high as $0.023 \mathrm{~g} / \mathrm{MT}$ of discharged uranium. If this latter estimate is correct, then the ${ }^{232} \mathrm{U}$ content at fuel discharge would be $\sim 0.013 \mathrm{~g} / \mathrm{MT}$ of discharged uranium based on extrapolating along the curve from Figure 9 of Reference [7]. However, whether the ${ }^{232} \mathrm{U}$ content is as low as $0.0055 \mathrm{~g} / \mathrm{MT}$ of discharged uranium as estimated above from Figure 9 of Reference [7] assuming a linear correlation with burnup 
or as high as $0.023 \mathrm{~g} / \mathrm{MT}$ of discharge uranium as estimated from by linearly extrapolating with burnup from the above tabulation, the ${ }^{232} \mathrm{U}$ concentration in PBMR used fuel exceeds the limit of the standard specification for reprocessed uranium from ASTM C787 of $0.005 \mathrm{~g} / \mathrm{MT}$ and will therefore, without blending, most likely exceed the specification limit of $0.05 \mathrm{~g} / \mathrm{MT}$ for enriched reprocessed uranium under ASTM C996 as the limits are quoted in Section 4.1.2.1 (page 29) of Reference [7].

Table A-5. Extrapolated estimates of ${ }^{232} \mathrm{U}$ in PBMR used fuel after cooling for 5 years

\begin{tabular}{|c|c|c|c|}
\hline $\begin{array}{c}\text { Data source from } \\
\text { Table 7 in } \\
\text { Reference [7] }\end{array}$ & $\begin{array}{c}{ }^{232} \mathbf{U} \text { discharged } \\
\text { concentration, } \\
\text { cooled for 5 years } \\
\text { (g/MT) }\end{array}$ & $\begin{array}{c}{ }^{236} \mathbf{U} \text { discharged } \\
\text { concentration, } \\
\text { cooled for 5 years } \\
\text { (g/MT) }\end{array}$ & $\begin{array}{c}\text { Estimated PBMR } \\
\text { c32 } \text { concentration, } \\
\text { cooled for 5 years } \\
\text { (g/MT) }\end{array}$ \\
\hline $\begin{array}{c}\text { LWR, } \\
40 \mathrm{GWD} / \mathrm{MT}, \\
4 \% \text { enriched }\end{array}$ & $1.71 \mathrm{E}-03$ & $4.96 \mathrm{E}+03$ & 0.0056 \\
\hline $\begin{array}{c}\text { LWR, } \\
48 \mathrm{GWD} / \mathrm{MT}, \\
4 \% \text { enriched }\end{array}$ & $2.78 \mathrm{E}-03$ & $5.29 \mathrm{E}+03$ & 0.0086 \\
\hline $\begin{array}{c}\text { LWR, } \\
48 \mathrm{GWD} / \mathrm{MT}, \\
4.5 \% \text { enriched }\end{array}$ & $2.86 \mathrm{E}-03$ & $5.83 \mathrm{E}+03$ & 0.0080 \\
\hline $\begin{array}{c}\mathrm{LWR}, \\
60 \mathrm{GWD} / \mathrm{MT}, \\
4.1 \% \mathrm{enriched}\end{array}$ & $4.28 \mathrm{E}-03$ & $5.68 \mathrm{E}+03$ & 0.0124 \\
\hline
\end{tabular}

${ }^{233} \mathrm{U}$ : The estimates for ${ }^{233} \mathrm{U}$ will use the same approach as above for ${ }^{232} \mathrm{U}$. Using Figure 10 in Reference [7] and scaling linearly with comparative burnup (90.8 GWD/MT in the PBMR versus $48 \mathrm{GWD} / \mathrm{MT}$ for the LWR in Figure 10 of Reference [7]), the estimated ${ }^{233} \mathrm{U}$ content just after reactor shutdown would be $\sim 0.0060 \mathrm{~g} / \mathrm{MT}$ of discharged uranium and after 5 years of cooling would be $\sim 0.0081 \mathrm{~g} / \mathrm{MT}$ of discharged uranium (accounting of the $6 \%$ difference in normalization). Based on Figure 10 of Reference [7], the ${ }^{233} \mathrm{U}$ content would be expected to rise linearly with time for at least 50 years following discharge from the reactor. However, as was done for ${ }^{232} \mathrm{U}$, the ${ }^{233} \mathrm{U}$ content may also be estimated by using the 5-year-cooled LWR spent fuel data in Tables 7 and correlating the PBMR used-fuel estimate of ${ }^{236} \mathrm{U}$ concentration $(\sim 16,400 \mathrm{~g} / \mathrm{MT}$ of discharged uranium) times the ratio of the values for ${ }^{233} \mathrm{U}$ divided by ${ }^{236} \mathrm{U}$ in Table 7 of Reference [7]. 
Table A-6. Extrapolated estimates of ${ }^{233} U$ in PBMR used fuel after cooling for 5 years

\begin{tabular}{|c|c|c|c|}
\hline $\begin{array}{c}\text { Data source from } \\
\text { Table 7 in } \\
\text { Reference [7] }\end{array}$ & $\begin{array}{c}{ }^{233} \mathbf{U} \text { discharged } \\
\text { concentration, } \\
\text { cooling for 5 years } \\
\text { (g/MT) }\end{array}$ & $\begin{array}{c}{ }^{236} \mathbf{U} \text { discharged } \\
\text { concentration, } \\
\text { cooling for 5 years } \\
\text { (g/MT) }\end{array}$ & $\begin{array}{c}\text { Estimated PBMR } \\
\text { 233 U concentration, } \\
\text { cooling for 5 years } \\
\text { (g/MT) }\end{array}$ \\
\hline $\begin{array}{c}\text { LWR, 40 GWD/MT, } \\
\mathbf{4 \%} \text { enriched }\end{array}$ & $2.90 \mathrm{E}-03$ & $4.96 \mathrm{E}+03$ & 0.0096 \\
\hline $\begin{array}{c}\text { LWR, 48 GWD/MT, } \\
\mathbf{4 \%} \text { enriched }\end{array}$ & $3.28 \mathrm{E}-03$ & $5.29 \mathrm{E}+03$ & 0.0102 \\
\hline $\begin{array}{c}\text { LWR, 48 GWD/MT, } \\
\mathbf{4 . 5 \%} \text { enriched }\end{array}$ & $3.81 \mathrm{E}-03$ & $5.83 \mathrm{E}+03$ & 0.0107 \\
\hline $\begin{array}{c}\text { LWR, 60 GWD/MT, } \\
\mathbf{4 . 1 \%} \text { enriched }\end{array}$ & $3.54 \mathrm{E}-03$ & $5.68 \mathrm{E}+03$ & 0.0102 \\
\hline
\end{tabular}

Unlike the linear relationship with burn-up for ${ }^{232} \mathrm{U}$, the concentration for ${ }^{233} \mathrm{U}$ estimated at a PBMR used-fuel burnup of $90.8 \mathrm{GWD} / \mathrm{MT}$ appears to converge to an average of $\sim 0.0102 \mathrm{~g} / \mathrm{MT}$ of discharged uranium. This is most likely due to the fact that, with relatively high thermal-neutron fission and capture cross sections in a thermal reactor, the ${ }^{233} \mathrm{U}$ reaches an equilibrium in which it is burning out at approximately the same rate that it is being created by decay. At the time of discharge from the reactor, the ${ }^{232} \mathrm{U}$ content would be $\sim 0.009 \mathrm{~g} / \mathrm{MT}$ of discharged uranium based on extrapolating along a parallel curve to that in Figure 10 of Reference [7]. There are no limits specified for ${ }^{233} \mathrm{U}$ in the reprocessed uranium standards ASTM C787 and ASTM C996.

${ }^{234} \mathrm{U}$ : Unlike ${ }^{232} \mathrm{U}$ and ${ }^{233} \mathrm{U}$, the extrapolation that could be done from Figure 11 and Table 9 of Reference [7] may not be strictly linear with the quoted ${ }^{234} U$ concentration since the fresh LEU enriched from natural uranium will have ${ }^{234} \mathrm{U}$ that varies with initial enrichment. As discussed above, PBMR fuel with an initial enrichment of $9.6 \%{ }^{235} \mathrm{U}$ will have an initial ${ }^{234} \mathrm{U}$ value of $\sim 0.09$ to $0.1 \%$ (i.e., 900 to $1,000 \mathrm{~g} / \mathrm{MT}$ of uranium). A LWR with $4 \%$ enriched LEU would have $\sim 0.037 \%{ }^{234} \mathrm{U}$ (or $370 \mathrm{~g} / \mathrm{MT}$ of uranium) and with $4.5 \%$ enriched LEU would have $\sim 0.042 \%{ }^{234} \mathrm{U}$ (or $420 \mathrm{~g} / \mathrm{MT}$ of uranium). The ${ }^{234} \mathrm{U}$ percentages were linearly extrapolated estimates from Table 5 of reference [7] where the extrapolations appear to be approximately correct since $93 \%$ enriched uranium has $\sim 1.0 \%{ }^{234} \mathrm{U}$ and the linear extrapolation to $93 \%$ enriched yields an estimate of $\sim 0.88 \%{ }^{234} \mathrm{U}$. Using the initial $\mathrm{LEU}{ }^{234} \mathrm{U}$ estimates, one may assume that is possible to extrapolate linearly from the differences between final and initial concentrations. However, using Figure 11 of Reference [7], which demonstrates an approximately linear relation for ${ }^{234} \mathrm{U}$ buildup in discharged fuel with cooling time, the ${ }^{234} \mathrm{U}$ concentration at LWR fuel discharge (initially $4.5 \%$ enriched, discharged at $48 \mathrm{GWD} / \mathrm{MT}$ ) is $\sim 210 \mathrm{~g} / \mathrm{MT}$ of discharged uranium while the initial ${ }^{234} \mathrm{U}$ is $\sim 420 \mathrm{~g} / \mathrm{MT}$ of uranium, indicating that the ${ }^{234} \mathrm{U}$ concentration decreases with burnup due no doubt to the transmutation and fissioning of ${ }^{234} \mathrm{U}$. Therefore, the best approximation that can be assumed to do the estimate is that the ${ }^{234} \mathrm{U}$ generation from ${ }^{238} \mathrm{Pu}$ decay and ${ }^{234} \mathrm{U}$ destruction from ${ }^{234} \mathrm{U}$ transmutation or fission have come into equilibrium at the end of irradiation and that this 
equilibrium varies in proportion to the concentration of ${ }^{236} \mathrm{U}$ as a function of burnup. To some extent, this assumption is borne out by Figure 12 of Reference [7] that demonstrates that the discharged ${ }^{234} U$ content decreases with burnup while the decaying source strength for producing ${ }^{234} \mathrm{U}$ increases with burnup, but whether equilibrium is achieved is simply an assumption. Using this assumption, which may not be totally correct, Figure 11 of Reference [7] corrected from 48 to $90.8 \mathrm{GWD} / \mathrm{MT}$ would yield an estimate of the ${ }^{234} \mathrm{U}$ concentration of $\sim 380 \mathrm{~g} / \mathrm{MT}$ of discharged uranium at fuel discharge and $\sim 430 \mathrm{~g} / \mathrm{MT}$ of discharged uranium at 5 years of cooling following fuel discharge from the reactor.

As was done for ${ }^{232} \mathrm{U}$ and ${ }^{233} \mathrm{U}$, the ${ }^{234} \mathrm{U}$ content will also be estimated by using the 5-year-cooled LWR spent fuel data in Tables 7 and correlating the PBMR used-fuel estimate of ${ }^{236} \mathrm{U}$ concentration $(\sim 16,400 \mathrm{~g} / \mathrm{MT}$ of discharged uranium) times the ratio of the values for ${ }^{234} U$ divided by ${ }^{236} U$ in Table 7 of Reference [7].

Table A-7. Extrapolated estimates of ${ }^{234} \mathrm{U}$ in PBMR used fuel after cooling for 5 years based on the assumption that ${ }^{234} \mathrm{U}$ is in equilibrium at the time of discharge and increases linearly after discharge

\begin{tabular}{|c|c|c|c|}
\hline $\begin{array}{c}\text { Data source from } \\
\text { Table 7 in } \\
\text { Reference [7] }\end{array}$ & $\begin{array}{c}{ }^{234} \mathbf{U} \text { discharged } \\
\text { concentration, after } \\
\text { cooling for 5 years } \\
\text { (g/MT) }\end{array}$ & $\begin{array}{c}{ }^{236} \mathbf{U} \text { discharged } \\
\text { concentration, after } \\
\text { cooling for 5 years } \\
\text { (g/MT) }\end{array}$ & $\begin{array}{c}\text { Estimated PBMR } \\
\text { concentration after } \\
\text { cooling for 5 years } \\
\text { (g/MT) }\end{array}$ \\
\hline $\begin{array}{c}\text { LWR, 40 GWD/MT, } \\
4 \% \text { enriched }\end{array}$ & $2.11 \mathrm{E}+02$ & $4.96 \mathrm{E}+03$ & $\sim 698$ \\
\hline $\begin{array}{c}\text { LWR, 48 GWD/MT, } \\
4 \% \text { enriched }\end{array}$ & $1.83 \mathrm{E}+02$ & $5.29 \mathrm{E}+03$ & $\sim 567$ \\
\hline $\begin{array}{c}\text { LWR, 48 GWD/MT, } \\
4.5 \% \text { enriched }\end{array}$ & $2.19 \mathrm{E}+02$ & $5.83 \mathrm{E}+03$ & $\sim 616$ \\
\hline $\begin{array}{c}\text { LWR, 60 GWD/MT, } \\
4.1 \% \text { enriched }\end{array}$ & $1.63 \mathrm{E}+02$ & $5.68 \mathrm{E}+03$ & $\sim 471$ \\
\hline
\end{tabular}

The data in Table A-7 indicates that, under the assumption of an equilibrium state for ${ }^{234} \mathrm{U}$, the ${ }^{234} \mathrm{U}$ content clearly decreases with burnup but also increases with initial enrichment. Lacking other relevant information and given the downward trend in Table A-7, the assumed value will be that from the extrapolation from Figure 11 as described above, namely, $\sim 430 \mathrm{~g} / \mathrm{MT}$ of discharged uranium at 5 years of cooling. The value at discharge would be $\sim 380 \mathrm{~g} / \mathrm{MT}$ of discharged uranium.

${ }^{237} \mathrm{U}$ : The ${ }^{237} \mathrm{U}$ content is assumed to be in equilibrium with that of ${ }^{236} \mathrm{U}$. Therefore, the ${ }^{237} \mathrm{U}$ content is estimated by using the 5-year-cooled LWR spent fuel data in Tables 7 of Reference [7] and correlating the PBMR used-fuel estimate of ${ }^{236} \mathrm{U}$ concentration $(\sim 16,400 \mathrm{~g} / \mathrm{MT}$ of discharged uranium) times the ratio of the values for ${ }^{237} \mathrm{U}$ divided by ${ }^{236} \mathrm{U}$ in Table 7 of Reference [7]. 
Table A-8.Extrapolated estimates of ${ }^{237} \mathrm{U}$ in PBMR used fuel after cooling for 5 years

\begin{tabular}{|c|c|c|c|}
\hline $\begin{array}{c}\text { Data Source from } \\
\text { Table 7 in } \\
\text { Reference [7] }\end{array}$ & $\begin{array}{c}{ }^{237} \mathbf{U} \text { discharged } \\
\text { concentration, after } \\
\text { cooling for 5 years } \\
\text { (g/MT) }\end{array}$ & $\begin{array}{c}{ }^{236} \mathbf{U} \text { discharged } \\
\text { concentration, after } \\
\text { cooling for 5 years } \\
\text { (g/MT) }\end{array}$ & $\begin{array}{c}\text { Estimated PBMR }{ }^{\mathbf{2 3 7} \mathbf{U}} \\
\text { concentration after } \\
\text { cooling for 5 years } \\
\text { (g/MT) }\end{array}$ \\
\hline $\begin{array}{c}\text { LWR, 40 GWD/MT, } \\
4 \% \text { enriched }\end{array}$ & $3.48 \mathrm{E}-05$ & $4.96 \mathrm{E}+03$ & $6.67 \mathrm{E}-4$ \\
\hline $\begin{array}{c}\text { LWR, 48 GWD/MT, } \\
4 \% \text { enriched }\end{array}$ & $4.40 \mathrm{E}-05$ & $5.29 \mathrm{E}+03$ & $1.36 \mathrm{E}-4$ \\
\hline $\begin{array}{c}\text { LWR, 48 GWD/MT, } \\
4.5 \% \text { enriched }\end{array}$ & $4.38 \mathrm{E}-05$ & $5.83 \mathrm{E}+03$ & $1.23 \mathrm{E}-4$ \\
\hline $\begin{array}{c}\text { LWR, 60 GWD/MT, } \\
4.1 \% \text { enriched }\end{array}$ & $4.99 \mathrm{E}-05$ & $5.68 \mathrm{E}+03$ & $1.44 \mathrm{E}-4$ \\
\hline
\end{tabular}

At 5 years of cooling, the ${ }^{237} \mathrm{U}$ concentration will be $\sim 1.3 \times 10^{-4} \mathrm{~g} / \mathrm{MT}$. From Fig. 13 of Reference [7], the ${ }^{237} \mathrm{U}$ concentration at discharge is $\sim 1.55 \times 10^{-4} \mathrm{~g} / \mathrm{MT}$.

Summary of Estimates for ${ }^{232} \mathrm{U},{ }^{233} \mathrm{U},{ }^{234} \mathrm{U}$, and ${ }^{237} \mathrm{U}$ : The following Table A-11 provides the best estimates for minor uranium isotopic contents of PBMR used fuel in terms of both $\mathrm{g} / \mathrm{MT}$ of discharged fuel and of a per-pebbles basis using the discharged pebble uranium mass of $0.000007875 \mathrm{MT}$ or $7.875 \times 10^{-6} \mathrm{MT}$ from Reference [4], as quoted above in Table A-2. These estimates are given at discharge and at 5 years of cooling of the discharged fuel.

Table A-9. Minor uranium isotope content in PBMR discharged fuel (90.8 GWD/MT) and in the discharged pebble at the time of discharge and after cooling for 5 years after discharge

\begin{tabular}{|c|c|c|c|c|}
\hline \multirow{2}{*}{$\begin{array}{c}\text { Uranium } \\
\text { isotope }\end{array}$} & \multicolumn{2}{|c|}{ At discharge } & \multicolumn{2}{c|}{ After cooling for 5 years } \\
\cline { 2 - 5 } & $\mathbf{g} / \mathbf{M T}$ & $\mathbf{g} /$ pebble & $\mathbf{g} / \mathbf{M T}$ & g/pebble \\
\hline${ }^{232} \mathrm{U}$ & $\begin{array}{c}0.013 \\
\text { (maximum) }\end{array}$ & $\sim 10^{-7}$ (maximum) & $\begin{array}{c}0.023 \\
\text { (maximum) }\end{array}$ & $\begin{array}{c}1.8 \times 10^{-7} \\
(\text { maximum) }\end{array}$ \\
\hline${ }^{233} \mathrm{U}$ & 0.009 & $7.1 \times 10^{-8}$ & 0.0102 & $8.0 \times 10^{-8}$ \\
\hline${ }^{234} \mathrm{U}$ & 380 & 0.003 & 430 & 0.0034 \\
\hline${ }^{237} \mathrm{U}$ & $1.6 \times 10^{-4}$ & $1.2 \times 10^{-10}$ & $1.3 \times 10^{-4}$ & $1 \times 10^{-10}$ \\
\hline
\end{tabular}

Estimated total uranium fissions per pebble and discharge ${ }^{235} U$ enrichment:

The total uranium fissions per pebble equal between $\sim 2.06 \times 10^{21}$ fissions per pebble and $\sim 2.19 \times 10^{21}$ fissions per pebble depending upon the actual applicable value of the net ${ }^{235} \mathrm{U}$ fission-to-absorption ratio $(0.8$ or 0.85$)$.

The ${ }^{235} \mathrm{U}$ discharge enrichment equals (the mass of residual ${ }^{235} \mathrm{U}$ )/(total mass of residual uranium $)=(0.185 \mathrm{~g}) /(0.003+0.185 \mathrm{~g}+0.129 \mathrm{~g}+7.690 \mathrm{~g})=\sim 0.0235$ or $2.35 \%$ enriched. 


\section{Estimates of plutonium fissions and transmutations:}

The average atomic mass of plutonium isotopes in a pebble at discharge can be estimated as follows using the values from Reference [2] as given in Table A-1:

Table A-10. Calculation of plutonium average atomic mass in PBMR pebble

\begin{tabular}{|c|c|c|c|c|}
\hline Isotope & $\begin{array}{c}\text { Mass (g) in } \\
\text { pebble }\end{array}$ & Mass fraction & $\begin{array}{c}\text { Atomic mass } \\
\text { (AMU) }\end{array}$ & $\begin{array}{c}\text { Average atomic } \\
\text { mass contribution }\end{array}$ \\
\hline${ }^{239} \mathrm{Pu}$ & $\sim 0.044$ & 0.386 & 239.052 & 92.273 \\
\hline${ }^{240} \mathrm{Pu}$ & $\sim 0.027$ & 0.237 & 240.054 & 56.893 \\
\hline${ }^{241} \mathrm{Pu}$ & $\sim 0.023$ & 0.202 & 241.057 & 48.694 \\
\hline${ }^{242} \mathrm{Pu}$ & $\sim 0.020$ & 0.175 & 242.059 & 42.360 \\
\hline $\mathrm{Sum}$ & $\sim 0.114$ & 1.000 & ----- & 240.2197 \\
\hline
\end{tabular}

Since the initial plutonium content in the pebble as irradiation starts will be all

${ }^{239} \mathrm{Pu}$ (at an atomic mass of 239.05 AMU) with the other plutonium isotopes building up gradually, the burn-up-averaged atomic mass should be $\sim 239.6$.

The total plutonium fissions per pebble can be estimated from:

- The mass difference between the total mass of ${ }^{238} \mathrm{U}$ transmuted to ${ }^{239} \mathrm{Pu}(0.439$ $\mathrm{g})$ and the total residual mass of plutonium isotopes $(0.140 \mathrm{~g})$

- Normalized to the burn-up averaged atomic mass (239.6)

- By ignoring the effects of fissions in the ${ }^{237} \mathrm{~Np} /{ }^{238} \mathrm{Pu}$ production chain and

- By assuming that non-fission contributions of the plutonium transmutations to Am and $\mathrm{Cm}$ will reduce the net number of fissions by a factor of 0.9 (that is, equivalent to assuming conservatively that $\sim 10 \%$ of the plutonium transmutations lead to Am and $\mathrm{Cm}$ without further secondary fissions of the transmuted isotopes - a guess that may be too low since the thermal and epithermal fission cross sections of $\mathrm{Am}$ and $\mathrm{Cm}$ are low whereas the thermal and epithermal fission cross sections for ${ }^{239} \mathrm{Pu}$ and ${ }^{241} \mathrm{Pu}$ are quite high): $[(0.9) \times(0.439 \mathrm{~g}-0.140 \mathrm{~g})] /\left[(239.6 \mathrm{AMU}) \times\left(1.66054 \times 10^{-24} \mathrm{~g} / \mathrm{AMU}\right)\right]=\sim 6.8 \mathrm{x}$ $10^{20}$ fissions of plutonium

\section{Total Estimated Fissions:}

Therefore, the total estimated fissions of uranium and plutonium in a pebble equal, assuming a uranium fission-to-absorption ratio of 0.8 : $\left[2.06 \times 10^{21}+0.68 \times 10^{21}\right]=2.74 \times 10^{21}$ fissions per pebble equating to a total burn-up of $1.02 \mathrm{MWD} /$ pebble or $\sim 113,000 \mathrm{MWD} / \mathrm{MT}$.

If the fission to absorption ratio is closer to 0.85 , then the total estimated fissions of uranium and plutonium in a pebble increases to: $\left[2.19 \times 10^{21}+0.68 \times 10^{21}\right]=2.87 \times 10^{21}$ fissions per pebble equating to a total burn-up of 1.64 MWD/pebble or $\sim 118,000 \mathrm{MWD} / \mathrm{MT}$. 
However, this ignores the fissions that would occur in ${ }^{236}$ Uand ${ }^{237} \mathrm{~Np}$. If we assume $1 \%$ of the ${ }^{236} \mathrm{U} \rightarrow{ }^{237} \mathrm{~Np}$ chain fissions, using the decrement in $235 \mathrm{U}$ mass as a starting point:

$\left[(0.6789\right.$ g per pebble $) \times\left(0.2\right.$ non-fissions per absorption in $\left.{ }^{235} \mathrm{U}\right) \times(0.01$ fissions in ${ }^{236} \mathrm{U} \rightarrow{ }^{237} \mathrm{~Np}$ chain $\left.)\right] /\left[(\sim 236.5 \mathrm{AMU}) \times\left(1.66054 \times 10^{-24} \mathrm{~g} / \mathrm{AMU}\right)\right]=\sim 3 \times 10^{18}$ fissions, which can be ignored.

\section{Conclusions:}

Compared to the analysis by PBMR (Pty) Ltd., the INL analyses yielded both:

- A burn-up that is $\sim 24 \%$ higher than the target burn-up used in the PBMR (Pty) Ltd. analysis (equating to $\sim 1.5$ additional passes for pebble recirculation through the core beyond the target number of 6 passes in the latter analysis) and

- An $\sim 23 \%$ higher amount of plutonium in the discharged pebble that, while linear with the excess burn-up, seems to be on the high side and inconsistent with the projected plutonium build-in trajectory calculated by PBMR (Pty) Ltd and estimated by visual projection to be $\sim 0.120 \mathrm{~g} / \mathrm{pebble}$ at the burn-up achieved in the INL analysis.

Another issue is the unspecified uranium enrichment at discharge for the PBMR (Pty) Ltd. analysis. Assuming the trajectory of the change in uranium enrichment is linear with each recirculation pass of the pebble, the change in uranium enrichment for the PBMR (Pty) Ltd analysis derived from that in the INL analysis will be approximately: $[6 \times(9.6 \%-2.35 \%)] / 7.5=5.8 \%$ so that the discharge enrichment will be approximately: $9.6 \%-5.8 \%=\sim 3.8 \%$.

For comparison, by a linear interpolation from the INL analysis of uranium burn-up over six recirculation passes compared to the 7.5 passes inferred for the burn-up of plutonium achieved in the INL analysis, the uranium inventory in the pebble at discharge with a burn-up of $90.8 \mathrm{GWD} / \mathrm{MT}$ should be approximately:

${ }^{236} \mathrm{U}: 0.103$ grams (or $\sim 1.26 \%$ or $\sim 12,560 \mathrm{~g} / \mathrm{MT}$ of discharged uranium)

${ }^{238} \mathrm{U}: 7.779$ grams

${ }^{235} \mathrm{U}: 0.321$ grams or $\sim 3.9 \%$ enriched or $\sim 0.312$ grams if $3.8 \%$ enriched is more correct.

Total uranium: 8.203 grams per pebble ignoring the third decimal place contribution from ${ }^{234} \mathrm{U}$.

Since the previous estimates for ${ }^{232} \mathrm{U},{ }^{233} \mathrm{U}$ and ${ }^{234} \mathrm{U}$ were based, to some extent in each case, on an assumed ${ }^{236} \mathrm{U}$ concentration of $\sim 16,400 \mathrm{~g} / \mathrm{MT}$ of discharged uranium derived from 0.129 grams per pebbles at discharge and a uranium discharge mass of $7.875 \times 10^{-6}$ MT per pebble, the revised value is:

$0.103 \mathrm{~g} / 8.203 \times 10-6 \mathrm{MT}$ per pebble $=\sim 12,560 \mathrm{~g} / \mathrm{MT}$ of discharged uranium Therefore, the revised estimates for the following uranium isotopes at discharge and at 5years cooling are: 
${ }^{232} \mathrm{U}: 0.010 \mathrm{~g} / \mathrm{MT}$

At discharge from the reactor:

${ }^{233} \mathrm{U}: 0.007 \mathrm{~g} / \mathrm{MT}$

${ }^{234} \mathrm{U}: 380 \mathrm{~g} / \mathrm{MT}$ (no change since it was based on an alternative estimate)

${ }^{237} \mathrm{U}: 1.2 \times 10^{-4} \mathrm{~g} / \mathrm{MT}$

At 5-years cooling after discharge from the reactor:

${ }^{232} \mathrm{U}: 0.018 \mathrm{~g} / \mathrm{MT}$

${ }^{233} \mathrm{U}: 0.0078 \mathrm{~g} / \mathrm{MT}$

${ }^{234} \mathrm{U}: 430 \mathrm{~g} / \mathrm{MT}$ (no change since it was based on an alternative estimate)

${ }^{237} \mathrm{U}: 1 \times 10^{-4} \mathrm{~g} / \mathrm{MT}$

The dilution of the residual special nuclear material (SNM) as ${ }^{235} \mathrm{U}$ in the discharged pebble would be $\sim 0.312 \mathrm{~g}$ of residual ${ }^{235} \mathrm{U}$ divided by 0.0002 MT per pebble or $\sim 1560$ ppm.

The dilution of total residual uranium in the discharged pebble would be $\sim 8.203$ grams divided by 0.0002 MT per pebble or $\sim 41,015 \mathrm{ppm}$.

At pebble discharge and using the $0.0253 \mathrm{eV}$ fission cross sections, it is estimated that greater than $70 \%$ of the thermal-neutron-induced fissions are still occurring in ${ }^{235} \mathrm{U}$ compared to ${ }^{239} \mathrm{Pu}$ and ${ }^{241} \mathrm{Pu}$-; therefore, neutron interrogation of PBMR "used fuel" will be dominated by uranium fissions. If residual uranium is the dominant basis for continued safeguards for nuclear material control and accountancy (NMC\&A) and the dilution of the plutonium is at or below the limits for termination of safeguards, then the focus of detection systems should be quantifying the net fissile content and not the content of plutonium. 